UNIVERSIDADE DE BRASÍLIA

PROGRAMA DE PÓS-GRADUAÇÃO EM AGRONOMIA

FACULDADE DE AGRONOMIA E MEDICINA VETERINÁRIA

MATÉRIA ORGÂNICA DO SOLO E EMISSÃO DE ÓXIDO NITROSO EM AGROECOSSISTEMAS DE LONGA DURAÇÃO NO CERRADO

ISIS LIMA DOS SANTOS

TESE DE DOUTORADO EM AGRONOMIA

BRASÍLIA/DF

OUTRUBRO/2016 


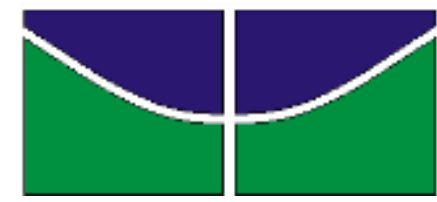

UNIVERSIDADE DE BRASÍLIA

FACULDADE DE AGRONOMIA E MEDICINA VETERINÁRIA PROGRAMA DE PÓS-GRADUAÇÃO EM AGRONOMIA

EMISSÃO DE ÓXIDO NITROSO E MATÉRIA ORGÂNICA DO SOLO EM AGROECOSSISTEMAS DE LONGA DURAÇÃO NO CERRADO

ISIS LIMA DOS SANTOS

ORIENTADOR: DOUTOR CÍCERO CÉLIO DE FIGUEIREDO CO-ORIENTADORA: DOUTORA ALEXSANDRA DUARTE DE OLIVEIRA

TESE DE DOUTORADO EM AGRONOMIA

PUBLICAÇÃO: 049D/2016

BRASÍLIA/DF

OUTUBRO/2016 


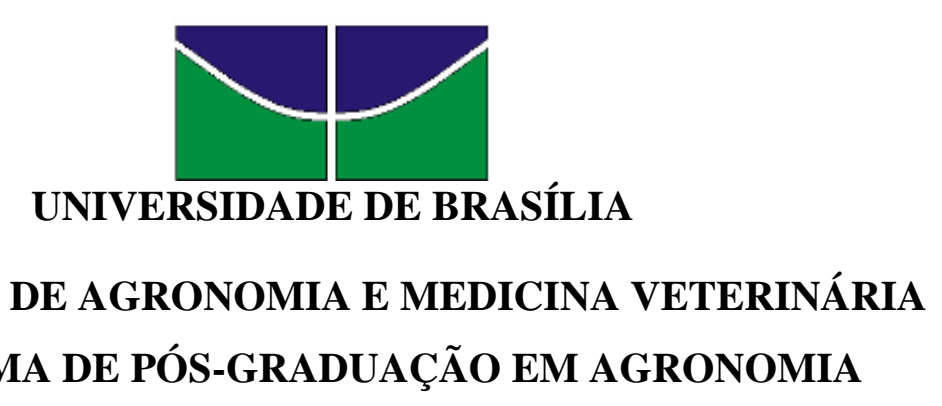

\title{
EMISSÃO DE ÓXIDO NITROSO E MATÉRIA ORGÂNICA DO SOLO EM AGROECOSSISTEMAS DE LONGA DURAÇÃO NO CERRADO
}

\author{
ISIS LIMA DOS SANTOS
}

TESE DE DOUTORADO SUBMETIDA AO PROGRAMA DE PÓS-GRADUAÇÃo EM AGRONOMIA, COMO PARTE DOS REQUISITOS NECESSÁRIOS À OBTENÇÃO DO GRAU DE DOUTORA EM AGRONOMIA.

Aprovada por:

CÍCERO CÉLIO DE FIGUEIREDO, Professor Doutor/ Universidade de Brasília-UnB/ e-mail: cicerocf@unb.br

ALESSANDRA MONTEIRO DE PAULA, Professora Doutora /Universidade de BrasíliaUnB/e-mail: ampaula21@gmail.com

THAIS RODRIGUES COSER, Professora Doutora/ Universidade de Brasília-UnB/ e-mail: tcoser@unb.br

GABRIELA BIELEFELD NARDOTO, Professora Doutora/ Universidade de Brasília-UnB/ e-mail: gbnardoto@unb.br

ELOISA APARECIDA BELLEZA FERREIRA, Pesquisadora Doutora/Embrapa Cerrados, DF/e-mail: eloisa.belleza@embrapa.br

BRASÍLIA/DF, 11 de OUTUBRO de 2016. 
Santos, Isis Lima dos

Emissão de óxido nitroso e matéria orgânica do solo em agroecossistemas de longa duração no Cerrado. / Isis Lima dos Santos; orientação de Cícero Célio de Figueiredo. - Brasília, 2016.

117 p.: il.

Tese de Doutorado - Universidade de Brasília/Faculdade de Agronomia e Medicina Veterinária, 2016.

1. Sistema plantio direto. 2. Rotações culturais. 3. Gases do efeito estufa. 4. Frações da matéria orgânica do solo. I. Figueiredo, C.C. II. Título.

CDU/FAO 
Ofereço a todos os professores, pesquisadores e estudantes,

que assim como eu, se dedicam ao estudo do uso

sustentável do SOLO!

À minha mãe, Ivete Lima dos Santos, que admiro pela coragem, dedicação e amor imensurável pela família;

Ao meu pai, Mariano Rodrigues dos Santos, pela sabedoria de vida sempre ensinada com muita paciência e compreensão;

A meu irmão, Deivid Lima dos Santos, pelo amor e amizade compartilhada em nossa família;

Ao meu esposo, Marcos Vinícius Dias Wieczorek, por todas as possibilidades trazidas na forma de conhecimento, companheirismo e amor dedicado;

Ao Isaac Abner Lima Wieczorek, meu filho, por me fazer mais feliz e completa.

DEDICO. 


\section{AGRADECIMENTOS}

Ao doutor Cícero Célio de Figueiredo, que além de aceitar me orientar, sempre foi um grande incentivador, transmitindo com muita paciência e, principalmente, profissionalismo, valiosos conhecimentos. A minha co-orientadora, doutora Alexsandra Duarte de Oliveira, pela oportunidade de crescer profissionalmente a partir de seus conhecimentos compartilhados e toda ajuda disponibilizada. Agradeço imensamente as doutoras e pesquisadoras Gabriela Bielefeld Nardoto, Thais Rodrigues Coser, Alessandra Monteiro de Paula e Eloisa Belleza Ferreira que aceitaram participar da minha banca examinadora de doutorado;

A Rose Mary Gonçalves Mariano, Daiane dos Santos Soares, Fabiana Campos Ribeiro, Nathália Batista Melo, Walda Monteiro Farias e Bruna Gehrke Schneider que orgulhosamente posso chamar de amigas por compartilharmos muitas risadas, desabafos, aprendizado e excelentes lições de vida profissionais e pessoais, durante minha estadia em Brasília, no decorrer do doutorado. E em especial a Helen Cristina Vieira e Juliana Hiromi Sato que não tenho palavras para descrever o imenso carinho que tenho por nossa amizade;

Aos amigos e colegas Alyson Silva e Túlio Moreira, que no Laboratório de Matéria Orgânica do Solo da UnB, juntamente com todos os demais estagiários da Embrapa Cerrados, contribuíram direta e indiretamente para esta tese;

Por fim, quero externar também os meus sinceros agradecimentos a Universidade de Brasília-UnB / Campus Darcy Ribeiro, Coordenação da Pós Graduação de Agronomia e Medicina Veterinária-FAV, professores e funcionários do curso, a todos os pesquisadores e funcionários da Embrapa Cerrados e a CAPES que possibilitaram a realização dessa pesquisa;

E a Deus, que possibilitou todas essas realizações! 


\section{RESUMO}

\section{EMISSÃO DE ÓXIDO NITROSO E MATÉRIA ORGÂNICA DO SOLO EM AGROECOSSISTEMAS DE LONGA DURAÇÃO NO CERRADO}

As alterações que ocorrem na conversão de ambientes naturais sob Cerrado em áreas agrícolas afetam diretamente a dinâmica da matéria orgânica do solo (MOS) e, consequentemente, a dinâmica do nitrogênio $(\mathrm{N})$. Como resultado, ocorre elevação das emissões de óxido nitroso $\left(\mathrm{N}_{2} \mathrm{O}\right)$ do solo para atmosfera. A adoção de agroecossistemas conservacionistas como o plantio direto (PD), com rotações culturais, tem sido proposta como uma estratégia para mitigar as emissões de $\mathrm{N}_{2} \mathrm{O}$ decorrentes da agricultura que utiliza o preparo convencional do solo (PC). O PD que preconiza o maior acúmulo de resíduos vegetais, em quantidade e qualidade, mediante a rotação e sucessão de culturas utilizadas em cada região agrícola, resulta na formação de diversos compostos orgânicos que são genericamente separados em frações lábeis e estáveis da MOS. Contudo, ainda não está claro como essas frações da MOS, a sazonalidade pluviométrica do Cerrado e os ciclos de rotações culturais de diferentes agroecossistemas interagem e se relacionam com as emissões de $\mathrm{N}_{2} \mathrm{O}$ do solo. Para compreender melhor essa dinâmica, o presente trabalho foi desenvolvido com o objetivo de avaliar os agroecossistemas convencionais e conservacionistas nos fluxos de $\mathrm{N}_{2} \mathrm{O}$ e no acúmulo de frações da MOS, em experimento de longa duração, sob influência da sazonalidade do Cerrado. Para tanto, o $\mathrm{N}_{2} \mathrm{O}$ emitido do solo sob PC, PD (dois sistemas com diferenças na rotação e sucessão de culturas) e o Cerrado nativo foi monitorado por um ano, através do uso de câmaras estáticas fechadas, juntamente, com a determinação das co-variáveis edafoclimáticas: nitrato, amônio, umidade do solo, espaço poroso saturado por água e temperatura do solo. Também foram determinados os teores e estoques totais de $\mathrm{C}$ e $\mathrm{N}$ orgânico e as seguintes frações da matéria orgânica do solo: carbono inerte, carbono oxidado por permanganato de potássio, carbono da biomassa microbiana, carbono particulado, substâncias húmicas (ácido húmico, ácido fúlvico e humina) e carbono associado aos macro e microagregados. A pesquisa foi desenvolvida na Embrapa Cerrados, em Planaltina, DF, em um experimento instalado em 1996, cujo delineamento estatístico foi em blocos casualizados, com três repetições. O Cerrado nativo foi utilizado como ambiente de referência. $\mathrm{O}$ PC apresentou os maiores picos de $\mathrm{N}_{2} \mathrm{O}$, principalmente, no período seco do ano, com maior emissão acumulado $\left(1,36 \mathrm{~kg} \mathrm{~N}_{2} \mathrm{O} \mathrm{ha}{ }^{-1}\right)$, com $75 \%$ do total, durante o pousio. Entre os agroecossistemas estudados as emissões acumuladas de $\mathrm{N}_{2} \mathrm{O}$ do solo foram influenciadas pela sazonalidade das precipitações pluviométricas, sistemas de manejo, rotação de culturas, assim como, pela interação entre esses fatores. Os sistemas integrados sob PD, quando comparados ao monocultivo de soja sob PC, contribuíram para a mitigação de emissões de $\mathrm{N}_{2} \mathrm{O}$. O PD com rotação milho/guandu apresentou a menor emissão acumulada $\left(0,48 / 0,15 \mathrm{~kg} \mathrm{~N}_{2} \mathrm{O}\right.$ ha $^{-1}$, respectivamente), sendo uma alternativa viável para reduzir as emissões de $\mathrm{N}_{2} \mathrm{O}$. Por meio de análise de componentes principais, observou-se, de maneira geral, uma separação do PC dos demais sistemas de uso do solo, como consequência da maior emissão de $\mathrm{N}_{2} \mathrm{O}$ por esse sistema associada aos baixos teores de $\mathrm{C}$ nas diversas frações da MOS. Conclui-se que sistemas de manejo do solo que incrementam $\mathrm{C}$ de forma equilibrada entre frações lábeis e estáveis da MOS, como ocorre no plantio direto, além de criar mecanismos de proteção desse $\mathrm{C}$ em agregados e apresentam baixa emissão de $\mathrm{N}_{2} \mathrm{O}$ do solo.

Palavras-chave: Savana brasileira, sistema plantio direto, rotações culturais, gases de efeito estufa, frações da matéria orgânica do solo. 


\begin{abstract}
NITROUS OXIDE EMISSION AND SOIL ORGANIC MATTER FRON LONG TERM AGROECOSYSTEMS IN THE CERRADO REGION OF BRAZIL
\end{abstract}

The changes in agricultural areas resulting from the conversion of natural environments in the savanna-like vegetation directly affect the dynamics of soil organic matter (SOM) and consequently nitrogen $(\mathrm{N})$ dynamics. As a result, the soil-to-atmosphere emissions of nitrous oxide $\left(\mathrm{N}_{2} \mathrm{O}\right)$ increase. Conservation agriculture in agroecosystens have been proposed, e.g., no tillage (NT) with crop rotation, as a strategy to reduce the $\mathrm{N}_{2} \mathrm{O}$ emissions generated by conventional tillage (CT) agriculture. In NT systems, the cumulative quantity and quality of plant residues is higher, due to region-specific crop rotation and succession, resulting in the formation of different organic compounds, generally separated into labile and stable SOM fractions. However, the interactions and relationships of $\mathrm{N}_{2} \mathrm{O}$ soil emissions with these SOM fractions, the rainfall seasonality of the Cerrado and crop rotation cycles in different agro-ecosystems are still poorly understood. To shed light on these dynamics, this study addressed the changes in $\mathrm{N}_{2} \mathrm{O}$ fluxes and accumulation of SOM fractions in conventional and conservation agricultural ecosystems in a long-term experiment, influenced by the seasonality of the Cerrado. To this end, $\mathrm{N}_{2} \mathrm{O}$ emissions from soil under $\mathrm{CT}$ and NT (systems with differences in crop rotation and succession) and from native Cerrado vegetation were monitored for one year with the use of static closed chanbers for quantitative measurement, aside from assessments of soil and climate co-variables: nitrate, ammonium, soil moisture, waterfilled pore space, and soil temperature. The total pools of organic carbon (C) and $\mathrm{N}$ were also determined, as well as the SOM fractions: inert carbon, potassium permanganate oxidized C, microbial biomass $\mathrm{C}$, particulate $\mathrm{C}$, humic substances (humic acid, fulvic acid and humin), and carbon associated with macro- and micro-aggregates. The study was carried out at Embrapa Cerrados, in Planaltina, Distrito Federal, as part of an experiment installed in 1996, arranged in a randomized block design with three replications. The native vegetation was used as reference environment. The highest $\mathrm{N}_{2} \mathrm{O}$ peaks were observed under $\mathrm{CT}$, mainly in the dry season, with highest cumulative emissions $\left(1.36 \mathrm{~kg} \mathrm{~N}_{2} \mathrm{O} \mathrm{ha}{ }^{-1}\right), 75 \%$ of the total, in the fallow period. In the studied agroecosystems, the cumulative $\mathrm{N}_{2} \mathrm{O}$ emissions from the soil were influenced by rainfall seasonality, management systems, crop rotation, as well as by interactions between these factors. Integrated systems under NT, compared to CT soybean monoculture, contributed to reduce $\mathrm{N}_{2} \mathrm{O}$ emissions. Cumulative emissions were lowest from NT maize/pigeon pea rotation $(0.48 / 0.15 \mathrm{~kg}$ $\mathrm{N}_{2} \mathrm{O}$ ha $^{-1}$, respectively), which is a viable alternative to reduce $\mathrm{N}_{2} \mathrm{O}$ emissions. Principal component analysis generally differentiated CT from the other land use systems, indicating higher $\mathrm{N}_{2} \mathrm{O}$ emissions and low $\mathrm{C}$ content in the various SOM fractions of this system. It was concluded that in soil management systems that increase $\mathrm{C}$ equally in the labile and stable SOM fractions, as in the case of no tillage, $\mathrm{N}_{2} \mathrm{O}$ soil emissions are low, apart from creating $\mathrm{C}$ protection mechanisms in aggregates.

Keywords: Brazilian savanna, no-tillage, crop rotation, greenhouse gases, fractions of soil organic matter. 


\section{LISTA DE FIGURAS}

\section{CAPÍTULO I}

Figura 1.1 Precipitação pluviométrica, temperatura do ar e umidade relativa do ar na área experimental no período de 1974 a 2003 (a) e durante o período de avaliação (b).

Figura 1.2 Esquema de implantação e condução da área experimental, desde o ano de 1996 até 2014, referente aos diferentes sistemas de manejo a serem utilizados na pesquisa. 53

Figura 1.3 Vista aérea do experimento. NT1/B1, NT1/B2 e NT1/B3: plantio direto com soja e safrinha de sorgo instalado nos blocos 1, 2 e 3; NT2/B1, NT2/B2 e NT2/B3: plantio direto com milho e safrinha de guandu instalado nos blocos 1, 2 e 3; CT/B1, CT/B2 e CT/B3: plantio convencional com soja instalado nos blocos 1, 2 e 3; CER/B1, CER/B2, CER/B3: cerrado dos blocos 1,2 e 3 .

Figura 1.4 Precipitação pluviométrica total na área experimental no período chuvoso e seco, durante o ano agrícola de 2013/2014, Planaltina, DF, Brasil. NTR1 = sistema de manejo plantio direto cultivado com soja e rotação com o sorgo BRS332 (Sorghum bicolor (L.) Moench); NTR2 = sistema de manejo plantio direto com milho e rotação com o guandu (Cajanus cajan); CT = sistema convencional com soja e posterior pousio do solo.

Figura 1.5 Fluxos diários de óxido nitroso (a), espaço poroso saturado com água - WFPS (b), nitrato $-\mathrm{NO}_{3}{ }^{-}$(c), amônio $-\mathrm{NH}_{4}{ }^{+}$(d) e temperatura do solo (e) do ano agrícola 2013/2014 sob os sistemas plantio direto (NTR1 e NTR2), convencional (CT) e cerrado nativo, em Latossolo, no período chuvoso e seco, Planaltina, DF, Brasil. As setas indicam eventos de fertilizações nitrogenadas. * Indicativo de diferença significativa, pelo teste de Tukey $(\mathrm{P}<0,05)$, entre os sistemas de manejo no período avaliado.

Figura 1.6 Acumulado anual de óxido nitroso do solo (a), no período chuvoso (b) e no período seco (c) sob os sistemas plantio direto (NTR1 e NTR2), convencional (CT) e Cerrado, Planaltina, DF, Brasil. NTR1 = sistema de manejo plantio direto cultivado com soja e rotação com o sorgo BRS332 (Sorghum bicolor (L.) Moench); NTR2 = sistema de manejo plantio direto com milho e rotação com o guandu (Cajanus cajan); CT = sistema convencional com soja e posterior pousio do solo na entressafra. As setas indicam eventos de colheita das leguminosas, soja (Harvest 1) e, guandu (Harvest 2). Treatments followed by the same letter do not differ statistically by Tukey's test at $\mathrm{P}<$ 0,05 .

Figura 1.7 Potencial de aquecimento global parcial (pGWP) dos sistemas de manejo de acordo a emissão acumulada de óxido nitroso expressa em equivalente de dióxido de carbono $\left(\mathrm{CO}_{2} \mathrm{eq}\right)$. NTR1= plantio direto com a primeira safra com soybean e a segunda safra com sorghum; NTR2 = plantio direto com a primeira safra com maize e segunda safra com pigeonpea; $\mathrm{CT}=$ plantio convencional com a safra de soybean e posterior fallow. Médias seguidas de letras iguais não diferem entre si pelo teste de Tukey $(\mathrm{P}<0,05)$.

Figura 1.8 Análise de componentes principais (PCA) no período chuvoso (a) e período seco (b) para os fluxos de $\mathrm{N}_{2} \mathrm{O}$ do solo e variáveis edafoclimáticas: nitrato $-\mathrm{NO}_{3}{ }^{-}$, amônio $-\mathrm{NH}_{4}{ }^{+}$, espaço 
poroso saturado por água - WFPS e temperatura do solo (Temp. Solo) sob diferentes sistemas de manejo e Cerrado nativo durante os seis meses de cada período.

\section{CAPÍTULO II}

Figura 2.1 Carbono orgânico total - COT (a) e nitrogênio orgânico total - NOT (b) no perfil do solo da área estudada. * indica que há diferença estatística entre os sistemas de manejo de acordo com o teste de Tukey $(\mathrm{P}<0,05)$..

Figura 2.2 Carbono da biomassa microbiana - CBM (a), carbono oxidado por permanganato de potássio - C- $\mathrm{KMnO}_{4}$ (b) e orgânico particulado - $\mathrm{COP}$ (c) em 0-20 $\mathrm{cm}$ de profundidade dos sistemas de manejo convencional (CT), plantios direto (NT1 e NT2) e cerrado nativo (CER). Letras iguais indicam que não há diferença estatística entre sistemas de manejo pelo teste de Tukey $(\mathrm{P}<0,05)$ .95

Figura 2.3 Carbono nas frações ácido húmico - AH, ácido fúlvico - AF, humina - HUM (a) e inerte -CI (b) em 0-20 cm de profundidade dos sistemas de manejo convencional (CT), plantios direto (NT1 e NT2) e cerrado nativo (CER). Letras diferentes indicam diferenças entre os sistemas de manejo de acordo com o teste de Tukey $(\mathrm{P}<0,05)$. 97

Figura 2.4 Diâmetro médio ponderado - DMP (a), carbono em macroagregados - CMAC e em microagregados - CMIC estáveis em água (b) na profundidade de 0-20 cm nos sistemas de manejo convencional (CT), plantios direto (NT1 e NT2) e cerrado nativo (CER). Letras iguais indicam que não há diferença estatística entre os sistemas de manejo pelo teste de Tukey $(\mathrm{P}<0,05)$. 102

Figura 2.5 Óxido nitroso acumulado total nos sistemas de manejo convencional (CT), plantios direto (NT1 e NT2) e cerrado nativo (CER) medido de outubro de 2013 a setembro de 2014. As setas indicam eventos de colheita da soja no CT e NT1 (Colheita 1) e guandu no NT2 (Colheita 2). Letras iguais indicam que não há diferença estatística entre os sistemas de manejo pelo teste de Tukey $(\mathrm{P}<0,05)$ 101

Figura 2.6 Análise de componentes principais - PCA somente para os agroecossistemas sob preparo convencional - CT e plantios diretos - NT1 e NT2 (a), e agroecossistemas mais o CER (b). Emissão acumulada de $\mathrm{N}_{2} \mathrm{O}$ do solo - $\mathrm{N}_{2} \mathrm{O}$ Acum. anual; carbono orgânico total - COT; nitrogênio total - NOT; carbono da biomassa microbiana - CBM, carbono oxidável em permanganato - C$\mathrm{KMnO}_{4}$, ácido fúlvico - AF, ácido húmico - $\mathrm{AH}$, humina - HUM, carbono orgânico particulado COP, carbono em microagregados - CMIC, carbono em macroagregados - CMAC durante o período avaliado. 103 


\section{LISTA DE TABELAS}

\section{CAPÍTULO I}

Tabela 1.1 Atributos químicos e físicos do solo da área experimental nos sistemas de manejo e Cerrado nativo em 2013, antes das medições realizadas. 52

Tabela 1.2 Descrição dos sistemas de manejo de solo estudados e resumo do histórico de cultivo nas parcelas experimentais.

Tabela 1.3 Emissão acumulada de óxido nitroso em função da produtividade das culturas nos diferentes sistemas de manejo do solo. 66

Tabela 1.4 Coeficientes de correlações entre as variáveis edafoclimáticas e os componentes principais (PC1 e PC2), em função da sazonalidade pluviometrica (período chuvoso e seco)..... 68

\section{CAPÍTULO II}

Tabela 2.1 Estoques de carbono (EstC) e nitrogênio (EstN) do solo na profundidade de 0-100 cm sob sistemas de manejo e cerrado nativo. 


\section{SUMÁRIO}

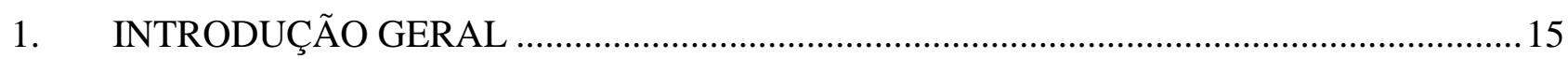

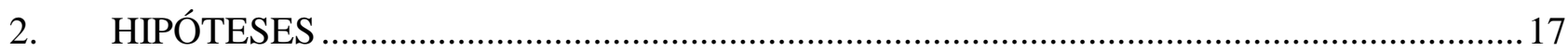

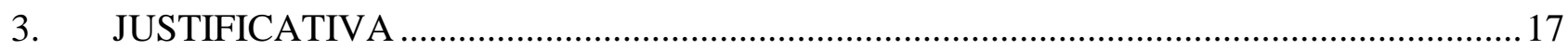

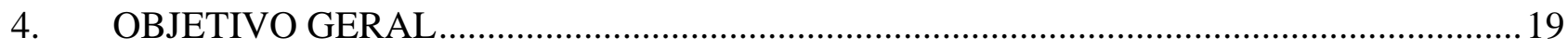

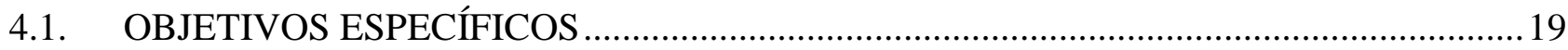

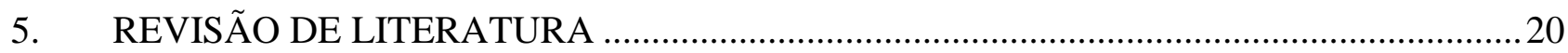

5.1. PRODUÇÕES DE ÓXIDO NITROSO EM SOLOS AGRÍCOLAS .....................................20

5.2. EFEITOS DOS SISTEMAS DE MANEJO NAS EMISSÕES DE ÓXIDO NITROSO NO

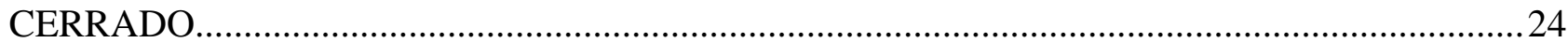

5.2.1. Co-variáveis edafoclimáticas e emissões de óxido nitroso ………………………………....2

5.3. FRAÇÕES LÁBEIS E ESTÁVEIS MATÉRIA ORGÂNICA E EMISSÕES DE ÓXIDO

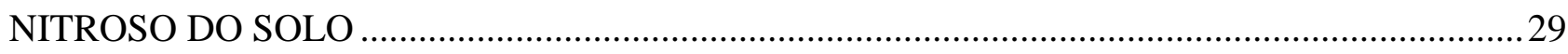

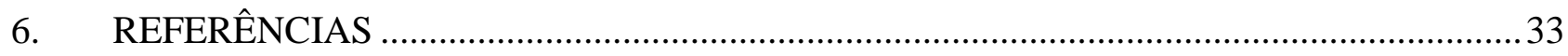

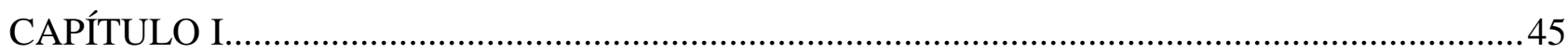

EMISSÕES DE $\mathrm{N}_{2} \mathrm{O}$ DO SOLO EM AGROECOSSISTEMAS DE LONGA DURAÇÃO: EFEITOS INTERATIVOS DA SAZONALIDADE PLUVIOMÉTRICA E ROTAÇÃO DE

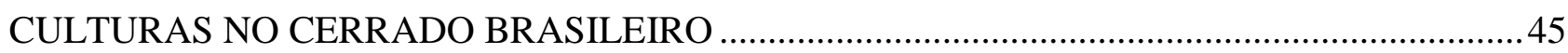

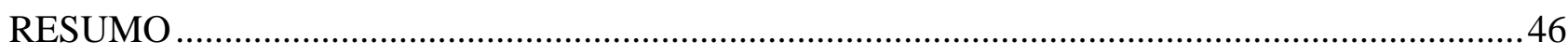

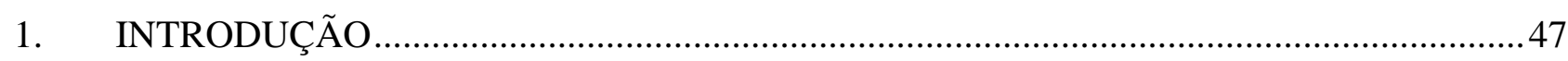

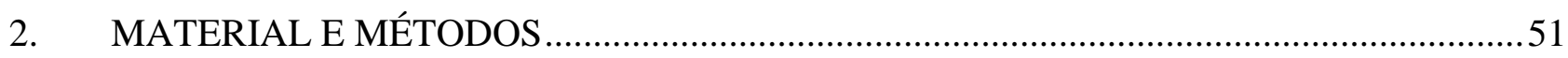

2.1. CARACTERÍSTICAS DA ÁREA EXPERIMENTAL E CLIMA LOCAL ..........................51

2.1. HISTÓRICO E CARACTERIZAÇÃO DO EXPERIMENTO_...........................................52

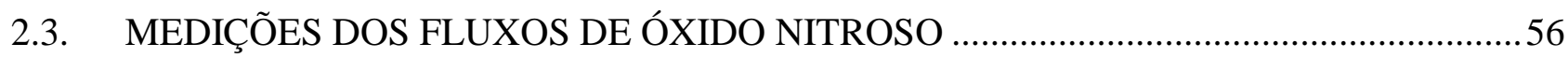

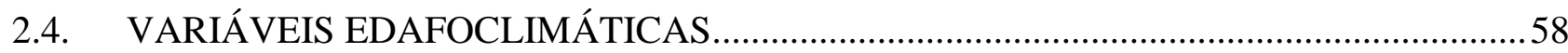

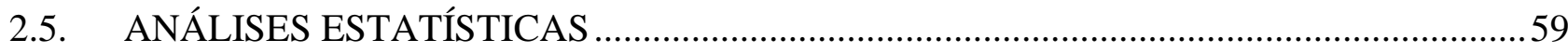


3. RESULTADOS

3.1. SAZONALIDADE PLUVIOMÉTRICA DURANTE O DESENVOLVIMENTO DAS CULTURAS NO CERRADO.

3.2. EMISSÕES DIÁRIAS E SAZONAIS DE N $\mathrm{N}_{2} \mathrm{O}$ E VARIÁVEIS EDAFOCLIMÁTICAS EM AGROECOSSISTEMAS DO CERRADO

3.3. VARIAÇÕES SAZONAIS DO WFPS, NITROGÊNIO MINERAL $\left(\mathrm{NO}_{3}^{-} \mathrm{E} \mathrm{NH}_{4}^{+}\right)$E TEMPERATURA DO SOLO.

3.4. EMISSÕES ACUMULADAS DE $\mathrm{N}_{2} \mathrm{O}$ DOS AGROECOSSISTEMAS EM FUNÇÃO DA SAZONALIDADE PLUVIOMÉTRICA E ROTAÇÃO DE CULTURAS

3.5. RELAÇÕES ENTRE OS FLUXOS DE $\mathrm{N}_{2} \mathrm{O}$ DO SOLO E VARIÁVEIS EDAFOCLIMÁTICAS DOS SISTEMAS DE MANEJO EM FUNÇÃO DA SAZONALIDADE PLUVIOMÉTRICA

4. DISCUSSÃO 69

4.1. EFEITOS DA SAZONALIDADE PLUVIOMÉTRICA, DOS SISTEMAS DE MANEJO E DA ROTAÇÃO CULTURAL NOS FLUXOS DE $\mathrm{N}_{2} \mathrm{O}$ 69

4.2. VARIÁVEIS EDAFOCLIMÁTICAS. 71

4.3. EMISSÕES ACUMULADAS E POTENCIAL DE AQUECIMENTO GLOBAL

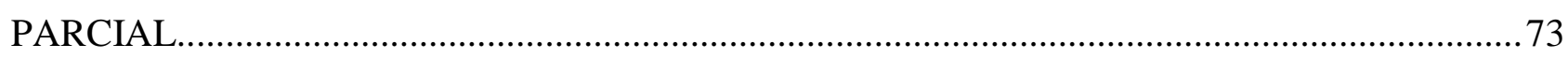

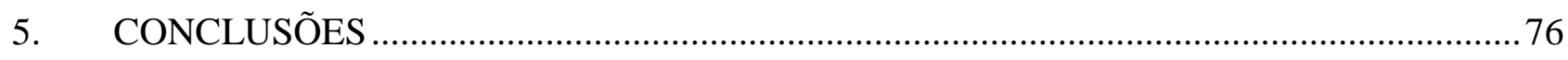

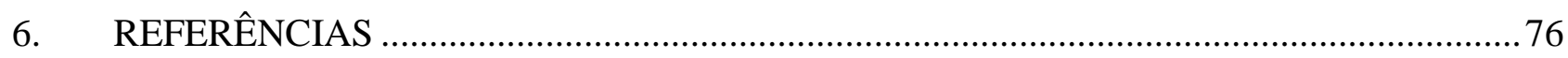

CAPÍTULO II 85

COMPARTIMENTOS DA MATÉRIA ORGÂNICA DO SOLO E EMISSÕES DE ÓXIDO NITROSO EM AGROECOSSISTEMAS NO CERRADO BRASILEIRO .85

RESUMO. 86

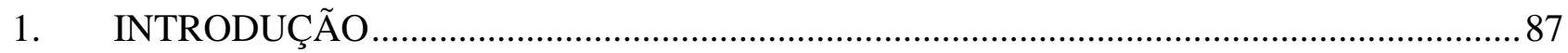

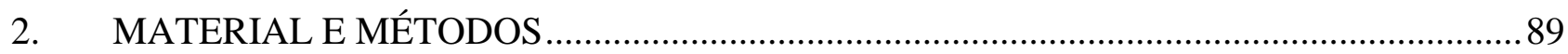

2.1. CARACTERIZAÇÃO DA ÁREA EXPERIMENTAL E CLIMA LOCAL ........................89

2.2. AMOSTRAGEM DO SOLO E DETERMINAÇÕES DOS ESTOQUES DE C E N, DA AGREGAÇÃO DO SOLO E DAS FRAÇÕES DA MOS 89 


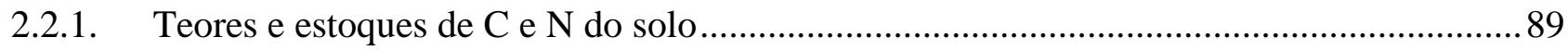

2.2.2. Agregação e teor de carbono em agregados do solo ..................................................... 90

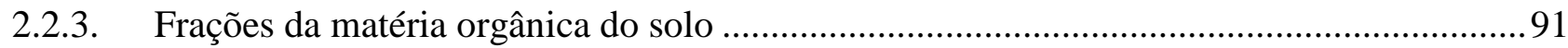

2.3. EMISSÃO DE ÓXIDO NITROSO ACUMULADO ....................................................... 92

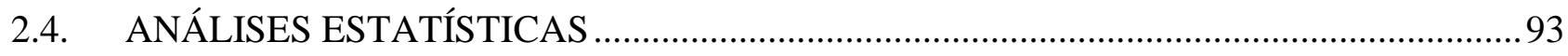

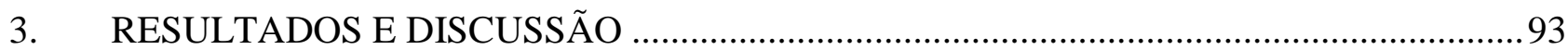

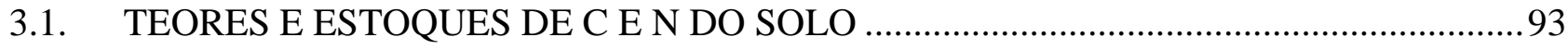

3.2. EFEITO DOS SISTEMAS DE MANEJO NAS FRAÇÕES DA MATÉRIA ORGÂNICA

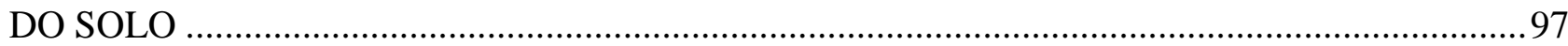

3.2.1. Frações lábeis da matéria orgânica do solo .....................................................................97

3.2.2. Frações estáveis da matéria orgânica do solo....................................................................99

3.2.3. Agregação do solo e C em macro e microagregados .................................................... 101

3.3. EMISSÕES ACUMULADAS DE $\mathrm{N}_{2} \mathrm{O}$ EM SOLOS SOB SISTEMAS DE MANEJO DO

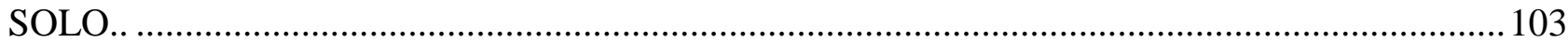

3.4. RELAÇÕES ENTRE AS FRAÇÕES DA MATÉRIA ORGÂNICA DO SOLO E AS

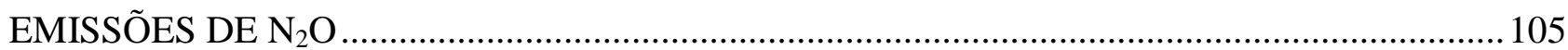

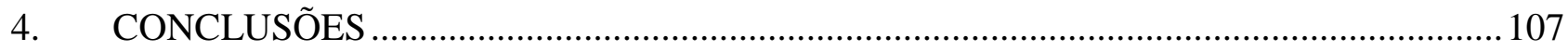

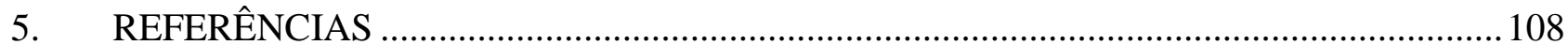

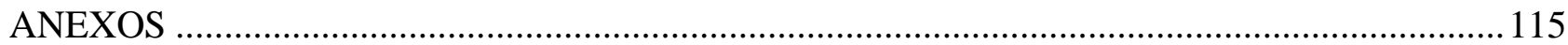




\section{INTRODUÇÃO GERAL}

A conversão de ambientes naturais sob vegetação nativa em áreas de cultivos agrícolas além de causar alterações de ordens físicas, químicas e biológicas no solo contribuem significativamente para as modificações climáticas globais. Essas modificações climáticas são perceptíveis e acompanhadas pelo incremento da emissão de determinados gases dos solos para a atmosfera. Entre esses gases, como resultante dessa conversão que promove alterações na dinâmica da matéria orgânica (Six et al., 2002), destaca-se o óxido nitroso $\left(\mathrm{N}_{2} \mathrm{O}\right)$.

Segundo o Ministério da Ciência, Tecnologia e Inovação (MCTI, 2014), no Brasil, os solos agrícolas são responsáveis por $64 \%$ das emissões diretas de $\mathrm{N}_{2} \mathrm{O}$. No setor agropecuário, a relação entre a agricultura e a emissão desse gás, provém da constatação de que a agricultura mundial é uma das principais fontes primárias antropogênicas do $\mathrm{N}_{2} \mathrm{O}$, contribuindo, nos últimos anos, em média, com 4,1 Tg de $\mathrm{N}_{2} \mathrm{O}$ ano $^{-1}$ (Davidson \& Kanter, 2014; Oenema et al., 2014). As últimas projeções do quinto relatório divulgado pelo Painel Intergovernamental de Mudanças Climáticas (IPCC, 2014) alertam que existe uma tendência de redução de áreas agricultáveis, tornando as terras impróprias para cultivos, devido, às mudanças climáticas.

O uso de implementos agrícolas para preparo do solo, manejo das culturas e resíduos orgânicos, condições gerais de acidez e fertilidade do solo, umidade do solo, e, principalmente, a adição de fertilizantes nitrogenados minerais (Mosier et al., 1998; IPCC, 2007; Miller et al., 2008; Kong et al., 2010; Fub et al., 2011), dentre outros fatores, interferem diretamente na atividade de comunidades microbianas responsáveis pelas reações de desnitrificação (Tatti et al., 2014) e nitrificação. Como resultado dessa atividade microbiana ocorrem alterações dos fluxos de $\mathrm{N}_{2} \mathrm{O}$, como produto intermediário das reações (Bouwman, 1996). Assim, a dinâmica do carbono (C) e nitrogênio $(\mathrm{N})$ orgânico no solo será fortemente influenciada pelos fatores supracitados, sendo determinante para que o solo funcione como fonte ou dreno de $\mathrm{C}$.

No Cerrado brasileiro um dos novos desafios é aliar altas produções com uma agricultura sustentável que forneça biomassa vegetal em quantidade adequada para uma boa cobertura do solo e em qualidade para que haja adequada ciclagem de nutrientes. Para tanto, o uso do sistema plantio direto (PD), tem sido relatado como alternativa para minimizar os impactos causados por práticas que incluem o revolvimento do solo e a 
baixa produção em qualidade de resíduos vegetais e em alguns casos a retirada de resíduos sobre o solo. Assim, o PD apresenta potencial para sequestrar $\mathrm{C}$ e consequentemente reduzir as emissões de gases (Carvalho et al., 2009; Carvalho et al., 2010). No Brasil, aproximadamente 71 milhões de hectares brasileiros estão sob cultivos agrícolas (IBGE, 2014), desse total, mais de 31 milhões de hectares são manejados sob PD (FEBRAPDP, 2012). Esse sistema de manejo, em expansão considerável, tem demandado por maiores esclarecimentos sobre o seu potencial mitigador em comparação ao sistema convencional (PC), no que se refere, especialmente, às emissões de $\mathrm{N}_{2} \mathrm{O}$. As pesquisas atuais, todavia, não correlacionam as emissões de $\mathrm{N}_{2} \mathrm{O}$ com a dinâmica das frações orgânicas formadas em agroecossistemas de longo prazo sob plantio direto.

A identificação de compartimentos ou frações da matéria orgânica do solo (MOS), em geral, ajuda na determinação do tempo de permanência do C no solo e é fundamental para se entender o efeito do manejo agrícola e das interferências edafoclimáticas. Essas frações vêm sendo utilizadas como índices ou indicadores eficientes para avaliar a qualidade da MOS por apresentarem elevada sensibilidade às mudanças no manejo do solo (Plaza-Bonilla et al., 2014). Apesar disso, ainda são escassos os trabalhos que explorem o efeito dos sistemas de manejo nesses diferentes compartimentos, principalmente, nos mecanismos de proteção de $\mathrm{C}$ e $\mathrm{N}$ no solo. Esses mecanismos podem explicar a relação entre o acúmulo de MOS e os fluxos de gases de efeito estufa como o $\mathrm{N}_{2} \mathrm{O}$.

É provável que as frações de maior labilidade como, por exemplo, o carbono lábil e MO particulada, devido ao baixo peso molecular e reduzida complexidade química de seus compostos e em rápida liberação de $\mathrm{C}$, e consequentemente em maiores emissões de $\mathrm{N}_{2} \mathrm{O}$ em solos agrícolas. Figueiredo et al. (2010) observaram que as maiores alterações de $\mathrm{C}$ orgânico por uso do solo no Cerrado ocorreram na fração da MO particulada, por ser mais lábil e, com isso, ser rapidamente decomposta. Nesse sentido, as frações mais estáveis, como os ácidos húmicos, carbono associado à fração mineral, carbono não-hidrolisável, carbono inerte, devido a uma maior capacidade de proteção física do C, em agregados do solo, e química por fortes interações organominerais, permanecem nos solos agrícolas por um período mais longo e, possivelmente, com reduzidas participações nas emissões de $\mathrm{N}_{2} \mathrm{O}$. Cruvinel et al. (2011) observaram fluxos de $\mathrm{N}_{2} \mathrm{O}$ em Latossolo sob PD no Cerrado e definiram como não conclusivos os resultados sobre as emissões de $\mathrm{N}_{2} \mathrm{O}$ e os estoques de $\mathrm{C}$ e $\mathrm{N}$ do solo por haver a 
necessidade de maiores esclarecimentos sobre os efeitos das rotações de culturas e dos fatores edafoclimáticos na dinâmica desse gás.

\section{HIPÓTESES}

$\checkmark \quad$ A conversão de áreas sob vegetação natural do Cerrado em agroecossistemas eleva as emissões de $\mathrm{N}_{2} \mathrm{O}$ do solo;

$\checkmark \quad$ Os fluxos de $\mathrm{N}_{2} \mathrm{O}$ no Cerrado são influenciados pela sazonalidade climática e pelos sistemas de uso do solo;

$\checkmark \quad$ Os agroecossistemas alteram os estoques e a distribuição do carbono orgânico e nitrogênio total no perfil do solo de maneira diferenciada e apresentam relação com as emissões de $\mathrm{N}_{2} \mathrm{O}$;

Sistemas de manejo que promovem maior acúmulo de carbono nas diferentes frações mais estabilizadas/recalcitrantes da matéria orgânica do solo reduzem as emissões de $\mathrm{N}_{2} \mathrm{O}$ para atmosfera;

\section{JUSTIFICATIVA}

Desde a década de 1970 com a expansão das fronteiras agrícolas iniciou-se a ocupação do Cerrado brasileiro. Mediante a excelente estrutura física dos solos do Cerrado, associada a ações que incluíram as correções de acidez e fertilidade dos solos e avanços tecnológicos foi possível que as áreas de cultivo sob o Cerrado atingissem a liderança na produção agrícola de grãos (Peixoto et al., 2010). Considerada atualmente uma das mais importantes fronteiras agrícolas mundiais (MMA, 2014), esse bioma com mais de 80 milhões de hectares ocupados por diferentes usos da terra (Sano et al., 2008), precisou adequar os sistemas de cultivos, culturas e sistemas de manejos. Estimativas indicavam que $50 \%$ dos solos do Cerrado eram potencialmente aráveis (Lopes, 1996) e a partir dessa potencialidade, grandes áreas sob vegetação nativa foram convertidas em cultivos agrícolas, principalmente, sob Latossolos, seguidos pelos Argissolos, que são os principais solos em extensão de área no bioma Cerrado. Contudo, as práticas de manejo convencionais aplicadas nos Latossolos, com quebra de agregados, movimentação e exposição do material orgânico à rápida decomposição e 
mineralização, promoveram impactos negativos na qualidade do solo (Devine et al., 2014).

O processo de conversão de áreas nativas em agrícolas envolve o corte e a queimada da vegetação natural, procedidas pela movimentação do solo, com uso de implementos agrícolas e quebra de estruturas físicas (agregados) com consequentes cultivos. Como consequência dessas alterações, ocorrem reduções dos estoques totais de C (Resck et al., 2008) do solo e interferências na ciclagem de N, juntamente, com emissões consideráveis de $\mathrm{N}_{2} \mathrm{O}$ e todos os demais gases responsáveis pelas mudanças climáticas globais $\left(\mathrm{CO}_{2}\right.$ e $\left.\mathrm{CH}_{4}\right)($ Smith, 1997). Esses gases emitidos da biosfera para a atmosfera (Bernoux et al., 2001) podem, até 2100, segundo projeções, elevar a temperatura média terrestre no Cerrado em 1 à $5,5^{\circ} \mathrm{C}$, reduzindo em até $45 \%$ o total das precipitações (PBMC, 2013).

Nesse contexto, a escolha de sistemas conservacionistas de uso do solo no Cerrado passou a ser condição fundamental para a manutenção da capacidade produtiva desse bioma.

Entre os gases responsáveis pelas mudanças climáticas globais o $\mathrm{N}_{2} \mathrm{O}$ é o que tem o maior potencial de aquecimento global (Signor et al., 2013) e tempo de permanência na atmosfera cerca de cem vezes maior do que o $\mathrm{CO}_{2}$. As maiores quantidades de $\mathrm{N}_{2} \mathrm{O}$ são mediadas por atividades dos microrganismos desnitrificadores dos solos. Como as emissões de $\mathrm{N}_{2} \mathrm{O}$ ocorrem durante o processo incompleto de desnitrificação do $\mathrm{NO}_{3}{ }^{-}$e mineralização das formas orgânicas de $\mathrm{N}$ do solo (Bouwman, 1996) a agricultura influenciará essas emissões mediante: a disponibilidade de nutrientes minerais nitrogenados $\left(\mathrm{NO}_{3}^{-} \mathrm{e} \mathrm{NH}_{4}{ }^{+}\right)$; materiais orgânicos facilmente decomponíveis; umidade, $\mathrm{pH}$ e temperatura dos solos favoráveis; concentração de $\mathrm{O}_{2}$, que é delimitado pelo grau de compactação do solo, textura e saturação dos poros por água; e entre outros fatores edafoclimáticos.

Além de ampliar a produção agrícola por área, a escolha de sistemas de cultivos e manejos que melhor se adequem as condições do Cerrado e que possam reduzir os impactos ambientais negativos por emissão de $\mathrm{N}_{2} \mathrm{O}$, é o mais recente desafio para a agricultura brasileira. Entre as alternativas apresentadas, encontra-se o sistema plantio direto no qual a semeadura é realizada diretamente sob os resíduos da cultura anterior, sem movimentação do solo, exceto na linha de semeadura, com reduções também dos processos erosivos. Apesar da expansão das áreas sob plantio direto e de substanciais ganhos no aumento da produtividade de grãos e na recuperação dos estoques de C, 
ainda existem muitas dúvidas sobre o efeito conservacionista desse sistema. E dada à tendência de muitas áreas sob sistema de manejo PC estarem em processo de conversão para PD, o que corresponde a mais de $40 \%$ do total das áreas agrícolas (FEBRAPDP, 2012; IBGE, 2014), a demanda por maiores esclarecimentos sobre esse sistema de manejo torna-se de fundamental importância. As informações são ainda incipientes, quando se busca resultados de estudos sobre os efeitos dos sistemas de manejo no tempo de ciclagem, formação de frações orgânicas e suas relações com as emissões de $\mathrm{N}_{2} \mathrm{O}$. Segundo Figueiredo et al. (2013) as mudanças nos estoques de carbono e na estratificação da matéria orgânica no perfil do solo podem impactar sobre as emissões de gases de efeito estufa do solo.

As informações sobre a participação das frações orgânicas nas emissões de $\mathrm{N}_{2} \mathrm{O}$ em experimentos de longa duração no Brasil ainda são escassas. Não se sabe quanto do $\mathrm{C}$ e $\mathrm{N}$ presente nessas frações fortemente protegidas e estabilizadas física, química e bioquimicamente participam das reações de desnitrificação. Existem evidências de que são as frações lábeis e ativas que mais participam das reações microbianas, em decorrência da maior disponibilidade dos compostos orgânicos, levando às reduções dos estoques totais de $\mathrm{C}$ e emissões de $\mathrm{CO}_{2}$ na agricultura (Júnior et al., 2017; Matson et al., 2017). Após longo período com entradas significativas de resíduos vegetais e acúmulos de diferentes frações orgânicas sob o PD, possivelmente, as frações estáveis pouco se correlacionariam com os maiores fluxos de $\mathrm{N}_{2} \mathrm{O}$. $\mathrm{O}$ entendimento da dinâmica da ciclagem do $\mathrm{C}$ e $\mathrm{N}$ no solo a partir das diferentes frações orgânicas possibilitaria avançar para respostas que confirmem o efeito mitigador de sistemas de manejo, como, por exemplo, o PD.

\section{OBJETIVO GERAL}

Avaliar o efeito de agroecossistemas sob plantio direto e convencional no acúmulo de frações da matéria orgânica do solo e a contribuição desses sistemas nas emissões de óxido nitroso em um experimento de longa duração no Cerrado.

\subsection{OBJETIVOS ESPECÍFICOS}

Avaliar o efeito dos agroecossistemas nos fluxos de óxido nitroso do solo; 
Avaliar o efeito da sazonalidade pluviométrica e das rotações culturais nos fluxos de óxido nitroso do solo;

Avaliar o efeito das co-variáveis edafoclimáticas (nitrato, amônio, espaço poroso saturado por água, umidade do solo e temperatura do solo) nos fluxos de óxido nitroso do solo sob diferentes usos;

Avaliar a influência de agroecossistemas no acúmulo de frações lábeis e estáveis da matéria orgânica do solo;

Avaliar a relação existente entre as emissões acumuladas de óxido nitroso e a formação de frações lábeis e estáveis da matéria orgânica do solo em diferentes sistemas de uso do solo.

\section{REVISÃO DE LITERATURA}

\subsection{PRODUÇÃO DE ÓXIDO NITROSO EM SOLOS AGRÍCOLAS}

$\mathrm{O}$ óxido nitroso $\left(\mathrm{N}_{2} \mathrm{O}\right)$ é um dos gases envolvidos no aquecimento global. $\mathrm{O}$ aquecimento da atmosfera provém dos raios ultravioletas e infravermelhos emitidos pelo sol. Os raios que não forem absorvidos ou refletidos pela superfície terrestre e corpos refletores serão absorvidos por gotas de água e gases presentes no ar. Desse modo, gases como, o $\mathrm{N}_{2} \mathrm{O}$, dióxido de carbono $\left(\mathrm{CO}_{2}\right)$ e metano $\left(\mathrm{CH}_{4}\right)$, chamados de gases do efeito estufa (GEE) e presentes na troposfera, irão absorver e emitir radiação infravermelha. Este processo de aquecimento é natural e auxilia na manutenção da temperatura e balanço energético da Terra em concentrações normais (IPCC, 2013). A grande preocupação da comunidade científica está justamente no aumento das concentrações dos gases supracitados, atribuídas às ações antrópicas realizadas nos últimos anos e relacionadas às mudanças climáticas vigentes. Entre esses gases, o $\mathrm{N}_{2} \mathrm{O}$ é um dos principais gases de relevância relacionado às atividades agrícolas.

$\mathrm{O}$ interesse nas altas emissões de $\mathrm{N}_{2} \mathrm{O}$ aumentou consideravelmente desde que foi identificado como a mais importante ameaça à camada de ozônio do século 21 (Ravishankara et al., 2009), além de ser um GEE. Em concentrações normais, consideravelmente baixas, quando comparadas às concentrações de $\mathrm{CO}_{2}, \mathrm{o} \mathrm{N}_{2} \mathrm{O}$ não seria uma ameaça se suas concentrações não estivessem aumentando. Cada gás apresenta uma capacidade de aquecimento em função de suas características 
moleculares e do seu tempo de permanência na atmosfera (Gomes, 2006). Baseado nessas características é realizado, para cada gás, um cálculo do potencial de aquecimento global (PAG) tendo como referência o $\mathrm{CO}_{2}$. $\mathrm{O} \mathrm{N}_{2} \mathrm{O}$ apresenta um PAG de 310 vezes a unidade de massa do $\mathrm{CO}_{2}$ (IPCC, 2007). Nesse contexto, as mais diversas pesquisas por todo o mundo alertam para um significativo aumento da concentração desse gás na atmosfera nas últimas décadas. Foi identificado um incremento relativo de $\mathrm{N}_{2} \mathrm{O}$ na atmosfera de $0,25 \%$ entre 2012 e 2013, o que significa um contínuo aumento médio nos últimos dez anos de $0,82 \mathrm{ppb}$ ano $^{-1}$ (WMO, 2014). Os solos agrícolas são as principais fontes primárias antropogênicas vinculadas às emissões desse gás de maior impacto nos países agrícolas e em desenvolvimento, como, por exemplo, o Brasil (MCTI, 2014).

Sob vegetação nativa de Cerrado, em períodos de baixa umidade do solo, as emissões e oscilações de $\mathrm{N}_{2} \mathrm{O}$ são muito baixas, quando comparadas às áreas de cultivos agrícolas (Cardoso et al., 2001) e influenciadas pelas variações climáticas sazonais (Siqueira Neto et al., 2011). A abertura de novas áreas agrícolas, com a intenção de expandir a agricultura e, o uso intensivo dos solos, com a substituição da vegetação nativa, queima de biomassa vegetal, monocultivos de leguminosas e, significativos usos de fertilizantes minerais nitrogenados, enquadraram o Brasil como um dos principais emissores de $\mathrm{N}_{2} \mathrm{O}$, entre os países da América Latina (Bustamante et al., 2014). Aliado a isso, vários estudos (Bouwman, 1996; Davidson, 2009; Baggs, 2011; UNEP, 2013; Stocker et al., 2013) também indicam que as atividades agrícolas, tais como a produção animal e vegetal, são fontes de formação de $\mathrm{N}_{2} \mathrm{O}$, por causa da grande demanda e uso crescente de fertilizantes nitrogenados.

A Organização Meteorológica Mundial (WMO, 2014) confirma que são as ações antrópicas, por uso em maior escala de fertilizantes nitrogenados sintéticos nos campos agrícolas, pela queima de combustíveis fósseis e biomassa vegetal, dentre outros, que resultam as maiores emissões de $\mathrm{N}_{2} \mathrm{O}$ para a atmosfera. Estudos recentes de modelagem, realizados por Thompson et al. (2014), concluíram que os solos tropicais e subtropicais da América do Sul tendem a ter maiores variações e serem fontes de emissões globais de $\mathrm{N}_{2} \mathrm{O}(13 \pm 4 \%)$, atrás apenas de regiões no Sul da Ásia $(20 \pm 3 \%)$. Os solos agrícolas tropicais e subtropicais são fortemente influenciados pela grande diversidade de zonas climáticas, com ampla faixa latitudinal e temperatura que contrastam com diferentes gradientes de precipitação afetando os processos bióticos (MCTI, 2014; Thompson et al., 2014). 
O processo de emissão de $\mathrm{N}_{2} \mathrm{O}$ no solo envolve processos bióticos e abióticos. Por mais que ocorram inúmeras reações metabólicas abióticas, os processos bióticos, ainda serão os processos dominantes. Por vias bióticas os processos de emissão de $\mathrm{N}_{2} \mathrm{O}$ do solo contribuem com aproximadamente $90 \%$ da produção global (Paul \& Clark, 1996). A ciclagem do nitrogênio (N) no solo com a formação de compostos bioativos, que inclui amina $\left(\mathrm{NH}_{2}\right)$, amônio $\left(\mathrm{NH}_{4}{ }^{+}\right)$, amônia livre $\left(\mathrm{NH}_{3}\right)$, nitrito $\left(\mathrm{NO}_{2}{ }^{-}\right)$, nitrato $\left(\mathrm{NO}_{3}{ }^{-}\right)$, é realizada por diversos microrganismos (Oliveira, 2012). Após a fixação de $\mathrm{N}_{2}$ e assimilação, deposição de resíduos orgânicos e fertilizações nitrogenadas ocorrem etapas de amonificação, nitrificação, desnitrificação e redução dissimilativa de compostos de nitrogênio oxidados. Para a ciclagem de N no solo e consequente emissão de $\mathrm{N}_{2} \mathrm{O}$, as etapas de nitrificação e desnitrificação são as mais relevantes (Matson \& Vitousek, 1990), embora esse gás não seja o produto final dessas reações. E, no que se refere à contribuição da agricultura para as emissões de $\mathrm{N}_{2} \mathrm{O}$, esses processos são os principais do ciclo do nitrogênio de importância para os solos (Signor \& Cerri, 2013).

A nitrificação que ocorre em condições aeróbias está relacionada ao suprimento de amônio e, é realizada por bactérias quimioautotróficas nas fases de nitritação e nitratação (Davidson et al., 1993; Signor \& Cerri, 2013). As comunidades de bactérias nitrificadoras, na maioria, oxidativas de amônia (AOB) e amônia archaea oxidante (AOA), oxidam o amônio $\left(\mathrm{NH}_{4}^{+}\right)$, na fase de nitritação, para nitrito $\left(\mathrm{NO}_{2}\right)$, por Nitrossomonas sp., Nitrosospira sp. e Nitrosococus sp. $\mathrm{O} \mathrm{NO}_{2}$ formado será oxidado, na fase de nitratação através das Nitrobacter sp., Nitrosospira sp. e Nitrococus sp., para nitrato $\left(\mathrm{NO}_{3}{ }^{-}\right)$(Moreira e Siqueira, 2006), além da participação de alguns tipos de fundos (Maeda et al., 2015).

Já a desnitrificação é realizada por bactérias heterotróficas anaeróbias facultativas e dependem da disponibilidade de $\mathrm{C}$ orgânico e $\mathrm{NO}_{3}{ }^{-}$. As desnitrificadoras reduzem o $\mathrm{NO}_{3}{ }^{-}$para $\mathrm{N}_{2}$, com $\mathrm{N}_{2} \mathrm{O}$ e óxido nítrico (NO), como produtos gasosos intermediários (Wrage et al., 2001). Em resumo, $\mathrm{o} \mathrm{NO}_{3}{ }^{-}$receberá elétrons reduzindo a $\mathrm{NO}_{2}^{-}$, NO e $\mathrm{N}_{2} \mathrm{O}$ (Thomson et al., 2012). O carbono envolvido na ciclagem fornecerá (doador) elétrons e será fonte de energia aos desnitrificadores heterotróficos. O processo de desnitrificação é catalisado por uma série de enzimas codificadas por diversos genes. Dentre elas a enzima nitrato redutase (codificada por genes Narg e Napa), nitrito redutase (codificada por genes nirK/S), óxido nítrico redutase (codificada por gene norB) e óxido nitroso redutase (codificado pelos genes nosZ) (Wrage et al., 2001; Bakken et al., 2012; Barton et al., 2013). Ressalta-se que os processos de nitrificação e 
desnitrificação podem ocorrer simultaneamente haja vista que no interior dos agregados podem ocorrer microssítios de aerobiose e anaerobiose (Giacomini et al., 2006).

A respiração microbiana dentro do ciclo do $\mathrm{N}$ está associada diretamente ao processo de desnitrificação, e juntamente com a redução do $\mathrm{NO}_{3}{ }^{-}$ocorre a oxidação da MOS para obtenção de energia pelos microrganismos. Esse processo é favorecido em condições de elevada umidade no solo, onde o oxigênio é limitado e o $\mathrm{NO}_{3}{ }^{-}$e $\mathrm{C}$ orgânico estão disponíveis às atividades microbianas (Luo et al., 2010). Durante a nitrificação e desnitrificação, por processos microbianos no solo, as interferências decorrentes do manejo agrícola incidirão na ciclagem dos nutrientes, causando alterações na composição da MOS (Six et al., 2002), formação de agregados (Borton et al., 2013) com rápida decomposição do C orgânico anteriormente protegido alterando os estoques totais de $\mathrm{C}$.

A produção e o uso intensivo de fertilizantes nitrogenados e a queima de combustíveis fósseis têm acelerado todos os processos do ciclo do nitrogênio e impulsionado a nitrificação e desnitrificação. Em agroecossistemas, $\mathrm{o} \mathrm{NO}_{3}{ }^{-}$é fornecido aos microrganismos desnitrificadores na forma de fertilizantes, dejetos animais, resíduos de colheitas e MOS e, em ecossistemas naturais, através da fixação biológica de $\mathrm{N}_{2}$ e deposição atmosférica (Bouwman et al., 2013). Na totalidade das reações que ocorrem no solo o processo de desnitrificação é tido como uma sobrecarga de $\mathrm{N}$, que se traduz em perdas de nitrogênio dos sistemas agrícolas. Tais perdas ocorrem na conversão de $\mathrm{NO}_{3}{ }^{-} \mathrm{em}$ formas gasosas de $\mathrm{N}$, incluindo o $\mathrm{N}_{2} \mathrm{O}$. Os microrganismos nitrificadores e desnitrificadores do solo transferem essa sobrecarga para a atmosfera com impactos significativamente negativos ao meio ambiente.

O que normalmente se observa nas pesquisas de campo, ao se analisar os efeitos da agricultura, bem como o efeito do preparo do solo, nas emissões de $\mathrm{N}_{2} \mathrm{O}$, são relatos com resultados contraditórios. A dificuldade em se concluir quais fatores são determinantes nas emissões desse gás, está justamente na interferência e variabilidade das interações das condições ambientais que são comumente amparadas pelo histórico agrícola da área (Hénault et al., 2012). Nesse contexto, podem ser consideradas as interferências de diversos fatores, chamados de co-variáveis nas emissões de $\mathrm{N}_{2} \mathrm{O}$ sob diferentes sistemas de manejo: teor de carbono orgânico, umidade do solo, temperatura do solo (Saggar et al., 2013) e do ar, pH do solo (Macdonald et al., 2011), diferentes doses e tipos de adubação nitrogenada, adubação orgânica (Ollivier et al., 2013), além do próprio sistema de manejo (Kong et al., 2010; Smith et al., 2010; Melero et al., 2011; 
Zhang et al., 2014). Também podem ser considerados os tipos de culturas e a microbiota do solo (Smith et al., 2010; Levy-Booth et al., 2014), genes e enzimas (Ollivier et al., 2013; Pauleta et al., 2013), métodos de amostragens (Jones et al., 2011; Wang et al., 2014), dentre outros. Essas determinações são de fundamental importância para a definição de quais padrões poderão ser adotados a fim de se reduzir e/ou mitigar as emissões de $\mathrm{N}_{2} \mathrm{O}$ em concentrações danosas para o meio ambiente através dos sistemas agrícolas.

\subsection{EFEITOS DOS SISTEMAS DE MANEJO NAS EMISSÕES DE ÓXIDO NITROSO NO CERRADO}

O cenário da agricultura brasileira desenvolvida, principalmente, na região do Cerrado sofreu intensas modificações desde o seu início em 1970, principalmente, após incentivos do governo federal para expandir a agricultura na região central do Brasil. Com o advento da agricultura o bioma passou a ter importante papel na produção de alimentos (Wendling et al., 2014), impulsionado pela crescente demanda por alimentos e crescente aumento populacional. Diversas são as pesquisas sob o Cerrado com o objetivo final de aumentar produções por área plantada, adaptações às variações edafoclimáticas e, principalmente, mudanças para sistemas de manejo mais sustentáveis. Aliada a essas mudanças, atualmente, há preocupações do efeito da agricultura mundial e produção de alimentos no aquecimento global, com foco nas emissões de $\mathrm{N}_{2} \mathrm{O}$ (Oenema et al., 2014). Não obstante, essa também é uma realidade para as áreas agrícolas no Cerrado (Siqueira Neto et al., 2011).

Os diferentes sistemas de manejos desenvolvidos em campo resultam em alterações da matéria orgânica do solo (MOS). Como a MOS é formada por $58 \%$ de C (Stevenson \& Cole, 1999), os estoques finais de C e N, também serão alterados caso ocorram mudanças na agregação do solo, que por sua vez, protege fisicamente o material orgânico da ação decompositora dos microrganismos e suas enzimas. Além do fator físico, a composição química das culturas, fragmentações dos resíduos orgânicos, maior exposição às intempéries climáticas, distribuição desses resíduos no perfil do solo, como também alterações químicas e da própria biologia edáfica irão interferir na ciclagem da MOS. Sabe-se que as comunidades dos microrganismos desnitrificantes são as responsáveis pelas maiores emissões de $\mathrm{N}_{2} \mathrm{O}$ nos solos agrícolas. Segundo Bouwman (1996), as emissões são resultantes de processos intermediários, em que os 
microrganismos respondem sensivelmente as mudanças ocorridas nos sistemas de manejos.

O sistema PD é beneficiado pela entrada de diferentes aportes orgânicos de $\mathrm{C} e$ N. A qualidade e quantidade dos aportes orgânicos significam diferentes taxas de ciclagem de C e N (Kong et al., 2010) que mediadas pelos microrganismos, resultarão na formação de diferentes frações orgânicas no solo. Já o sistema de manejo convencional, contrário ao PD, por muitos anos causou alterações de ordens físicas, químicas e biológicas nos solos agrícolas do Cerrado sem o fornecimento ou reposição de modo significativo de C orgânico.

Todavia, quanto às emissões de $\mathrm{N}_{2} \mathrm{O}$ observadas sob o enfoque de sistemas de manejo e práticas agrícolas as informações são pouco precisas, divergentes e, muitas vezes, sem diferença entre os sistemas PD e PC. A existência de co-variáveis edafoclimáticas delimita tanto uma dependência entre esses diversos fatores como também interferem nos resultados das pesquisas. E devido às dificuldades de se conduzir experimentos de longa duração e coletar dados com base nos protocolos estabelecidos pelo IPCC, são reduzidos os trabalhos de monitoramento de óxido nitroso conduzido no Brasil. Entre esses trabalhos, por exemplo, Carvalho et al. (2006) relataram que as emissões de $\mathrm{N}_{2} \mathrm{O}$ após cinco dias da adubação em cobertura com uréia em milho, sob sistema PC e PD em Cerrado, foram abaixo do limite de detecção, resultando em diferenças não significativas entre os sistemas de manejo.

Já sob outras condições edafoclimáticas, em trabalho realizado na Espanha, Melero et al. (2011) compararam o PD com o PC de longa duração (27 anos) sob rotação de culturas. Nas avaliações realizadas por esses autores em um Vertissol, observaram que os fluxos de $\mathrm{N}_{2} \mathrm{O}$ no PD foram menores apenas durante o crescimento das culturas, quando comparado ao PC. Relataram que após a colheita o número de populações de desnitrificadores no PD reduziu, levando a concluírem que são limitados os impactos positivos desse sistema para reduzirem as emissões em Vertissol, no regime de rotação e fertilização, com emissões similares ao PC. Do mesmo modo, Bandyopadhyay \& Lal (2014) não observaram diferenças nas emissões acumuladas de $\mathrm{N}_{2} \mathrm{O}$ entre os sistemas PD e PC, em experimento de 16 anos em Columbus, Ohio. Os resultados do estudo anterior confirmaram que existiriam sim, maiores fluxos de $\mathrm{N}_{2} \mathrm{O}$ na conversão das áreas de florestas para sistemas agrícolas a partir da ruptura dos macroagregados em estudos de incubação de solo. 
Em outro experimento de longa duração, Wagner-Riddle et al. (2007), no Canadá, confirmaram o efeito do PD nas reduções das emissões de $\mathrm{N}_{2} \mathrm{O}$, quando comparado ao sistema de produção convencional. Na mesma área experimental, Smith et al. (2010), reafirmaram os resultados obtidos por Wagner-Riddle e seus colaboradores, ao avaliarem o efeito dos sistemas PD e PC nas emissões de $\mathrm{N}_{2} \mathrm{O}$, no inverno e primavera, e os impactos em comunidades nitrificadoras e desnitrificadoras. Ressaltaram a ocorrência de mudanças no ciclo do $\mathrm{N}$, com maiores acúmulos de $\mathrm{NH}_{4}{ }^{+}$, no inverno, e um aumento no fluxo de $\mathrm{N}_{2} \mathrm{O}$ no degelo da primavera. Os autores concluíram que, as estruturas das comunidades nitrificantes e desnitrificantes variam tanto com a estação do ano, como com as práticas agrícolas.

Em cenários agrícolas estudados sob o enfoque de modelagem existe ainda a possibilidade de ocorrerem maiores fluxos de $\mathrm{N}_{2} \mathrm{O}$ decorrentes do PD devido aumento na disponibilidade de $\mathrm{N}$ (Del Grosso et al., 2002). As maiores emissões de $\mathrm{N}_{2} \mathrm{O}$ provenientes dos sistemas orgânicos são perceptíveis principalmente, após incorporações recentes de resíduos orgânicos de $\mathrm{C}$ e $\mathrm{N}$ que intensificam as atividades microbianas (Risk et al., 2013). Nesse contexto, a qualidade dos resíduos orgânicos, a partir de suas composições químicas, irá interferir substancialmente não só na ciclagem de $\mathrm{C}$ e $\mathrm{N}$, mas também, na dinâmica dos microrganismos nitrificadores e desnitrificadores do solo mediante a relação $\mathrm{C} / \mathrm{N}$ que for estabelecida. Baixas quantidades de $\mathrm{N}$ disponível $\left(\mathrm{NH}_{4}{ }^{+}\right.$e $\left.\mathrm{NO}_{3}{ }^{-}\right)$implicam em reduzidas imobilizações, em contraste, maiores emissões de $\mathrm{N}_{2} \mathrm{O}$ podem ocorrer por maior disponibilidade de $\mathrm{N}$ aos nitrificadores e desnitrificadores (Baggs et al., 2000). Cheng et al. (2014) relataram que os efeitos de temperaturas do solo acima de $30^{\circ} \mathrm{C}$ sobre as taxas líquidas de emissão de $\mathrm{N}_{2} \mathrm{O}$ variaram de acordo com as espécies de árvores que existem nas florestas subtropicais.

A escolha de culturas como leguminosas com elevado potencial de fixação de nitrogênio, gramíneas com sistemas radiculares de ação agregadora das partículas do solo, resultam em efeitos benéficos sobre as propriedades físicas, químicas e biológicas do solo. Do mesmo modo, para mitigar os impactos negativos causados pela agricultura e reduzir as emissões de $\mathrm{N}_{2} \mathrm{O}$, também são utilizadas estratégias que envolvem a rotação e/ou sucessão de culturas. Segundo avaliações de Siqueira Neto et al. (2011), os maiores fluxos de $\mathrm{N}_{2} \mathrm{O}$ estavam correlacionadas com o maior conteúdo de $\mathrm{C}$ e $\mathrm{N}$ microbiano no sistema de semeadura direta de 12 de anos de implantação. 
A influência do maior aporte orgânico de $\mathrm{C}$ e $\mathrm{N}$ também foi observado por Ball et al. (2014) em período chuvoso na Escócia. Sob rotação de culturas entre espécies de gramíneas/leguminosas o efeito da incorporação de resíduos nos cultivos orgânicos foi suficiente para aumentar as emissões de $\mathrm{N}_{2} \mathrm{O}$. Esses resultados possivelmente estão vinculados a maior disponibilidade de material orgânico como $\mathrm{C}$ e $\mathrm{N}$ aos microrganismos edáficos. Os resíduos vegetais provenientes da gramínea Uruchloa ruziziensis resultaram em acréscimo de $\mathrm{C}$ orgânico, e, maior atividade microbiana sob cultivo de feijão-comum (Carvalho et al., 2012). Esses resultados favoreceram também a formação de maiores fluxos de $\mathrm{N}_{2} \mathrm{O}$, independente das adubações com $\mathrm{N}$. O evento da sucessão de culturas com a utilização de plantas de cobertura, na forma de adubação nitrogenada orgânica, age interferindo na ciclagem de $\mathrm{C}$ e $\mathrm{N}$, produção de $\mathrm{NO}_{3}{ }^{-}, \mathrm{NH}_{4}{ }^{+} \mathrm{e}$ $\mathrm{C}$ orgânico dissolvido e, consequente, oscilações nos fluxos de $\mathrm{N}_{2} \mathrm{O}$. Contudo, a utilização da fertilização nitrogenada com uréia, ainda assim, resultará em emissões de $\mathrm{N}_{2} \mathrm{O}$ duas vezes maiores que a incorporação dos resíduos de leguminosas, usadas como plantas de cobertura e adubação verde (Bayer et al., 2015).

Todas essas possibilidades de cultivo vinculadas aos sistemas de manejo abrem questionamentos para muitas possibilidades na maneira de conduzir cada área de cultivo agrícola a fim de minimizar as emissões de óxido nitroso. Ou seja, os resultados são muito divergentes e em cada localidade e seu microclima haverá efeitos pontuais considerando o bioma que os cultivos agrícolas estarão inseridos.

\subsubsection{Co-variáveis edafoclimáticas e emissões de óxido nitroso}

$\mathrm{O}$ processo de síntese e emissão de $\mathrm{N}_{2} \mathrm{O}$ é fortemente influenciado por fatores que vão além de rotação de culturas, fontes de nitrogênio e mobilização do solo (Signor \& Cerri, 2013). Através dos microrganismos nitrificadores e desnitrificadores do solo, ocorrem interações com fatores climáticos como temperatura, umidade, e interferência de fatores edáficos como textura, $\mathrm{pH}$ e temperatura do solo, material orgânico disponível, principalmente, a participação dos nutrientes $\mathrm{C}$ e N. Todos esses fatores terão influência primordial no potencial de desnitrificação resultando em variadas emissões de $\mathrm{N}_{2} \mathrm{O}$ (Thomson et al., 2012). Geralmente, uma combinação de clima, histórico de cultivos, variabilidade sazonal e práticas de campo desempenham um papel importante na quantidade de $\mathrm{N}_{2} \mathrm{O}$ que é emitida de uma propriedade agrícola (Smith et al., 2010). Até mesmo a abundância de genes de comunidades de microrganismos 
desnitrificadores é menor em solos com maiores disponibilidades de $\mathrm{C}$ e $\mathrm{N}$, com menos cópias de Genes, menor será a capacidade de fecharem o ciclo do $\mathrm{N}$ e produzir $\mathrm{N}_{2} \mathrm{O}$ (Clark et al., 2012).

Como a desnitrificação é um processo anaeróbio, o oxigênio $\left(\mathrm{O}_{2}\right)$ presente no solo funciona como um importante regulador das reações (Tiedje, 1988). Morley \& Baggs (2010) relataram que as emissões de $\mathrm{N}_{2} \mathrm{O}$, após a adição de $\mathrm{NO}_{3}{ }^{-}$e diferentes fontes de $\mathrm{C}$, variaram conforme a quantidade de $\mathrm{C}$ e das concentrações de $\mathrm{O}_{2}$. Dada a importância da aeração do solo quanto ao seu conteúdo de $\mathrm{O}_{2}$, os fatores compactação e, consequentemente, densidade do solo, também terão significativos efeitos nas emissões de $\mathrm{N}_{2} \mathrm{O}$, bem como, os espaços porosos saturados por água de infiltração (EPSA). Solos com baixa umidade refletem em reduzidas comunidades nitrificadoras e desnitrificadoras, assim como, reduzida fixação de N (Bisset et al., 2011). O aumento da saturação dos espaços porosos é seguido, normalmente, por aumentos correlacionados de maiores fluxos gasosos de $\mathrm{N}_{2} \mathrm{O}$ (Mecdonald et al., 2011). Com mais de $80 \%$ dos EPSA as reações de desnitrificações aumentam e, consequentemente, ocorrem aumentos nos fluxos de $\mathrm{N}_{2} \mathrm{O}$ (Menéndez et al., 2012). No entanto, esse conteúdo de umidade dos solos e sua correlação com as intensidades das emissões de $\mathrm{N}_{2} \mathrm{O}$, são regulados também pela textura de cada tipo de solo e sistema de aeração proporcionado.

$\mathrm{O} \mathrm{pH}$ do solo é outro fator edáfico que interfere nas reações de nitrificação e desnitrificação. Em áreas de cultivos inundadas a correção do $\mathrm{pH}$ do solo é determinante para minimizar as reações de desnitrificação (Hansen et al., 2014). De modo que, o baixo $\mathrm{pH}$ do solo desfavorece as populações de microrganismos nitrificadores (Bijlsma et al., 2000). O pH do solo é um importante parâmetro, por exemplo, em trabalhos em que são aplicados substratos de origens animais e avaliação de emissões de $\mathrm{N}_{2} \mathrm{O}$, com maiores emissões desse gás em solos ácidos, quando comparados aos solos alcalinos (Robinson et al., 2014). Em solos agrícolas ácidos, no Japão, que produziam chá ( $C$. sinensis L.), a aplicação de calcário mais $\mathrm{N}$ reduziu os processos de nitrificação e desnitrificação (Yamamoto et al., 2014). A aplicação do calcário provavelmente interferiu nas atividades microbianas e suas reações, com reduções nas emissões de $\mathrm{N}_{2} \mathrm{O}$.

As atividades dos microrganismos além de serem reguladas pela umidade do solo também são reguladas pela temperatura, determinando a intensidade das reações que ocorrem. Para as emissões de $\mathrm{N}_{2} \mathrm{O}$ esses fatores também devem ser considerados ao se analisar a intensidade dos nitrificadores e desnitrificadores edáficos. A mineralização 
do $\mathrm{C}$ do solo juntamente com maiores fluxos de $\mathrm{N}_{2} \mathrm{O}$ deverá acontecer na medida em que a temperatura do solo aumenta (Wang et al., 2014). Em temperaturas amenas as taxas de conversão de $\mathrm{N}$ são menores (Hao et al., 2001). Em solos com temperatura inferiores a $5^{\circ} \mathrm{C}$ ou superiores a $40^{\circ} \mathrm{C}$ e em excesso de água a taxa de nitrificação é próxima de zero (Lewis, 1986). A exponencial relação formada entre o aumento de temperatura do solo e as variações nas emissões de $\mathrm{N}_{2} \mathrm{O}$ explica a influência sazonal nas diferenças de fluxos (Zang \& Han, 2008) por estimular a respiração do solo e, aumentar também os sítios de anaerobiose onde à desnitrificação pode acontecer (Signor \& Cerri, 2013).

As fertilizações nitrogenadas com efeito determinante para a ocorrência de maiores fluxos de óxido nitroso são as mais questionadas entre as co-variáveis de interferência. Alguns trabalhos, realizados principalmente sob condições extremas de clima enfatizam que as maiores diferenças nas emissões de $\mathrm{N}_{2} \mathrm{O}$ não estão somente entre os sistemas de manejo, mas sim, nas fontes de fertilização nitrogenada. Sob cultivo convencional regional, no inverno, por um ano na Alemanha, Lebender et al. (2014) verificaram em três áreas que, independente das fontes nitrogenadas aplicadas, as emissões acumuladas de $\mathrm{N}_{2} \mathrm{O}$ foram sempre superiores aos controles não-fertilizados. Já nos trópicos, Signor et al. (2013), em dois canaviais com mais de 20 anos conduzidos no Brasil, relataram que não só as diferentes doses de fertilização nitrogenada aplicadas ao solo influenciaram as perdas de $\mathrm{N}$ por emissões de $\mathrm{N}_{2} \mathrm{O}$ como também as diferentes fontes de adubos nitrogenados. Mesmo sem diferenças significativas entre os tratamentos avaliados, Hickman et al. (2014) observaram que no oeste do Quênia, África, as maiores emissões de $\mathrm{N}_{2} \mathrm{O}$ ocorreram após aplicação da maior dose de $\mathrm{N}$ aplicada $\left(200 \mathrm{~kg} \mathrm{ha}^{-1}\right)$. Todos esses resultados relatados mostram que as análises de fluxos de óxido nitroso não podem ser isoladas, visto que existe interferência não apenas de uma variável, mas, sim, de diversos fatores que agem diferentemente de acordo o tipo de solo, clima e manejo de cada microrregião agrícola.

\subsection{FRAÇÕES LÁBEIS E ESTÁVEIS MATÉRIA ORGÂNICA E EMISSÕES DE ÓXIDO NITROSO DO SOLO}

Devido à grande complexidade e diversidade estrutural no seu processo de formação, a MOS possui variados compostos orgânicos na sua constituição. Para facilitar a compreensão dos diferente compostos orgânicos na sua constituição, a MOS 
pode ser estudada por meio de suas frações ou compartimentos (Wander, 2004). Todavia, a compreensão real da formação de cada compartimento orgânico e a dinâmica de funcionamento no solo ainda não foram totalmente esclarecidas. Com base na complexidade de suas estruturas químicas e possíveis mecanismos de formação dos compartimentos, diferentes modelos conceituais foram criados para fracionar a MOS. Os atuais modelos conceituais baseiam-se no grau de localização, composição química ou grau de estabilidade da matéria orgânica (Diekow, 2003). Duxbury et al. (1989) descrevem os componentes orgânicos em três reservatórios: biológico (formado pelos microrganismos); lábil (formado por materiais prontamente disponíveis para decomposição); e físico-químico (física e quimicamente protegidos do ataque de microrganismos).

De modo geral, os compartimentos ou reservatórios da MOS estão intimamente relacionados às diferenças na dinâmica de formação desses compartimentos baseados em fatores biológicos, físicos e químicos, ou, na interação entre eles. A funcionalidade e atuação desses fatores, por fim, também irão definir o tempo de permanência desses compostos orgânicos no solo. Materiais orgânicos mais recentes são biologicamente mais ativos; os intermediários contribuem para o estado físico do solo; e materiais de maior tempo de resistência terão influências sobre as reações físico-químicas do solo (Wander, 2004). A lenta degradação da MOS pode ocorrer em escala de tempo de centenas a milhares de anos (Oades, 1995). A primeira fase da decomposição leva cerca de 1 a 2 anos com rápida decomposição, por isso, denominado de compartimento lábil ou ativo (Jenkinson \& Ladd, 1981). Alguns autores enquadram o termo "ativo" apenas para o C que compõem os microrganismos. A fase intermediária de decomposição leva cerca de 10 a 100 anos, e a muito lenta responsável por depósitos orgânicos muito estabilizados, de 100 a mais de 1000 anos (Falloon \& Smith, 2000).

Os componentes orgânicos que permanecem por mais tempo no solo são chamados de resistentes, recalcitrantes ou estáveis. As frações estáveis no processo de formação sofreram influência de mecanismos que possibilitaram a estabilização dessas frações por meio de proteção ao ataque microbiano edáfico. Os mecanismos de estabilização da MOS também possibilitam a separação dos compartimentos orgânicos do solo em lábeis, ativos e estáveis, onde os estáveis foram formados por interferência dos mecanismos físicos e químicos. A estabilidade física da MOS é caracterizada pela sua proteção em agregados do solo, que reduzem o ataque microbiano (Elliot \& Coleman, 1988) e intempéries climáticas. A estabilidade química ocorre por meio de 
fortes associações organo-minerais (Stevenson, 1994; Chistensem, 1996; Sollins et al., 1996; Baldodock \& Skjemstad, 2000; Von Lutzow et al., 2006). Christensen (1996) e Stevenson (1994) propõem a existência de mais um terceiro mecanismo de estabilização chamado de bioquímico. A estabilização bioquímica ocorre devido a uma complexa composição química dos materiais orgânicos que pode ser inerente ao material vegetal ou ser atingido durante a decomposição através da condensação e complexação dos resíduos, o que torna essa fração mais resistente (Six et al., 2002). No entanto, a proporção de contribuição desses diferentes processos na estabilização da MOS ainda não está clara (Mikutta et al., 2006).

Além disso, também não se sabe como estes processos atuam nas disponibilidade de $\mathrm{N}$ e, consequentemente, nos fluxos de $\mathrm{N}_{2} \mathrm{O}$ do solo, o que poderia confirmar, ou não, se o potencial mitigador de sistemas de manejo como o PD está baseado na estruturação do solo e no acúmulo de MOS. A compreensão de quanto as frações da MOS participam nas emissões de $\mathrm{N}_{2} \mathrm{O}$ é de extrema importância para o correto manejo dos solos agrícolas, uma vez que as pesquisas até então realizadas, tiveram enfoque apenas nas relações entre MOS e emissões de $\mathrm{CO}_{2}$.

Os procedimentos químicos e físicos de separação das frações orgânicas do solo diversificam-se em função do objetivo da extração por tipo de fração orgânica que se deseja isolar e identificar. Usualmente utiliza-se o fracionamento químico para determinar as substâncias húmicas (humina, ácido húmico, ácido fúlvico e ácido fúlvico livre). Estas frações representam mais de $80 \%$ do C presente no solo e são diferenciadas pela cor, massa molecular, grupos funcionais e grau de polimerização (Stevenson, 1994), características estas, que as qualificam como frações de maior estabilidade. Ao avaliar os métodos de separação químico, físico e a combinação dos dois para determinação de CO estável, Jagadamma \& Lal (2010) relatam que para isolamento de frações estáveis da MOS os procedimentos por métodos físicos foram significativamente mais expressivos que os métodos químicos. Lopez-Sangil \& Rovira (2013) acrescentam que apesar dos métodos químicos serem eficientes para expor diferentes frações organo-minerais, a sua utilização para extrações de frações estáveis do complexo organo-minerais pode não solubilizar essas frações por inteiro, devido às fortes ligações químicas entre os minerais e as frações orgânicas. Alguns autores relatam que as fortes ligações do material mineral na fração argila juntamente com os óxidos de ferro e alumínio em superfície e em maiores profundidades são os agentes mais importantes na estabilidade da matéria orgânica, responsáveis pelas maiores 
formações do complexo organo-mineral (Rumpel et al., 2008; Rumpel \& Kogelknabner, 2011). A matéria orgânica associada a minerais do solo é constituída principalmente por tecidos microbianos ou metabólitos que são estabilizados por meio de interação organo-mineral, através de diversos processos de adsorção (Kleber et al., 2011). Essa associação de carbono com partículas minerais é dita como preferencial nas frações finas e com uma retenção de carbono de longo prazo.

No que se refere às frações lábeis e ativas, como por exemplo, o C lábil e fração leveda MOS (lábeis) e o carbono da biomassa microbiana (ativo), também são fracionadas por procedimentos físicos e químicos. Essas frações são comumente utilizadas para avaliar as mudanças recentes decorrentes do sistema de manejo agrícola. Através do advento de incorporação dessas frações a agentes ligantes como, raízes e polissacarídeos de plantas, hifas de fungos e agregados do solo (Tisdall \& Oades, 1982; Six et al., 2002) ficarão disponíveis à decomposição microbiana por ruptura dos agregados após destruição das estruturas do solo devido movimentação por implementos agrícolas. O rompimento dos agregados do solo possibilita mudanças no ambiente do solo, ou seja, temperatura, umidade, e oxigênio, afetando, assim, a atividade microbiana, com maior acesso dos processos microbianos ao $\mathrm{CO}$ (Tivet et al., 2013). Estes autores enfatizam também que a conversão de áreas nativas para PC em algumas regiões brasileiras resultou em impactos negativos com perdas de $\mathrm{C}$ das frações lábeis e estáveis e que só houve recuperação a partir da conversão para o PD. Ao avaliar os efeitos do manejo nas emissões de $\mathrm{N}_{2} \mathrm{O}$ a partir do rompimento de agregados do solo, Bandyopadhyay \& Lal (2014) relataram maiores emissões nas frações de macroagregados (diâmetros $>250 \mu \mathrm{m}$ ). Os resultados confirmam que o rompimento dos macroagregados no processo de conversão de áreas de florestas para áreas agrícolas expõe o $\mathrm{C}$ e $\mathrm{N}$ a fácil mineralização que, normalmente, resulta em maiores emissões de $\mathrm{N}_{2} \mathrm{O}$ do solo. Six \& Paustian (2014) reforçam que o estudo de microagregados é de grande importância para a compreensão do mecanismo de estabilização da MOS.

O sistema de manejo do solo, em particular o PD, influencia fortemente os mecanismos de estabilização e dinâmica do C orgânico (Lutzow et al., 2006). Pandey et al. (2014), por exemplo, observaram que as entradas de resíduos orgânicos no solo por longo período foram maiores sob qualquer forma de condução do sistema PD. O experimento registrou implicações diretas tanto na formação de frações orgânicas lábeis como também na formação de frações estáveis. Para solos de regiões tropicais e subtropicais a estabilidade química por complexos organo-minerais também é uma 
característica importante quanto ao acúmulo de MOS (Duxbury et al., 1989; Bayer et al., 2002), por relacionar-se a formação direta de agregados dos solos. A formação e a estabilização de agregados do solo são fortemente influenciadas pelo tipo argila, óxidos de ferro e alumínio, manejo, tipo de culturas, bem como, a qualidade do material orgânico que está sendo depositado sobre o solo, além de resíduos de bactérias, fungos, protozoários e os produtos excretados por estes (Bossuyt et al., 2001). Desse modo, a separação das frações por procedimento físico é também muito importante devido a sua utilidade na distinção dos compartimentos da MOS sob efeito do manejo e, por isso, tem sido relacionado com a estabilidade da MOS (Pinheiro et al., 2014).

Como a estabilidade bioquímica é decorrente, provavelmente, de estoques orgânicos muito antigos (Six et al., 2002), a determinação de outras frações estáveis, além das substâncias húmicas, que explicam parcialmente a recalcitrância através das características químicas e arranjos estruturais (Wander, 2004), pode auxiliar melhor na compreensão da dinâmica do $\mathrm{N}$ no solo e fluxos gasosos.

Com identificação de frações estáveis, Pandey et al. (2013) sugeriram que o sistema PD foi eficaz para sequestrar C a longo prazo. Contudo, não foram encontradas relações realizadas entre os tipos de frações estáveis com as emissões de $\mathrm{N}_{2} \mathrm{O}$. Como não podem ser considerados apenas os estoques totais de C para a avaliação da MOS, por não expressar todas as mudanças decorrentes dos sistemas de manejo (Figueiredo et al., 2013), para experimentos de longa duração no Cerrado, seria de grande interesse, considerar também o efeito das frações estáveis decorrentes dos mecanismos de estabilização. A correlação dessas frações com as emissões de $\mathrm{N}_{2} \mathrm{O}$ tão pouco foi avaliada em agroecossistemas de longa duração no Cerrado.

\section{REFERÊNCIAS}

BAEDE, A. P. M.; AHLONSOU, E.; DING, Y.; SCHIMEL, D. In: HOUGHTON, J. T.; DING, Y.; GRIGGS, D. J.; NOGUER, M.; VAN DER LINDEN, P. J.; DAI, X.; MASKELL, K.; JOHNSON, C. A. (eds.). Climate Change 2001: The Scientific Basis. Cambridge: Cambridge University Press, p. 37-98, 2001.

BALL, B. C.; GRIFFITHS, B. S.; TOPP, C. F. E.; WHEATLEY, R.; WALKER, R. L.; REES, R. M.; WATSON, C. A.; GORDON, H.; HALLETT, P. D.; MCKENZIE, B. M.; NEVISON, I. M. Seasonal nitrous oxide emissions from field soils under reduced 
tillage, compost application or organic farming. Agriculture, Ecosystems and Environment, n. 189, p. 171-180, 2014.

BAGGS, E. M.; REES, R. M.; SMITH, K. A.; VINTEN, A. J. A. Nitrous oxide emission from soils after incorporating crop residues. Soil Use and Management, v. 16 , n. 2, p. 82-87, 2000.

BAGGS, E. M. Soil microbial sources of nitrous oxide: recent advances in knowledge, emerging challenges and future direction. Current Opinion in Environmental Sustainability, v. 3, n. 5, p. 321-327, 2011.

BANDYOPADHYAY, K. K.; LAL, R. Effect of land use management on greenhouse gas emissions from water stable aggregates. Geoderma, n. 232, p. 363-372, 2014.

BAKKEN, L. R.; BERGAUST, L.; LIU, B.; FROSTEGARD, A. Regulation of denitrification at the cellular level: a clue to the understanding of $\mathrm{N}_{2} \mathrm{O}$ emissions from soils. Philosophical Transactions of the Royal Society B, n. 367, p. 1226-1234, 2012.

BAYER, C.; MIELNICZUK, J.; MARTIN-NETO, L.; ERNANI, P. R. Stocks and humification degree of organic matter fractions as affected by no-tillage on a subtropical soil. Plant \& Soil, v. 238, n. 1, p. 133-140, 2002.

BAYER, C.; GOMES, J.; ZANATTA, J. A.; VIEIRA, F. C. B.; PICCOLO, M. C.; DIECKOW, J.; SIX, J. Soil nitrous oxide emissions as affected by long-term tillage, cropping systems and nitrogen fertilization in Southern Brazil. Soil \&Tillage Research, n. 146, 213-222, 2015.

BERNOUX, M.; CARVALHO, M.C.S.; VOLKOFF, B. \& CERRI, C.C. CO2 emission from mineral soils following land cover change in Brazil. Global Change Biologycal, n. 7, p. 779-787, 2001.

BIJLSMA, R. J.; LAMBERS, H.; KOOIJMAN, S.A dynamic whole plant model of integrated metabolism of nitrogen and carbon. 1. Comparative ecological implications of ammonium-nitrate interactions. Plant and Soil, n. 220, p. 49-69, 2000.

BORTON, L.; GLEESON, D.B.; MACCARONE, L. D.; ZUNIGA, L. P.; MARPHY, D. V. Is liming soil a strategy for mitigating nitrous oxide emissions from semi-arid soils? Soil Biology \& Biochemistry, n. 62, p. 28-35, 2013.

BOUWMAN, A. F. Direct emissions of nitrous oxide from agricultural soil. Nutrient Cycling in Agroecosystems, v. 46, p. 53-70, 1996.

BOUWMAN, A. F.; BEUSEN, A. H. W.; GRIFFIOEN, J. W.; VAN GROENIGEN, J. W.; HEFTING, M. M.; OENEMA, O.; VAN PUIJENBROEK, P. J. T. M.; SEITZINGER, S.; SLOMP, C. P.; STEHFEST, E. Global trends and uncertainties in terrestrial denitrification and $\mathrm{N}_{2} \mathrm{O}$ emissions. Philosophical Transactions of the Royal Society B, n. 368, 2013. 
BISSET, A.; RICHARDSON, A. E.; BAKER, G.; THRALL, P. H.; Long-term land use effects on soil microbial community structure and function. Applied Soil Ecology, n. 51, p. 66-77, 2011.

BOSSUYT, H.; SIX, J.; HENDRIX, P. F. Aggregate-Protected Carbon in No-tillage and Conventional Tillage Agroecosystems Using Carbon-14 Labeled Plant Residue. Soil Science Society of American Journal, v. 66, n. 6, p. 1965-1973, 2002.

BUSTAMANTE, M. M. C.; MARTINELLI, L. A.; OMETTO, J. P. H. B.; CARMO, J. B.; JARAMILLO, V.; GAVITO, M. E.; ARAUJO, P. I.; AUSTIN, A. T.; PÉREZ, T.; MARQUINA, S. Innovations for a sustainable future: rising to the challenge of nitrogen greenhouse gas management it in Latin America. Current Opinion in Environmental Sustainability, n. 9, v. 10, p. 73-81, 2014.

CARDOSO, A. N.; SAMINEZ, T. C.; VARGAS, M. A. Fluxo de gases traço de efeito estufa na interface solo/atmosfera em solos de cerrado. (Boletim de Pesquisa e Desenvolvimento, 17), Planaltina: Embrapa Cerrados, 2001. 23 p.

CARVALHO, A. M.; BUSTAMANTE, M. M. C.; KOZOVITS, A. R.; MIRANDA, L. N.; VIVALDI, L. J. V.; SOUSA, D. M. Emissão de óxidos de nitrogênio associada à aplicação de uréia sob plantio convencional e direto. Pesquisa Agropecuária Brasileira, Brasília, v. 41, n. 4, p. 679-685, 2006.

CARVAlHO, J. L. N.; CERRI, C. E. P.; FEIGL, B. J.; PICOLlO, M. C.; GODINHO, V. P.; CERRI, C.C. Carbon sequestration in agricultural soils in the Cerrado region of the Brazilian Amazon. Soil \&Tillage Research, n. 103, p. 342-349, 2009.

CARVAlHO, J. L. N.; AVANZI, J. C.; SILVA, M. L. N.; MELlO, C. R.; CERRI, C. E. P. Potencial de sequestro de carbono em diferentes biomas do Brasil. Revista Brasileira de Ciência do Solo, v. 34, p. 277-289, 2010.

CARVALHO, M. T. M.; MADARI, B. E.; LEAL, G. O.; COSTA, A. R.; MACHADO, P. L. O. A.; SILVEIRA, P. M.; MOREIRA, J. A.; HEINEMANN, A. B. Nitrogen fluxes from irrigated common-bean as affected by mulching and mineral fertilization. Pesquisa Agropecuária Brasileira, v. 48, n. 5, p. 478-486, 2013.

CLARK, I. M.; BUCHKINA, N.; JHURREEA, D.; GOULDING, K. W. T.; HIRSCH, P. R. Impacts of nitrogen application rates on the activity and diversity of denitrifying bacteria in the Broadbalk Wheat Experiment. Philosophical Transactions of the Royal Society B, n. 367, p. 1235-1244, 2012.

CHRISTENSEN, B. T. Carbon in primary and secondary organo mineral complexes. In: Structure and organic matter storage in agricultural soils. C. R. C Press, p. 97-165, 1996. 
CHENG, Y.; WANG, J.; WANG, S.; CAI, Z.; WANG, L. Effects of temperature change and tree species composition on $\mathrm{N}_{2} \mathrm{O}$ and $\mathrm{NO}$ emissions in acidic Forest soils of subtropical China. Journal of Environmental Sciences, n. 26, p. 617-625, 2014.

CRUVINEL, E. B. F.; BUSTAMANTE, M. M. C.; KOZOVITS, A. R.; ZEPP, R. G. Soil emissions of $\mathrm{NO}, \mathrm{N}_{2} \mathrm{O}$ and $\mathrm{CO}_{2}$ from croplands in the savanna region of central Brazil. Agriculture, Ecosystems and Environment, n. 144, p. 29-40, 2011.

DAVIDSON, E. A. The contribution of manure and fertilizer nitrogen to atmospheric nitrous oxide since 1860. Nature Geoscience, n. 2, p. 659-662, 2009.

DAVIDSON, E. A.; KANTER, D. Inventories and scenarios of nitrous oxide emission. Environment Research Letters, n. 9, p. 1-12, 2014.

DAVIDSON, E. A.; MATSON, P. A.; VITOUSEK, P. M.; RILEY, R.; DUNKIN, K.; GARCIA-MENDEZ, G.; MAASS, J. M. Processes Regulating Soil Emissions of NO and $\mathrm{N}_{2} \mathrm{O}$ in a Seasonally Dry Tropical Forest. Ecology, v. 74, n. 1, p. 130-139, 1993.

DEL GROSSO, S. J.; OJIMA, D.; PARTON, W.; MOSIER, A. Simulated effects of tillage and timing of $\mathrm{N}$ fertilizer application on net greenhouse gás fluxes and $\mathrm{n}$ losses from agricultural soils in the Midwestern, USA. Mill Press, p. 23-29, 2002.

DEVINE, S.; MARKEWITZ, D.; HENDRIX, P.; COLEMAN, D. Soil Aggregates and Associated Organic Matter under Conventional Tillage, No-Tillage, and Forest Succession after Three Decades. Plos One, v. 9, n. 1, p. e84988, 2014.

DIEKOW, J. Estoque e qualidade da matéria orgânica do solo em função de sistemas de culturas e adubação nitrogenada no sistema plantio direto. Porto Alegre-Universidade Federal do Rio Grande do Sul, 2003. 164p. Tese de Doutorado.

DUXBURY, J. M.; SMITH, M. S.; DORAN, J. W. Soil organic matter as a source and sink of plant nutrients. In: COLEMAN, D.C.; OADES, J. M.; UEHARA, G. Dynamics of soil organic matter in tropical ecosystems. Honolulu: University of Hawaii Press, 1989, p. 33-69.

ELliOT, E., T.; COLEMAN, D. C. Let the Soil Work for Us. Ecological Bulletins, n. 39, 23-32, 1988.

FALLOON, P. D.; SMITH, P. Modelling refractory soil organic matter. Biology and Fertility of Soils, n. 30, p. 388-398, 2000.

FEDERAÇÃO BRASILEIRA DE PLANTIO DIRETO NA PALHA - FEBRAPDP. Área do sistema plantio direto 2011-2012. Disponível em: http://febrapdp.org.br/download/PD_Brasil_2013.jpg. Acesso em: Novembro de 2015. 
FIGUEIREDO, C. C.; RESCK, D. V. S.; CARNEIRO, M. A. C. Labile and stable fractions of soil organic matter under management systems and native cerrado. Revista Brasileira de Ciência do Solo, n. 34, p. 907-916, 2010.

FIGUEIREDO, C.C.; RESCK, D.V.S.; CARNEIRO, M.A.C.; RAMOS, M.L.G. \& SÁ, J.C.M. Stratification ratio of organic matter pools influenced by management systems in a weathered Oxisol from a tropical agro-ecoregion in Brazil. Soil Researchs, n. 51, v. 2, p. 133-141, 2013.

FUB, R.; RUTHA, B.; SCHILling, R.; SCHERBC, H.; MUNCHA, J. C. Pulse emissions of $\mathrm{N}_{2} \mathrm{O}$ and $\mathrm{CO}_{2}$ from an arable field depending on fertilization and tillage practice. Agriculture, Ecosystems \& Environment, n. 144, p. 61-68, 2011.

GIACOMINI, S. J.; JANTALIA, C. P.; AITA, C.; URQUIAGA, S. S.; ALVES, B. J. R. Emissão de óxido nitroso com a aplicação de dejetos líquidos de suínos em solo sob plantio direto. Pesquisa Agropecuária Brasileira, v. 41, n. 11, p. 1653-1661, 2006.

GOMES, J. Emissão de gases de efeito estufa e potencial de mitigação do aquecimento global por sistemas conservacionistas de manejo. Porto Alegre: Faculdade de Agronomia-Universidade Federal do Rio Grande do Sul, 2006. 126p. Tese Doutorado.

HÉNAULT, C.; GROSSEL, A.; MARY, B.; ROUSSEL, M.; LÉONARD, J. Nitrous Oxide Emission by Agricultural Soils: A Review of Spatial and Temporal Variability for Mitigation. Pedosphere, v. 22, n. 4, p. 426-433, 2012.

HANSEN, M.; CLOUGH, T. J.; ELBERLING, B. Flooding-induced $\mathrm{N}_{2} \mathrm{O}$ emission bursts controlled by $\mathrm{pH}$ and nitrate in agriculture soils. Soil Biology \& Biochemistry, n. 69, p. 17-24, 2014.

HAO, X.; CHANG, C.; CAREFOOT, J. M.; JANZEN, H. H.; ELLERT, B. H. Nitrous oxide emissions from an irrigated soil as affected by fertilizer and straw management. Nutrient Cycling in Agroecosystems, v. 60, n. 1, p. 1-8, 2001.

HICKMAN, J. E.; PALM, C. A.; MUTUO, P.; MELILLO, J. M.; TANG, J. Nitrous oxide $\left(\mathrm{N}_{2} \mathrm{O}\right)$ emissions in response to increasing fertilizer addition in maize (Zea mays L.) agriculture in westrn Kenya. Nutrient Cycling in Agroecosystems, n. 100, p. 177$187,2014$.

INSTITUTO BRASILEIRO DE GEOGRAFIA E ESTATÍSTICA - IBGE Levantamento sistemático de produção agrícola-Estimativas Outubro/Novembro, 2014. Disponívelem: $<$ htt://www.ibge.gov.br/home/estatística/indicadores/agropecuária /ispa/ispa_201411_1.shtm>. Acesso em: 15 de Dezembro de 2014.

INTERGOVERNMENTAL PANEL ON CLINTERGOVERNMENTAL PANEL ON CLIMATE CHANGE - CIMATE CHANGE - IPCC. Climate Change 2013: The Physical Science Basis: Working Group I Contribution to the 661 Fifth Assessment 
Report of the Intergovernmental Panel on Climate Change. Cambridge University 662 Press, UK.

INTERGOVERNMENTAL PANEL ON CLINTERGOVERNMENTAL PANEL ON CLIMATE CHANGE - CIMATE CHANGE - IPCC. Summary for Policymakers. In: Climate Change 2014, Mitigation of Climate Change. Contribution of Working Group III to the Fifth Assessment Report of the Intergovernmental Panel on Climate Change Eds. PICHS-MADRUGA, O. R.; SOKONA, Y.; FARAHANI, E.; KADNER, S.; SEYBOTH, K.; ADLER, A.; BAUM, I.; BRUNNER, S.; EICKEMEIER, P.; KRIEMANN, B.; SAVOLAINEN, J.; SCHLOMER, S.; VON STECHOW, C.; ZWICKEL, T.; MINX, J. C. Cambridge University Press, Cambridge, United Kingdom and New York, NY, USA, 2014.

INTERGOVERNMENTAL PANEL ON CLIMATE CHANGE - IPCC: Climate Change 2007: Synthesis Report. Contribution of Working Groups I, II and III to the Fourth Assessment Report of the Intergovernmental Panel on Climate Change. Eds. PACHAURI, R. K; REISINGER, A. Geneva, Switzerland: IPCC, 2007.

JAGADAMMA, S.; LAL, R. Distribution of organic carbon in physical fractions of soils as affected by agricultural management. Biology \& Fertility of Soils, v. 46, n. 6, p. 543-554, 2010.

JENKINSON, D. S.; LADD, J. N. Microbial biomass in soil: measurement and turnover. In: Soil Biochemistry, p. 415-471, 1981.

JONES, S. K.; FAMULARI, D.; DI MARCO, C. F.; NEMITZ, E.; SKIBA, U. M.; REES, R. M.; SUTTON, M. A. Nitrous oxide emissions from managed grassland: a comparison of eddy covariance and static chamber measurements. Atmospheric Measurement Techniques, v. 4, p. 2179-2194, 2011.

JUNIOR, M. J. G. A. F; JUNIOR, R. C. O.; SILVA, R.; MOURA, J. M. S.; NETO, A. F.; PONTE , M. X.; BELDINI, T. P. Assessing the impact of different tillage systems and land uses on $\mathrm{CO}_{2}-\mathrm{C}$ emissions in Eastern Amazonia. African Journal of Agricultural Research, v. 12, n. 30, p. 2427-2441, 2017.

KONG, A. Y. Y.; HRISTOVA, K.; SCOWB, K. M.; SIX, J. Impacts of different N management regimes on nitrifier and denitrifier communities and $\mathrm{N}$ cycling in soil microenvironments. Soil Biology \& Biochemistry, n. 42, p. 1523-1533, 2010.

KLEBER, M.; NICO, P. S.; PLANTE, A.; FILLEY, T.; KRAMER, M.; SWANSTON, C.; SOLLINS, P. Old and stable soil organic matter is not necessarily chemically recalcitrant: implications for modeling concepts and temperature sensitivity. Global Change Biology, v. 17, n. 2, p. 1097-1107, 2011. 
LEVY-BOOTH, D. J.; PRESCOTT, C. E.; GRAYSTON, S. J. Microbial functional genes involved in nitrogen fixation, nitrification and denitrification in forest ecosystems. Soil Biology \& Biochemistry, v. 75, p. 11-25, 2014.

LEWIS, O. A. M. Plants and Nitrogen. London, Cambridge Press, 1986. 100p.

LEBENDER, U.; SENBAYRAM, M.; LAMMEL, J.; KUHLMANN, H. Effect of mineral nitrogen fertilizer forms on $\mathrm{N}_{2} \mathrm{O}$ emissions from arable soils in winter wheat production. Journal Plant and Nutrition Soil Science, n. 177, p. 722-732, 2014.

LOPES, A. S. Soils under Cerrado: a success story in soil management. Better Crops International, v. 10, p. 9-15, 1996.

LOPEZ-SANGIL, L.; ROVIRA, P. Sequential chemical extractions of the mineralassociated soil organic matter: An integrated approach for the fractionation of organomineral complexes. Soil Biology \& Biochemistry, v. 62, p. 57-67, 2013.

LUO, J.; DE KLEIN, C. A. M.; LEDGARD, S. F.; SAGGAR, S. Management options to reduce nitrous oxide from intensively grazed pasture: a review. Agriculture, Ecosystems \& Environment, n. 136, p. 282-291, 2010.

MACDONALD, B. C. T.; DENMEAD, O. T.; WHITE, I.; BYRANT, G. Gases nitrogen losses from Coastal acid sulfate soils: a short-term study. Pedosphere, v. 21, n. 2, p. 197-206, 2011.

MAEDA, K.; SPOR, A.; EDEL-HERMANN, V.; HERAUD, C.; BREUIL, M.; BIZOURD, F.; TOYODA, S.; YOSHIDA, N.; STEINBERG, C.; PHILIPPOT, L. N2O production, a widespread trait in fungi. Scientific Reports, v. 5, n. 9697, 2015.

MATSON, P. A.; VITOUSEK, P. M. Ecosystem approach to a global nitrous oxide budget. Bio Science, v. 40, n. 9, p. 667-672, 1990.

MATSON, A. L.; MATSON, M. D.; LANGS, K.N; VELDKAMP, E. Soil trace gas fluxes along orthogonal precipitation and soil fertility gradients in tropical lowland forests of Panama. Biogeosciences, v. 14, p. 3509-3524, 2017.

MELERO, S.; PÉREZ-DE-MORA, A.; MURILLU, J. M.; BUEGGER, F.; KLEINEDAM, K.; KUBLIK, S.; VANDERLINDEN, K.; MORENO, F.; SCLOTER, M. Denitrification in a Vertisol under long-term tillage and no-tillage management in dry land agricultural systems: Key genes and potential rates. Apllied Soil Ecology, n. 47, p. 221-225, 2011.

MENÉNDEZ, E.; BARRENA， I.; SETIEN, I.; GONZÁLEZ-MURUA， C.; ESTAVILLO, J. M. Efficiency of nitrification inhibitor DMPP to reduce nitrous oxide emissions under different temperature and moisture conditions. Soil Biology \& Biochemistry, v. 53, p. 82-89, 2012. 
MILLER, M. N.; ZEBARTH, B. J.; DANDIE, C. E.; BURTON, D. L.; GOYER, C.; TREVORS, J. T. Crop residue influence on denitrification, $\mathrm{N}_{2} \mathrm{O}$ emissions and denitrifier community abundance in soil. Soil Biology \& Biochemistry, v. 40, p. 2553$2562,2008$.

MINISTÉRIO DA CIÊNCIA, TECNOLOGIA E INOVAÇÃO - MCTI. Sumário Executivo, 2013. Estimativas anuais de emissões de gases de feito estufa no Brasil. Brasília, Brasil, 164p., 2013.

MINISTÉRIO DA CIÊNCIA, TECNOLOGIA E INOVAÇÃO - MCTI. Sumário Executivo, 2014. Estimativas anuais de emissões de gases de feito estufa no Brasil. $2^{\mathrm{a}}$ Edição. Brasília, Brasil, 80 p., 2014.

MINISTÉRIO DO MEIO AMBIENTE - MMA. PROBIO: Projeto de conservação e utilização sustentável da diversidade biológica brasileira. Disponível em: <http://www.mma.gov.br>. Acesso em: 08 de outubro de 2014.

MIKUTTA, R.; KLEBER, M.; TORN, M. S.; JAHN, R. Stabilization of soil organic matter: Association with minerals or chemical recalcitrance? Biogeochemistry, n. 77, p. 25-56, 2006.

MOREIRA, F. M. S.; SIQUEIRA, J. O. Nitrificação. In: Microbiologia e Bioquímica do solo. 2. ed. Atual. E ampl. - Lavras: Editora UFLA, 2006, p. 352-357.

MORLEY, N.; BAGGS, E. M. Carbon and oxygen controls on $\mathrm{N}_{2} \mathrm{O}$ and $\mathrm{N}_{2}$ production during nitrate reduction. Soil Biology \& Biochemistry, n. 42, p. 1864-1871, 2010.

MOSIER, A. R.; DUXBURY, J.M; FRENEY, J. R.; HEINEMEYER, O.; MINAMI, K. Assessing and mitigating $\mathrm{N}_{2} \mathrm{O}$ emissions from agricultural soils. Climatic Change, $\mathrm{n}$. 40, p. 7-38, 1998.

OADES, J. M. Organic Carbon in Soils. The role of nonliving organic matter in the earth's carbon cycle, v. 16, 1995, p. 293.

OENEMA, O.; JU, X.; KLEIN, C.; ALFARO, M.; DEL PRADO, A.; LESSCHEN, J. P.; ZHENG, X.; VELTHOF, G.; MA, L.; GAO, B.; KROEZE, C.; SUTTON, M. Reducing nitrous oxide emissions from the global food system. Current Opinion in Environmental Sustainability, n. 9, v. 10, p. 55-64, 2014.

OLIVEIRA, A. C. D. G. Bactérias heterotróficas e autotróficas envolvidas na remoção de nitrogênio de lixiviado de aterro sanitário em reator de leito móvel. 130f. Dissertação (Mestrado) - Universidade Estadual de Londrina, 2012.

PAUL, E. A.; CLARK, F. E. Soils Microbiology and Biochemistry. San Diego: Academic Press, 340 p., 1996. 
PAULETA, S. R.; ACQUA, S. D.; MOURA, I. Nitrous oxide reductase. Coordination Chemistry Reviews, v. 257, n. 2, p. 332-349, 2013.

PANDEY, D.; AGRAWAL, M.; BOHRA, J. S. Impact of four tillage permutations in rice-wheat system on GHG performance of wheat cultivation througt carbon footprinting. Ecological Engineering, v. 60, p. 261-270, 2013.

PEIXOTO, R. S; CHAER, G. M.; FRANCO, N.; REIS JUNIOR, F. B.; MENDES, I. C.; ROSADO, A. S. A decade of land use contributes to changes in the chemistry, biochemistry and bacterial community structures of soils in the Cerrado. Antonie van Leeuwenhoek, v. 98, n. 3, p. 403-413, 2010.

PINHEIRO, E. F. M.; CAMPOS, D. V. B.; BALIEIRO, F. C.; ANJOS, L. H. C.; PEREIRA, M. G. Tillage systems effects on soil carbon stock and physical fractions of soil organic matter. Agricultural Systems, v. 132, p. 35-39, 2014.

PLAZA-BONILlA, D.; ÁlVARO-FUENTES, J.; CANTERO-MARTINEZ， C. Identifying soil organic carbon fractions sensitive to agricultural management practices. Soil \& Tillage Research, v. 139, p. 19-22, 2014.

PAINEL BRASILEIRO DE MUDANÇAS CLIMÁTICAS - PBMC, 2013. Impactos, Vulnerabilidade e Adaptação. Contribuição do grupo de trabalho 2 ao primeiro relatório de avaliação nacional do painel brasileiro de mudanças climáticas. Sumário Executivo do GT2. Rio de Janeiro, Brasil, 2013, 28p.

RAVISHANKARA, A. R.; DANIEL, J. S.; PORTMANN, R. W. Nitrous oxide $\left(\mathrm{N}_{2} \mathrm{O}\right)$ : The dominant ozone-depleting substance emitted in the 21 st century. Science, v. 326, n. 123, 2009. Disponível em: <www.sciencemag.org>. Acesso em: 19 de outubro de 2014.

RESCK, D. V. S.; FERRREIRA, E. A. B.; FIGUEIREDO, C. C.; ZINN, Y. L. Dinâmica da matéria orgânica no Cerrado. In: SANTOS, G. A.; SILVA, L. S.; CANELlAS, L. P.; CAMARGO, F. A. O. (eds.) Fundamentos da matéria orgânica do solo: Ecossistemas tropicais e subtropicais. 2.ed. Porto Alegre, p. 359-417, 2008.

RISK, N.; SNIDER, D.; WAGNER-RIDDLE, C. Mechanisms leading to enhanced soil nitrous oxide induce by freeze-thaw cycles. Canadian Journal of Soil Science, n. 93, p. 401-414, 2013.

ROBINSON A.; DI, H. J.; CAMERON, K. C.; PODOLYAN, A.; HE, J. The effect of soil $\mathrm{pH}$ and dicyandiamide (DCD) on $\mathrm{N}_{2} \mathrm{O}$ emissions and ammonia oxidiser abundance in a stimulated grazed pasture soil. Journal Soils Sediments, n. 14, p. 434-1444, 2014.

RUMPEL, C.; CHAPLOT, V.; CHABBI, A.; LARGEAU, C.; VALENTIN, C. Stabilisation of $\mathrm{HF}$ soluble and $\mathrm{HCl}$ resistant organic matter in sloping tropical soils under slash and burn agriculture. Geoderma, v. 145, n. 3, p. 347-354, 2008. 
RUMPEL, C.; KOGEL-KNABNER, I. Deep soil organic matter-a key but poorly understood component of terrestrial C cycle. Plant \& Soil, v. 338, n. 1, p. 143-158, 2011.

SAGGAR, S.; JHA, N.; DESLIPPE, J.; BOLAN, N. S.; LUO, J.; GILTRAP, D. L.; KIM, D. G.; ZAMAN, M.; TILLMAN, R. W. Denitrification and $\mathrm{N}_{2} \mathrm{O}: \mathrm{N}_{2}$ production in temperate grasslands: Processes, measurements, modelling and mitigating negative impacts. Science of The Total Environment, v. 465, p. 173-195, 2013.

SANO, E.E.; ROSA, R.; BRITO, J.L.S.; FERREIRA, L.G.; BEZERRA, H.S. Mapeamento da Cobertura vegetal natural e antrópica do bioma Cerrado por meio de imagens Landsat ETM. In: XIV Simpósio Brasileiro de Sensoriamento Remoto, Natal, Brasil, p. 1199-1206, 2008.

SIGNOR, D.; CERRI, C. E. P. Nitrous oxide emissions in agricultural soils: a review. Pesquisa Agropecuária Tropical, n. 43, v. 3, p. 322-338, 2013.

SIGNOR, D.; CERRI, C. E. P.; CONANT, R. $\mathrm{N}_{2} \mathrm{O}$ emissions due to nitrogen fertilizer applications in two regions of sugarcane cultivation in Brazil. Environment Research Letters, n. 8, 2013.

SIQUEIRA NETO, M.; PICCOLO, M. C.; JUNIOR, C. C.; CERRI, C. C.; BERNOUX, M. Emissão de gases do efeito estufa em diferentes usos da terra no bioma Cerrado. Revista Brasileira de Ciência do Solo, v. 35, p. 63-76, 2011.

SIX, J.; FELLER, C.; DENEF, K.; OGLE, S. M.; SÁ, J. C. M.; ALBRECHT, A. Soil carbon matter, biota and aggregation in temperate and tropical soils: Effects of notillage. Agronomie, v. 22, p. 755-775, 2002.

SIX, J.; PAUSTIAN, K. Aggregate-associated soil organic matter as an ecosystem property and a measurement tool. Soil Biology \& Biochemistry, n. 68, p. 44-49, 2014.

SOLLINS, P.; HOMANN, P.; CALDWELL, B. A. Stabilization and destabilization of soil organic matter: mechanisms and controls. Geoderma, v. 74, n. 2, p. 65-105, 1996.

SMITH, R. The potential for feedback effects induced by global warming on emissions of nitrous oxide by soils. Global Change Biology, v. 3, n. 4, p. 327-338, 1997.

SMITH, J.; WGNER-RIDDLE, C.; DUNFIELD, K. Season and management related changes in the diversity of nitrifying and denitrifying bacteria over winter and spring. Applied Soil Ecology, v. 44, n. 2, p. 138-146, 2010.

STEVENSON, F. J. Humus chemistry: Genesis, composition, reactions. John Wiley \& Sons, New York. 496 p., 1994.

STEVENSON, F. J.; COLE, M. A. Cycles of soils: carbon, nitrogen, phosphorus, sulfur, micronutrients. 2. ed. New York: J. Wiley, 427 p, 1999. 
STOCKER, T. F.; QIN, D.; PLATTNER, G. K.; TIGNOR, M.; ALLEN, S. K.; BOSCHUNG, J.; NAUELS, A.; XIA, Y.; BEX, V.; MIDGLEY, P. M. Climate change 2013: the physical science basis. Intergovernmental Panel on Climate Change, Working Group I Contribution to the IPCC Fifth Assessment Report (AR5). New York: Cambridge University Press, 2013.

TATTI, E.; GOYER, C.; CHANTIGNY.; WERTZ, S.; ZEBARTH, B.; BURTON, D. L.; FILION, M. Influences of over winter conditions on denitrification and nitrous oxide-producing microorganism abundance and structure in an agricultural soil amended with different nitrogen sources. Agriculture, Ecosystems and Environment, n. 183, p. 47-59, 2014.

TIEDJE, J. M. Ecology of denitrification and dissimilatory nitrate reduction to ammonium. Wiley, New York, p. 179-244, 1988.

TISDALL, J. M.; OADES, J. M. Organic matter and water-stable aggregates in soils. European Journal of Soil Science, v. 33, n. 2, p. 141-163, 1982.

TIVET, F.; SÁ, J. C. M.; LAL, R.; BORSZOWSKEI, P. R.; BRIEDIS, C.; SANTOS, J. B.; SÁ, M. F. M.; HARTMAN, D. C.; EURICH, G.; FARIAS, A.; BOUZINAC, S.; SÉGUY, L. Aggregate $\mathrm{C}$ depletion by plowing and its restoration by diverse biomass-C inputs under no-till in sub-tropical and tropical regions of Brazil. Geoderma, n. 209, p. 214-225, 2013.

THOMSON, A. J.; GIANNOPOUlOS, G.; PRETTY, J.; BAGGS, E. M.; RICHARDSON, D. J. Biological sources and sinks of nitrous oxide and strategies to mitigate emissions. Philosophical Transactions the Royal Society, n. 367, p. 11571168, 2012.

THOMPSON, R. L.; CHEVALLIER, F.; CROTWELL, A. M.; DUTTON, G.; LANGENFELDS, R. L.; PRINN, R. G.; WEISS, R. F.; TOHJIMA, Y.; NAKAZAWA, T.; KRUMMEL, P. B.; STEELE, L. P.; FRASER, P.; O’DOHERTY, S.; ISHIJIMA, K.; AOKI, S. Nitrous oxide emissions 1999 to 2009 from a global atmospheric inversion. Atmosphere Chemistry and Physics, n. 14, v. 4, p. 1801-1817, 2014.

UNITED NATIONS ENVIRONMENT PROGRAMME - UNEP. Drawing Down $\mathbf{N}_{\mathbf{2}} \mathbf{O}$ to Protect Climate and the Ozone Layer. A UNEP Synthesis Report. Nairobi, Kenya: United Nations Environment Programme (UNEP), 2013.

WAGNER-RIDDLE, C.; FURON, A.; MCLAUGHLIN, N.; LEE, I.; BARBEAU, J.; JAYASUNDARA, S.; PARKIN, G.; VON BERTOLDI, P.; WARLAND, J. Intensive measurement of nitrous oxide emissions from a corn-soybean-wheat rotation under two contrasting management systems over 5 years. Global Change Biology, n. 13, p. 1-15, 2007. 
WANDER, M. Soil organic matter fractions and their relevance to soil function. In: soil organic matter in sustainable agriculture. CRC Press, p. 67-102, 2004.

WANG, J.; SONG, C.; ZHANG, J.; WANG, L.; ZHU, X.; SHI, F. Temperature sensitivity of soil carbon mineralization and nitrous oxide emission in different ecosystems along a mountain wetland-forest ecotone in the continuous permafrost of Northeast China. Catena, n. 121, p. 110-118, 2014.

WENDLING, B.; JUCKSCH, I.; SÁ MENDONÇA, E.; ALMEIDA, R.F.; ALVARENGA, R. C. Simulação de estoques de carbono e nitrogênio pelo modelo century em Latossolos, no Cerrado brasileiro. Revista Ciência Agronômica, v. 45, n. 2, p. 238-248, 2014.

WORLD METEOROLOGICAL ORGANIZATION - WMO. Greenhouse gas bulletin: The state of greenhouse gases in the atmosphere based on global observations through 2013. Geneva, Suiça, n.10, 8p, 2014. Disponível em: <http://www.wmo.int/gaw $>$. Acesso em: 13 de Novembro de 2014.

WRAGE, N.; VELTHOF, G. L.; VAN BEUSICHEM, M. L.; OENEMA, O. Role of nitrifier denitrification in the production of nitrous oxide. Soil Biology \& Biochemistry, v. 33, p. 1723-1732, 2001.

YAMAMOTO, A.; AKIYAMA, H.; NAOKAWA, T.; MIYAZAKI, Y.; HONDA, Y.; SANO, Y.; NAKAJIMA, Y.; YAGI, K. Lime-nitrogen application effects nitrification, denitrification, and N2O emission in an acidic tea soil. Biologycal \& Fertility Soils, n. 50, p. 53-62, 2014.

ZHANG, J. F.; X. G. HAN. $\mathrm{N}_{2} \mathrm{O}$ emission from the semi-arid ecosystem under mineral fertilizer (urea and superphosphate) and increased precipitation in northern China, Atmospheric Environment, n. 42, p. 291-302, 2008.

ZHANG, Y.; MU, Y.; ZHOU, Y.; LIU, J.; ZHANG, C. Nitrous oxide emissions from maize-wheat field during 4 successive years in the north China plain. Biogeosciences, $\mathrm{n}$. 11, p. 1717-1726, 2014. 


\section{CAPÍTULO I \\ EMISSÕES DE $\mathrm{N}_{2} \mathrm{O}$ DO SOLO EM AGROECOSSISTEMAS DE LONGA DURAÇÃO: EFEITOS INTERATIVOS DA SAZONALIDADE PLUVIOMÉTRICA E ROTAÇÃO DE CULTURAS NO CERRADO BRASILEIRO \\ Publicado na revista:}

Agriculture, Ecosystems and Environment; DOI: 10.1016/j.agee.2016.08.027 


\section{RESUMO}

\section{EMISSÕES DE $\mathrm{N}_{2} \mathrm{O}$ DO SOLO EM AGROECOSSISTEMAS DE LONGA DURAÇÃO: EFEITOS INTERATIVOS DA SAZONALIDADE PLUVIOMÉTRICA E ROTAÇÃO DE CULTURAS NO CERRADO BRASILEIRO}

Em seu estado natural o bioma Cerrado é naturalmente mitigador das emissões de óxido nitroso do solo $\left(\mathrm{N}_{2} \mathrm{O}\right)$. No entanto, a incorporação desse bioma para atividades agropecuárias tem promovido alterações na dinâmica do nitrogênio $(\mathrm{N})$, com consequente elevação das emissões de $\mathrm{N}_{2} \mathrm{O}$ para atmosfera. Avaliamos por um ano as emissões de $\mathrm{N}_{2} \mathrm{O}$ sob influência interativa da sazonalidade pluviométrica e rotação cultural em agroecossistemas conduzidos por dezenove anos no Cerrado. Os sistemas agrícolas utilizados incluíram: (i) plantio direto, com uma safra de soja, seguida por uma segunda safra de sorgo (NTR1); (ii) plantio direto, com uma safra de milho e posterior, segunda safra de guandu (NTR2); (iii) sistema convencional, com uma safra de soja seguida de pousio do solo (CT); (iv) e o cerrado nativo $(\mathrm{CN})$, utilizado como ambiente de referência. As medições foram realizadas de outubro de 2013 a setembro de 2014 através do uso de câmara estática fechada, com determinação dos fluxos, por cromatografia gasosa. Os fluxos de $\mathrm{N}_{2} \mathrm{O}$ foram relacionados às seguintes variáveis edafoclimáticas: nitrato $\left(\mathrm{NO}_{3}{ }^{-}\right)$, amônio $\left(\mathrm{NH}_{4}{ }^{+}\right)$, temperatura do solo e espaço poroso saturado por água (WFPS). Os fluxos anuais de $\mathrm{N}_{2} \mathrm{O}$ entre os agroecossistemas variaram de zero a $266 \mu \mathrm{g} \mathrm{m}^{-2} \mathrm{~h}^{-1}$. O Cerrado nativo apresentou os menores fluxos, com influxos em determinados períodos do ano, principalmente na época seca. No acumulado total anual o CT, NTR1 e NTR2 emitiram: 1,36; 1,00 e $0,70 \mathrm{~kg} \mathrm{~N}_{2} \mathrm{O}$ ha $^{-1}$, respectivamente. O $\mathrm{CN}$ apresentou um acumulado total anual de $0,27 \mathrm{~kg} \mathrm{~N}_{2} \mathrm{O} \mathrm{ha}^{-1}$. O CT apresentou os maiores picos de $\mathrm{N}_{2} \mathrm{O}$ no período seco, principalmente, após a colheita da soja, no pousio. Isso levou o CT a um maior potencial de aquecimento global parcial (pGWP), de $406 \mathrm{~kg}$ de $\mathrm{CO}_{2}$ eq ha ${ }^{-1}$ e, consequentemente, uma maior emissão acumulada por grãos/MS produzidos, de $619 \mathrm{mg} \mathrm{N}_{2} \mathrm{O} \mathrm{m} \mathrm{kg}^{-1}$ grãos/MS, entre os agroecossistemas $(\mathrm{P}<0,05)$. Do total das emissões acumuladas no $\mathrm{CT}, 50 \%$ ocorreram durante o período seco e $75 \%$ no pousio, sugerindo que para o regime pluviométrico sazonal do Cerrado, o monocultivo com soja, seguido de pousio do solo, não é uma condição adequada. Entre os diferentes sistemas de plantio direto avaliados o NTR2 foi o que apresentou menor acumulado de $\mathrm{N}_{2} \mathrm{O}$, menor pGWP (189 kg de $\mathrm{CO}_{2}$ eq ha ${ }^{-1}$ ), portanto, uma rotação de culturas mais eficiente para a mitigação de $\mathrm{N}_{2} \mathrm{O}$, com picos de emissão que não ultrapassaram $100 \mu \mathrm{g} \mathrm{m}^{-2} \mathrm{~h}^{-1}$, enquanto no NTR1, no período chuvoso, quase chegou a $270 \mu \mathrm{g} \mathrm{m}^{-2} \mathrm{~h}^{-1}$. O NTR2 também apresentou a menor emissão acumulada por grãos/DM produzidos, sendo as práticas de manejo e rotação de cultura desse sistema de manejo, uma alternativa viável para reduzir as emissões de $\mathrm{N}_{2} \mathrm{O}$ em áreas agrícolas na região de Cerrado.

Palavras-chave: Savana brasileira, mudanças climáticas, potencial de aquecimento global parcial, precipitações pluviométricas, rotação cultural. 


\section{ABSTRACT \\ SOIL $\mathrm{N}_{2} \mathrm{O}$ EMISSIONS FROM LONG-TERM AGROECOSYSTEMS: INTERACTIVE EFFECTS OF RAINFALL SEASONALITY AND CROP ROTATION IN THE BRAZILIAN CERRADO}

In its natural state, the Cerrado biome is a mitigator of soil emissions of nitrous oxide $\left(\mathrm{N}_{2} \mathrm{O}\right)$. However, the integration of this biome in agricultural activities induced changes in nitrogen $(\mathrm{N})$ dynamics, consequently increasing $\mathrm{N}_{2} \mathrm{O}$ emissions to the atmosphere. For one year, $\mathrm{N}_{2} \mathrm{O}$ emissions were evaluated under interactive effects of rainfall seasonality and crop rotation in 19-year-old agricultural ecosystems in the Cerrado. The agricultural systems included: (I) no-tillage soybean in the main and sorghum in the late growing season (NTR1); (II) no-tillage maize in the main and pigeon pea in the late growing season (NTR2); (III) soybean in the main and fallow in the late growing season under conventional tillage (CT); (IV) and native Cerrado (NC), as a reference environment. Measurements in a closed static chamber were carried out from October 2013 to September 2014 to determine the fluxes by gas chromatography. The $\mathrm{N}_{2} \mathrm{O}$ fluxes were related to the following soil and climate variables: nitrate $\left(\mathrm{NO}_{3}{ }^{-}\right)$, ammonium $\left(\mathrm{NH}_{4}{ }^{+}\right)$, soil temperature (Soil temp.), and water-filled pore space (WFPS). The annual $\mathrm{N}_{2} \mathrm{O}$ average fluxes of the agroecosystems ranged from zero to $266 \mu \mathrm{g} \mathrm{m}^{-2}$ $\mathrm{h}^{-1}$. Fluxes were lowest in the native Cerrado, and in certain periods of the year, especially in the dry season, inflows were observed. The total annual cumulative fluxes from CT, NTR1 and NTR2 were: $1.36 ; 1.00$ and $0.70 \mathrm{~kg} \mathrm{~N}_{2} \mathrm{O} \mathrm{ha}^{-1}$, respectively. In NC, the annual cumulative total was $0.27 \mathrm{~kg} \mathrm{~N}_{2} \mathrm{O} \mathrm{ha}^{-1}$. Under CT, $\mathrm{N}_{2} \mathrm{O}$ peaks were highest in the dry period, especially after soybean harvest, from fallow soil. The highest partial global warming potential (pGWP) of $406 \mathrm{~kg}$ of $\mathrm{CO}_{2} \mathrm{eq} \mathrm{ha}^{-1}$ was observed in the CT and, consequently, a higher cumulative emission of grains/DM produced, of $619 \mathrm{mg} \mathrm{N}^{2} \mathrm{O} \mathrm{m}^{-2}$ $\mathrm{kg}^{-1}$ grains/MS, among agroecosystems $(\mathrm{P}<0.05)$. Of the total cumulative emissions in $\mathrm{CT}, 50 \%$ were accumulated during the dry season and $75 \%$ during the fallow period, indicating that for the Cerrado with rainfall seasonality, monoculture soybean followed by fallow soil is not an appropriate crop rotation sequence. Among the different tillage systems, NTR2 had the lowest cumulative $\mathrm{N}_{2} \mathrm{O}$ emissions. This crop rotation is therefore indicated as the most efficient to mitigate $\mathrm{N}_{2} \mathrm{O}$, with emission peaks not exceeding $100 \mu \mathrm{g} \mathrm{m}^{-2} \mathrm{~h}^{-1}$, while in NTR1, emissions in the rainy season reached almost $270 \mu \mathrm{g} \mathrm{m}^{-2} \mathrm{~h}^{-1}$.

Keywords: Brazilian savanna, climate changes, partial global warming potential, Rainfall, crop rotation.

\section{INTRODUÇÃO}

O bioma Cerrado (Brazilian savana) abrange mais de 2 milhões de $\mathrm{km}^{2}$, o que equivale a $24 \%$ do território nacional. O bioma também apresenta acentuada biodiversidade sendo considerado um dos 34 hotspots mundiais (Bustamante et al., 2012). Nas últimas quatro décadas, quase um milhão de $\mathrm{km}^{2}$, ou $50 \%$ da extensão total 
do Cerrado, foram convertidos em áreas agrícolas, principalmente, de 1990 a 2011 (Lapola et al., 2014; Bustamante et al., 2014). Aproximadamente 60\% da produção brasileira de soja e $48 \%$ da produção de milho encontram-se em áreas agrícolas do Cerrado (Conab, 2015).

A rápida expansão agrícola na região do Cerrado promoveu substanciais mudanças nos ciclos biogeoquímicos (Cruvinel et al., 2011). Dentre as mudanças já observadas, decorrentes das perturbações químicas, físicas e biológicas do solo destacam-se as alterações na dinâmica do nitrogênio (N) (Bustamante et al., 2006; Bustamante et al., 2012, Martins et al., 2015). Como uma das consequências da interferência antrópica na dinâmica do $\mathrm{N}$, são as alterações perceptíveis nas concentrações de óxido nitroso $\left(\mathrm{N}_{2} \mathrm{O}\right)$, um dos gases relacionados às mudanças climáticas globais. As complexas interações entre as práticas de alguns sistemas de manejo e fatores edafoclimáticos, por interferirem na rápida mineralização da matéria orgânica, resultam no aumento das emissões de $\mathrm{N}_{2} \mathrm{O}$ dos solos agrícolas para a atmosfera (Jerecki e Lal, 2006; Ussiri et al., 2009; Huang et al., 2015).

Os fluxos de $\mathrm{N}_{2} \mathrm{O}$ no Cerrado nativo normalmente estão abaixo do limite de detecção (Carvalho et al., 2006; Bustamante et al., 2012), sendo que alguns trabalhos atribuem a influxos esses valores negativos que se concentram, principalmente, em períodos secos durante o ano (Metay et al., 2007; Carvalho et al., 2013). Os recentes relatos de pesquisas indicam que o Cerrado sob vegetação nativa é um bioma naturalmente mitigador das emissões de $\mathrm{N}_{2} \mathrm{O}$ (Martins et al., 2015). As explicações para esse comportamento do Cerrado incluem a boa drenabilidade e aeração do solo (Urquiaga et al., 2010; Martins et al., 2015), a composição e a abundância de comunidades microbianas desnitrificadoras (Lammel et al., 2015; Hamilton et al., 2016), a elevada acidez do solo e a ocorrência de veranicos durante a estação de crescimento, além da existência de uma estação seca bem definida (Davidson et al., 2001). Os Latossolos do Cerrado, em geral, apresentam teores de $\mathrm{N}$ e taxas de nitrificação limitados, o que também contribui para os baixos valores de fluxos de $\mathrm{N}_{2} \mathrm{O}$ nesses solos (Nardoto \& Bustamante 2003; Carvalho et al., 2006; Chapuis-Lardy et al., 2007; Cruvinel et al., 2011; Martins et al., 2015). No entanto, assim como já mencionado, o manejo do solo tem o potencial de mudar bruscamente as propriedades edáficas e as trocas gasosas dos ecossistemas (Castaldi et al., 2006).

Entre as práticas agrícolas que interferem nas emissões de $\mathrm{N}_{2} \mathrm{O}$, já são bem estabelecidas o preparo do solo, que altera a estrutura e aeração, bem como a 
concentração de oxigênio (Butterbach-Bahl et al., 2013), a deposição e a incorporação de resíduos orgânicos (Ball et al., 2014; Schwenke et al., 2015; Zhang et al., 2015a), que aceleram o processo de decomposição e mineralização de N (Signor e Cerri, 2013), dependendo da composição química dos resíduos vegetais (Carvalho et al., 2012; 2015). Além disso, características como o estádio fenológico das culturas (Hayashi et al., 2015), condições de acidez e fertilidade, temperatura do ar e do solo (Uchida et al., 2011; Butterbach-Bahl et al., 2013; Luo et al., 2013; Gelfand et al., 2015; Benoit et al., 2015), adição de fertilizantes nitrogenados minerais e a umidade do solo (ButterbachBahl et al., 2013; Deng et al., 2015; Fub et al., 2011; Harrison-Kirk et al., 2013; Luo et al., 2013; Martins et al., 2015; Miller et al., 2008; Pimentel et al., 2015; Kong et al., 2010; Raut et al., 2015; Soares et al., 2015) também interferem nas emissões de $\mathrm{N}_{2} \mathrm{O}$. Essa interferência é decorrente de alterações nas reações de nitrificação e desnitrificação, responsáveis pela formação de $\mathrm{N}_{2} \mathrm{O}$ nos solos (Tatti et al., 2014; Yano et al., 2014). Na América Latina, o Brasil é o principal emissor desse gás (Bustamante et al., 2014) e a principal fonte de emissão de $\mathrm{N}_{2} \mathrm{O}$, no Brasil, são os solos agrícolas, que respondem por 64\% das emissões totais diretas (MCTI, 2014).

Apesar do grande número de trabalhos nos últimos anos sobre os efeitos de sistemas de manejo nas emissões de $\mathrm{N}_{2} \mathrm{O}$ do solo, ainda são divergentes os resultados de pesquisa sobre o potencial de emissão/mitigação dos sistemas de plantio direto (NT) e convencional (CT) (Abdalla et al. 2013; Yao et al., 2013; Petitjean et al., 2015; Zhang et al, 2015b). Comparado ao sistema convencional, há pesquisas que mostram maiores emissões do NT (Liu et al., 2007; Escobar et al., 2010; Siqueira Neto et al., 2011) e outras pesquisas apresentam o potencial mitigador desse sistema (Alves et al., 2010; Tellez-Rio et al., 2015). No NT o uso da rotação de culturas, com deposição ou incorporação dos resíduos orgânicos (leguminosas/gramíneas), sob condições ideais de umidade, temperatura do solo e formação de compostos orgânicos solúveis, em diferentes épocas, tem sido considerada promissora para o decréscimo das emissões de $\mathrm{N}_{2} \mathrm{O}$ dos solos agrícolas (Dyer et al., 2012; Abdalla et al., 2013; Huang et al., 2015; Zhang et al., 2015b). No entanto, o entendimento sobre a interação que ocorre entre as práticas do NT com a rotação de culturas a partir do uso de gramíneas e leguminosas, assim como observado no Sul do Brasil por Bayer t al. (2014) e em outros países (Cai et al., 2013; Liu et al., 2014; Migliorate et al., 2015; Zhang et al., 2015c), é complexo e pouco compreendido, principalmente, porque essa interação é regulada por fatores 
ambientais (Escobar et al., 2010; Jensen et al., 2012; Schwenke et al., 2015; Pimentel et al., 2015; Plaza-Bonilla et al., 2016).

Desse modo, como a maioria dos estudos sobre os efeitos combinados das práticas citadas nas emissões de $\mathrm{N}_{2} \mathrm{O}$ do solo foi realizado sob outras condições edafoclimáticas, principalmente, em regiões de clima úmido, e por apenas uma safra de cultivo (Chen et al., 2015; Tellez-Rio et al., 2015; Zhang et al., 2015c), pouco se conhece sobre esses efeitos interativos para as condições de sequeiro no Cerrado brasileiro. Aliado a isso, o acompanhamento de um ciclo completo de rotação de culturas também é importante, pois permite definir quanto de emissão acumulada de $\mathrm{N}_{2} \mathrm{O}$ por grãos produzidos os sistemas de manejo respondem e qual o seu potencial de aquecimento global parcial (pGWP) (Pramanik et al., 2014; Bayer et al., 2015; Jain et al., 2016). Segundo o último relatório do Painel Brasileiro de Mudanças Climáticas (PBMC, 2014) os resultados disponíveis sobre as emissões de $\mathrm{N}_{2} \mathrm{O}$, ainda são insuficientes, para permitir uma caracterização, com baixos índices de incertezas, das emissões produzidas pelos sistemas agrícolas, devido, à grande diversidade de ambientes no território brasileiro.

Além desses efeitos do manejo do solo, o período chuvoso no Cerrado, onde se concentram $90 \%$ das precipitações, perdura por seis meses, de outubro a março (Klink \& Machado, 2005). O Cerrado apresenta estações climáticas bem definidas, que interferem, nas reações de nitrificação e desnitrificação, principalmente, na ocorrência de precipitações pluviométricas episódicas que promovem o reumedecimento do solo, após períodos de seca. A variabilidade das precipitações em um ano agrícola poderá interferir nas emissões de $\mathrm{N}_{2} \mathrm{O}$ por estimular a mineralização da matéria orgânica do solo, promovendo acúmulo de nitrato durante os períodos de seca e, no período chuvoso, favorecer as emissões de $\mathrm{N}_{2} \mathrm{O}$ (Liu et al., 2014; Rowlings et al., 2015; Migliorati et al., 2015).

Esse efeito da sazonalidade pluviométrica do Cerrado nas emissões de $\mathrm{N}_{2} \mathrm{O}$ já foi destacado por outros autores (Cardoso et al., 2001; Alves et al., 2010; Escobar et al., 2008; Martins et al., 2015), porém de forma isolada, sem considerar os efeitos interativos da época, dos sistemas de manejo e das rotações culturais de agroecossistemas de longa duração. Interações como essas que podem resultar em picos de $\mathrm{N}_{2} \mathrm{O}$ de diferentes magnitudes em agroecossistemas são complexas de entender e podem variar muito a depender da época e período (Sommer et al., 2015; Zhang et al., 2015a). Portanto, nosso objetivo foi avaliar as emissões de $\mathrm{N}_{2} \mathrm{O}$ por um ano sob 
influência interativa da sazonalidade pluviométrica e rotação cultural em agroecossistemas conduzido por dezenove anos no Cerrado.

\section{MATERIAL E MÉTODOS}

\subsection{CARACTERÍSTICAS DA ÁREA EXPERIMENTAL E CLIMA LOCAL}

O estudo foi conduzido por um ano, de outubro de 2013 a setembro de 2014, na área experimental da Embrapa Cerrados, localizada em Planaltina, DF, Brasil (15³3’33,99”' S, 4744'12,32" W e altitude de 1.035 m). O clima da região é estacional e corresponde ao tipo Aw-tropical chuvoso (Köppen), com dois períodos bem definidos e presença de verões chuvosos, de outubro a março, correspondente ao período chuvoso, e invernos secos, de abril a setembro, correspondente ao período seco. Para caracterização das precipitações pluviométricas no bioma Cerrado, foi considerado o intervalo de outubro a março como período chuvoso, por concentrar, em média, 90\% das precipitações, que se estabelecem a partir de outubro (Silva et al., 2014), e os demais meses, como período seco. A precipitação pluviométrica média anual (1974-2003) na cidade de Planaltina foi de $1346 \mathrm{~mm}$, temperatura do ar oscilando entre $16,5^{\circ} \mathrm{C}$ a $27,7^{\circ} \mathrm{C}$ e umidade relativa do ar entre $37,6 \%$ a $97,7 \%$ (Silva et al., 2014), conforme descrito na normal climatológica observada na Figura 1.1a. As precipitações pluviométricas, temperatura média do ar e umidade relativa do ar mensal durante o período avaliado são apresentadas na Figura $1.1 \mathrm{~b}$.

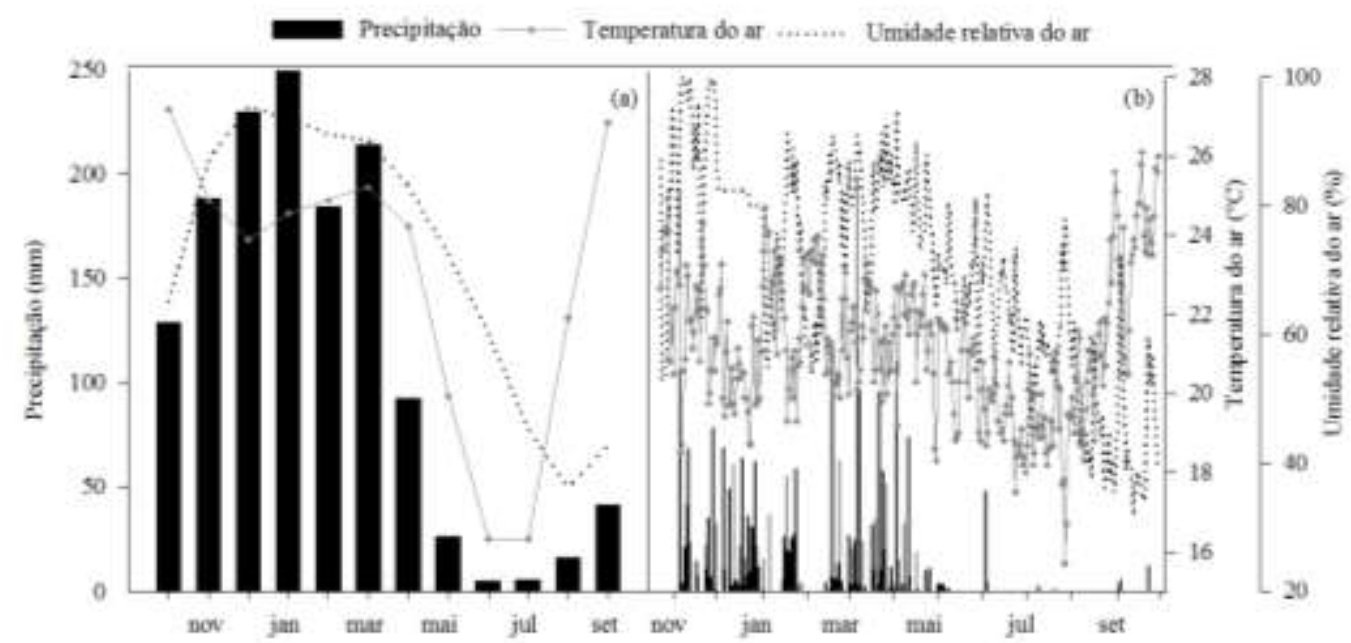

Figura 1.1 Precipitação pluviométrica, temperatura do ar e umidade relativa do ar na área experimental no período de 1974 a 2003 (a) e durante o período de avaliação (b). 
O solo da área experimental é classificado como Latossolo Vermelho distrófico de textura argilosa, um Latossolo argiloso (Typic Haplustox) (Soil Survey Staff, 2006). Os atributos químicos e físicos do solo $(0-20 \mathrm{~cm})$ são apresentados na Tabela 1.1. Segundo descrição de Reatto et al. (2007) a composição mineralógica do horizonte diagnóstico estudado consiste de: caulinta $\left(320 \mathrm{~g} \mathrm{~kg}^{-1}\right)$, gibbsita $\left(496 \mathrm{~g} \mathrm{~kg}^{-1}\right)$, hematita $\left(142 \mathrm{~g} \mathrm{~kg}^{-1}\right) \mathrm{e}$ goethita $\left(42 \mathrm{~g} \mathrm{~kg}^{-1}\right)$.

Tabela 1.1 Atributos químicos e físicos do solo da área experimental nos sistemas de manejo e Cerrado nativo em 2013, antes das medições realizadas.

\begin{tabular}{lcccc}
\hline Atributos do solo* & NTR1 & NTR2 & CT & Cerrado nativo \\
\hline Matéria Orgânica $\left(\mathrm{g} \mathrm{kg}^{-1}\right)$ & 30,0 & 30,0 & 30,0 & 34,0 \\
$\mathrm{pH}\left(\mathrm{H}_{2} \mathrm{O}\right)$ & 5,5 & 5,0 & 5,5 & 4,7 \\
$\mathrm{Al}^{3+}\left(\mathrm{cmol}_{\mathrm{c}} \mathrm{kg}^{-1}\right)$ & 0,4 & 0,4 & 0,2 & 1,4 \\
$\mathrm{H}+\mathrm{Al}\left(\mathrm{cmol}_{\mathrm{c}} \mathrm{kg}^{-1}\right)$ & 6,4 & 6,6 & 6,6 & 9,9 \\
$\mathrm{Ca}^{2+}\left(\mathrm{cmol}_{\mathrm{c}} \mathrm{kg}^{-1}\right)$ & 2,6 & 2,5 & 2,3 & 0,1 \\
$\mathrm{Mg}^{2+}\left(\mathrm{cmol}_{\mathrm{c}} \mathrm{kg}^{-1}\right)$ & 1,1 & 0,8 & 0,9 & 0,1 \\
$\mathrm{P}\left(\mathrm{mg} \mathrm{dm}^{-3}\right)$ & 17,1 & 20,5 & 16,1 & 1,3 \\
$\mathrm{~K}^{+}\left(\mathrm{mg} \mathrm{dm}^{-3}\right)$ & 161,8 & 93,8 & 153,1 & 39,1 \\
Densidade do solo $\left(\mathrm{g} \mathrm{cm}^{-3)}\right.$ & 1,2 & 1,2 & 1,2 & 1,1 \\
Argila $\left(\mathrm{g} \mathrm{kg}^{-1}\right)$ & 468 & 475 & 483 & 508 \\
Silte $\left(\mathrm{g} \mathrm{kg}^{-1}\right)$ & 95 & 55 & 80 & 89 \\
Areia $\left(\mathrm{g} \mathrm{kg}^{-1}\right)$ & 437 & 470 & 437 & 403 \\
*Determinação média em 0-20 cm de profundidade segundo a Embrapa (2011); NTR1 e NTR2 = sistema \\
plantio direto; CT = sistema convencional.
\end{tabular}

\subsection{HISTÓRICO E CARACTERIZAÇÃO DO EXPERIMENTO}

A área experimental, implantada em 1996, foi projetada para estudar a dinâmica de preparo do solo e rotação de culturas, com alternância no espaço e no tempo, conforme ilustrado na Figura 1.2. 


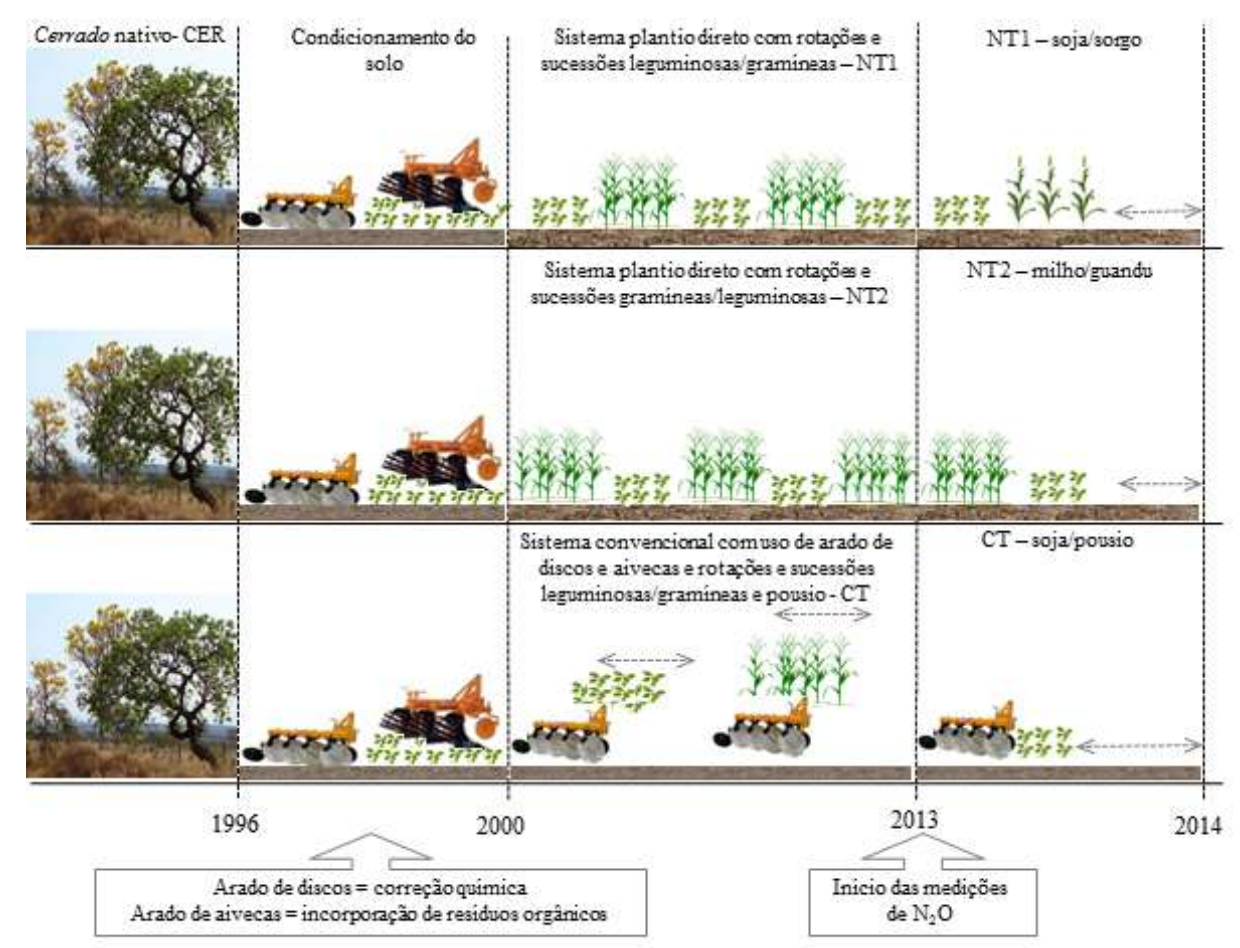

Figura 1.2 Esquema de implantação e condução da área experimental, desde o ano de 1996 até 2014, referente aos diferentes sistemas de manejo a serem utilizados na pesquisa.

Após a derrubada da vegetação natural do Cerrado em 1995/1996 houve o condicionamento do solo, para todas as parcelas, com uso de arado de discos para correção química e arado de aivecas para incorporação de resíduos orgânicos em profundidade e, somente no quinto ano após essas atividades, que os sistemas de manejo se diferenciaram. Cada parcela experimental mede $22 \mathrm{~m}$ de comprimento e $18 \mathrm{~m}$ de largura, distribuídas em delineamento de blocos ao acaso, com três repetições. Foram selecionados para esse estudo, dois sistemas de manejo sob plantio direto, sistema convencional e a área do Cerrado sensu stricto denso, utilizada como tratamento de referência (Figura 1.3). 


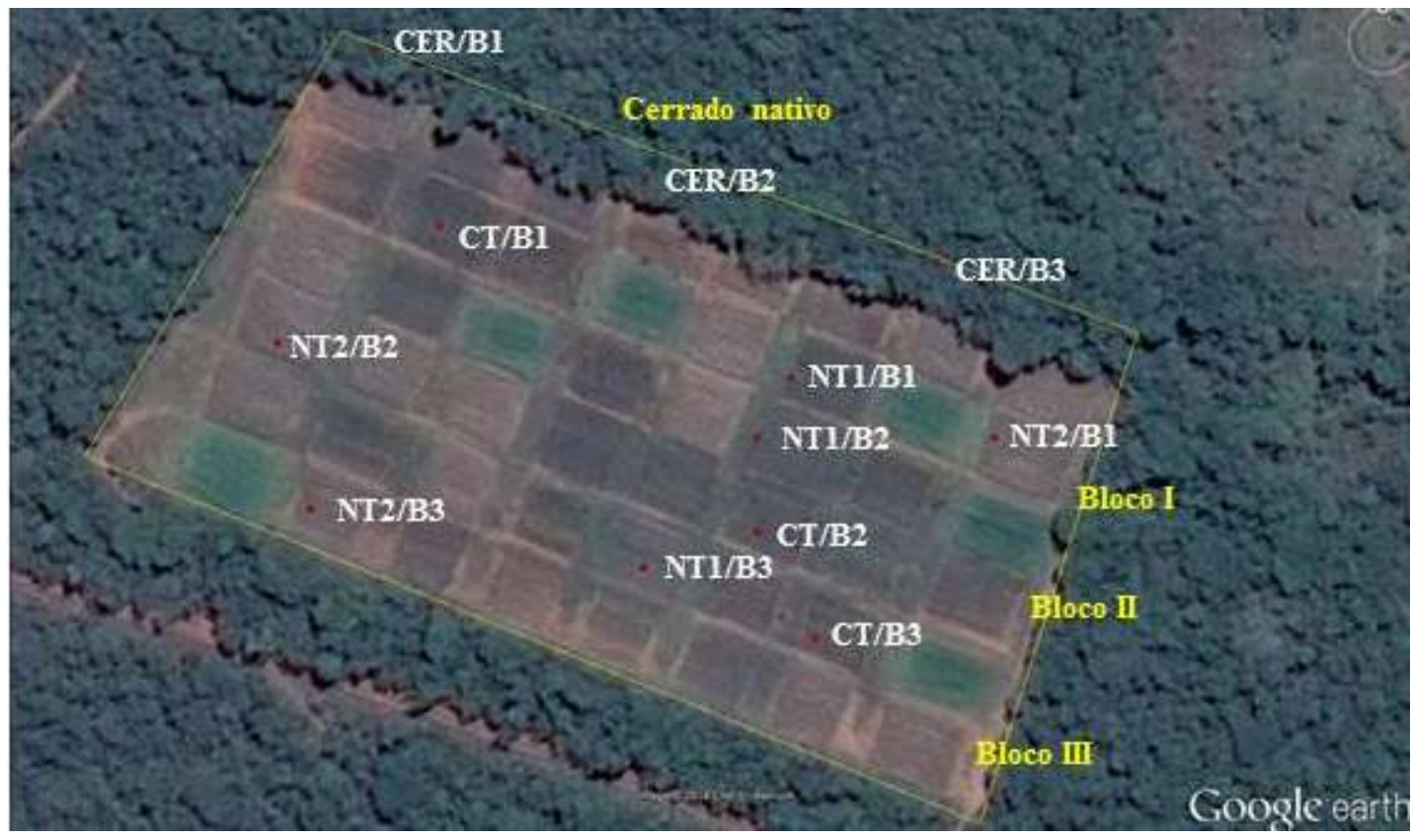

Figura 1.3 Vista aérea do experimento. NT1/B1, NT1/B2 e NT1/B3: plantio direto com soja e safrinha de sorgo instalado nos blocos 1, 2 e 3; NT2/B1, NT2/B2 e NT2/B3: plantio direto com milho e safrinha de guandu instalado nos blocos 1, 2 e 3; CT/B1, CT/B2 e CT/B3: plantio convencional com soja instalado nos blocos 1, 2 e 3; CER/B1, CER/B2, CER/B3: cerrado dos blocos 1,2 e 3.

O resumo do histórico de cultivo de cada parcela experimental e tratos culturais no ano em que se iniciou a coleta de dados encontram-se descritos na Tabela 1.2 e o histórico completo encontra-se descrito em anexo (Tabela A1). 
Tabela 1.2 Descrição dos sistemas de manejo de solo estudados e resumo do histórico de cultivo nas parcelas experimentais.

\begin{tabular}{lll}
\hline Sistema de manejo & Símbolo & Descrição $^{1}$
\end{tabular}

Plantio convencional com uso de grade pesada e rotação bienal leguminosas-gramíneas

Plantio direto com rotações bienais de leguminosasgramíneas e segunda safras alternadas de gramíneasleguminosas.

Plantio direto com rotações

bienais de gramíneasleguminosas e safrinhas alternadas de leguminosasgramíneas.
Preparo do solo com uso de grade pesada e cultivado somente com leguminosas nos dois anos iniciais. Posteriormente, rotação bienal gramíneasleguminosas. Em 20/10/2013, após o preparo do solo plantou-se soja superprecoce BRS $6780(\approx 100$ dias $)$ em espaçamento de $0.45 \mathrm{~m}$ (safra principal). AplicouCT se $400 \mathrm{~kg} \mathrm{ha}^{-1}$ da formulação 0-20-20 com tratamento de semente (fungicida Vitax tyram ${ }^{\circledR} 120 \mathrm{~mL}^{\circ} \mathrm{kg}^{-1} \mathrm{e}$ inseticida Standak ${ }^{\circledR} 80 \mathrm{~mL}$ ) e inoculação da semente com Bradyrhizobium japonicum turfoso (estirpes CPAC 7 e CPAC 15). Também foi aplicado no solo o herbicida pré-emergente Dual gold ${ }^{\circledR}\left(2 \mathrm{~L} \mathrm{ha}^{-1}\right)$. Após a colheita da soja (29/01/2014) a área permaneceu em pousio até a instalação da próxima cultura.

Preparo com arado de discos nos dois primeiros anos e arado de aivecas nos dois anos seguintes. A partir do quinto ano, foi implantado o sistema de plantio direto, com rotação bienal combinado a sucessões de safrinhas. Em outubro de 2013 plantouse soja superprecoce $(\approx 100$ dias), como cultivo de primeira safra, em espaçamento de $0.45 \mathrm{~m}$ com as mesmas adubações e inoculação realizada no sistema CT. Logo após a colheita da soja, em 29 de janeiro de 2013, foram deixados os restos culturais sobre o solo. E no dia 10/02/2014 plantou-se o sorgo, como cultura de segunda safra, em espaçamento de $0.50 \mathrm{~m}$, com adubação de plantio de $300 \mathrm{~kg} \mathrm{ha}^{-1}$ da fórmula 4-3016 (N-P-K). Em 09/03/2014 foi realizada uma adubação de cobertura de $50 \mathrm{~kg} \mathrm{ha}^{-1}$ de $\mathrm{N}$ (uréia). $\mathrm{O}$ sorgo foi colhido em 09/06/2014.

Preparo com arado de discos nos dois primeiros anos e arado de aivecas nos dois anos seguintes. A partir do quinto ano, foi implantado o sistema de manejo plantio direto, com rotação bienal combinado a sucessões de safrinhas. Em 22/10/2013 plantou-se um híbrido de milho (cultivo de primeira safra), em espaçamento de $0.70 \mathrm{~m}$. Na adubação de plantio aplicou-se $350 \mathrm{~kg} \mathrm{ha}^{-1}$ da fórmula 4-30-16 (N-P-K) e para as duas adubações de cobertura utilizou-se $70 \mathrm{~kg}$ ha $^{-1}$ de N (uréia) em cada aplicação, aos 20 e 47 dias após o plantio. Após a colheita do milho (10/03/2014), deixando os restos culturais no solo, plantou-se a cultura do guandu (cultivo de segunda safra), em espaçamento de $0.50 \mathrm{~m}$ no dia $12 / 03 / 2014$. O guandu foi colhido em 09/06/2014.

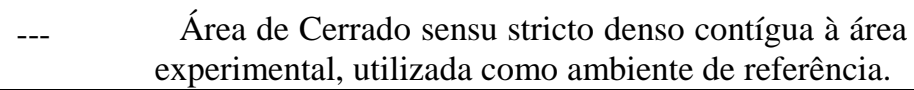

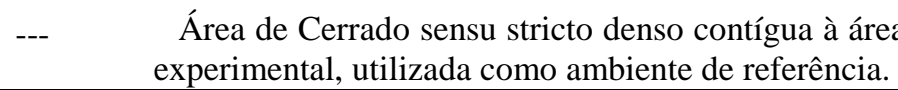

Cerrado nativo

\footnotetext{
${ }^{1}$ As espécies de leguminosas e gramíneas, respectivamente, utilizadas nos dois tratamentos com plantio direto no verão, foram soja e milho e as utilizadas nas rotações como segunda safra foram guandu (Cajanus cajan), após o milho e o sorgo BRS332 (Sorghum bicolor (L.) Moench), após a soja.
} 


\subsection{MEDIÇÕES DOS FLUXOS DE ÓXIDO NITROSO}

Os fluxos de $\mathrm{N}_{2} \mathrm{O}$ foram medidos durante um ano através do método da câmara estática fechada (Mosier, 1989), de 23 de outubro de 2013 a 29 de setembro de 2014. O total dos fluxos de $\mathrm{N}_{2} \mathrm{O}$ foi determinado em 88 eventos, com 22 eventos entre os meses de outubro a dezembro de 2013 e mais 66 eventos entre os meses de janeiro a setembro de 2014.

A frequência de amostragem dos fluxos de $\mathrm{N}_{2} \mathrm{O}$ foi tal que representasse adequadamente os sistemas de produção avaliados e permitisse mensurar suas diferenças. Sendo assim, a periodicidade dos intervalos de coleta ocorreu em função de eventos que sabidamente intensificam o fluxo de $\mathrm{N}_{2} \mathrm{O}$ (Wang et al., 2011). Foram realizadas amostragens diárias por pelo menos 3 dias consecutivos após eventos de: precipitação pluviométrica seguida de mais de uma semana sem chuva, preparo do solo, plantios, colheitas e fertilizações nitrogenadas.

Em cada parcela experimental, foram instaladas três câmaras estáticas, distanciadas ao acaso nas linhas, que permaneceram por aproximadamente 25 dias após a emergência das culturas e, posteriormente, nas entrelinhas, em função do crescimento das culturas. Cada câmara estática era formada por uma base metálica $(0,38 \mathrm{~m}$ x 0,58 m) inserida no solo e uma parte superior de PVC, revestida por uma manta térmica de alumínio, que juntamente com a base metálica veda o espaço delimitado pela câmara, formando um microambiente, onde os gases se acumulam, para posterior coleta e determinação. Nas câmaras foram feitos orifícios centrais vedados com silicone onde foi inserida uma mangueira de borracha conectada a uma válvula de três vias para controle da saída de gases conforme ilustrado em anexo (Fig. A1, B). Em uma das três câmaras também foi acoplado um termômetro digital para acompanhamento da temperatura média dentro das câmaras. Outro termômetro digital foi inserido no solo para determinação da temperatura do solo a $5 \mathrm{~cm}$ de profundidade nos tempos determinados para coletas de gases. As amostragens de gases foram realizadas entre 09:00 e 11:00 horas, representando a média da condição diária da emissão (Alves et al., 2012). Amostras de ar do interior da câmara foram coletadas aos 0,15 e 30 minutos após o fechamento das câmeras, com seringas de polipropileno de $60 \mathrm{~mL}$ com válvulas de três vias acoplada, no entanto, eram coletados apenas $25 \mathrm{~mL}$ dos gases. Adicionalmente, para referenciar o padrão do ar atmosférico, era coletada uma amostra em cada bloco. 
Os vials eram transportados em caixas térmicas com gelo até o laboratório conforme ilustrado em anexo (Fig. A2).

A concentração de $\mathrm{N}_{2} \mathrm{O}$ no ar armazenado nos vials foi determinada por cromatografia gasosa (Trace 1310 GC Ultra, Thermo Scientific, Milão, Itália) com coluna preenchida com "Parapak Q" e detector de captura de elétrons (Anexo 3B). A calibração do cromatógrafo para o $\mathrm{N}_{2} \mathrm{O}$ é feita por quatro padrões, nas concentrações de 200, 600, 1000 e 1500 ppb de $\mathrm{N}_{2} \mathrm{O}$. Os fluxos de $\mathrm{N}_{2} \mathrm{O}\left(\mathrm{FN}_{2} \mathrm{O}\right)$ medidos pela alteração linear da concentração do gás com o tempo de incubação nas câmaras de amostragens, foram calculados pela equação 1, segundo Steudler et al. (1989):

$$
\left.\mathrm{FN}_{2} \mathrm{O}=(\delta \mathrm{C} / \delta \mathrm{t}) \times(\mathrm{V} / \mathrm{A}) \times \mathrm{m} / \mathrm{Vm}\right)
$$

em que o $\mathrm{FN}_{2} \mathrm{O}$ é o fluxo de $\mathrm{N}_{2} \mathrm{O}\left(\mu \mathrm{g} \mathrm{N}-\mathrm{N}_{2} \mathrm{O} \mathrm{m}{ }^{-2} \mathrm{~h}^{-1}\right) ; \delta \mathrm{C} / \delta \mathrm{t}$ é a alteração na concentração de $\mathrm{N}_{2} \mathrm{O}$ na câmara em função do tempo $\left(\mathrm{mol} \mathrm{mol}^{-1} \mathrm{~s}^{-1}\right)$; $\mathrm{V}$ e A são respectivamente o volume $\left(\mathrm{m}^{3}\right)$ e a área da câmara $\left(\mathrm{m}^{2}\right)$; e/P é a pressão da água /pressão atmosférica na câmara $\left(\mathrm{kPa} \mathrm{kPa}^{-1}\right)$; e Vm é o volume molar da câmara $\left(\mathrm{m}^{3} \mathrm{~mol}^{-}\right.$ $\left.{ }^{1}\right)$.

As emissões diárias foram obtidas pelo valor médio das três câmaras instaladas em cada parcela experimental, formando um total de nove câmaras por tratamento. Os fluxos de $\mathrm{N}-\mathrm{N}_{2} \mathrm{O}$ foram então determinados por regressão linear da concentração de $\mathrm{N}$ $\mathrm{N}_{2} \mathrm{O}$ em função do tempo de amostragem (Livingston and Hutchinson, 1995), enquanto que as emissões acumuladas de $\mathrm{N}_{2} \mathrm{O}$ foram determinadas a partir da interpolação linear dos valores diários de emissão de $\mathrm{N}_{2} \mathrm{O}$ do solo (Dobbie et al., 1999; Allen et al., 2010; Bayer et al., 2015).

Os valores das emissões acumuladas por rendimento dos grãos $\left(\mathrm{mg} \mathrm{N}_{2} \mathrm{O} \mathrm{m} \mathrm{kg}^{-1}\right.$ grãos) foram calculados como sendo a razão entre os valores acumulados por cultura e as produções em grãos (com 13\% de umidade) ou massa seca de cada cultura.

O potencial de aquecimento global parcial de emissão (GWP, em um horizonte de 100 anos), que se refere somente ao potencial do $\mathrm{N}_{2} \mathrm{O}$ (pGWP), e usado para avaliar o impacto dos sistemas agrícolas no efeito estufa, é expresso em equivalente de dióxido de carbono - $\mathrm{CO}_{2}$ eq (Bayer et al., 2015) e foi calculado multiplicando-se as emissões acumuladas de $\mathrm{N}_{2} \mathrm{O}$ pela forçante radioativa do referido gás. Para isso, foi utilizado o fator de conversão de $298 \mathrm{~kg} \mathrm{CO}_{2} \mathrm{~kg}^{-1} \mathrm{~N}_{2} \mathrm{O}$ (IPCC, 2013), como segue na equação 2: 
em que o pGWP é o potencial de aquecimento global parcial $\left(\mathrm{kg} \mathrm{CO}_{2} \mathrm{eq} \mathrm{ha}{ }^{-1}\right)$, e o $\mathrm{N}_{2} \mathrm{O}$ representa as emissões acumuladas $\left(\mathrm{kg} \mathrm{ha}^{-1}\right)$. Para esse estudo, no cálculo do pGWP, não foram consideradas as emissões de metano $\left(\mathrm{CH}_{4}\right)$, devido pequena contribuição do GWP desse gás e a ocorrência de influxos nas medições realizadas nos cultivos de sequeiro sob os Latossolos do Cerrado brasileiro (Bustamante et al., 2009).

\subsection{VARIÁVEIS EDAFOCLIMÁTICAS}

Simultaneamente às coletas dos gases, foram coletadas amostras de solo para determinação de $\mathrm{NO}_{3}{ }^{-}$e $\mathrm{NH}_{4}{ }^{+}$do solo, na profundidade de $0-5 \mathrm{~cm}$, em seis pontos das entrelinhas de forma sistematizada, formando uma amostra composta. De cada amostra de solo foi retirada uma alíquota para determinação da umidade do solo. A determinação do nitrogênio mineral do solo nas formas de $\mathrm{NO}_{3}{ }^{-}$e $\mathrm{NH}_{4}{ }^{+}$foi realizada com a extração em $50 \mathrm{~mL}$ de $\mathrm{KCl} 2 \mathrm{~mol} \mathrm{~L}^{-1}$, segundo o método proposto por Bremmer e Mulvaney (1982) procedendo-se a destilação pelo método Kjeldahl.

As variáveis, temperatura média do ar e a precipitação pluviométrica, foram registradas em estação meteorológica automática (Campbell Scientific) instalada na área experimental. Nas parcelas também foram realizadas determinações da densidade do solo e de partículas, pelo método do anel volumétrico e balão volumétrico, respectivamente (Embrapa, 1997). A umidade gravimétrica do solo foi calculada pela secagem de uma subamostra de solo em estufa a $105^{\circ} \mathrm{C}$ por 48 horas. Com base nos resultados de umidade do solo, densidade aparente e de partículas do solo foram calculados o espaço poroso saturado por água (\% WFPS) de cada avaliação, para determinar o nível de anoxia na camada $0-5 \mathrm{~cm}$ de profundidade, pela equação 3 , descrita por Paul e Clark (1996):

$\mathrm{WFPS}=(\theta \times(\mathrm{BD} / \mathrm{WD}) \times 100) /[1-(\mathrm{BD} / \mathrm{PD})]$

em que: WFPS é o espaço poroso saturado por água (\%); $\Theta$ é a umidade gravimétrica do solo $\left(\mathrm{g} \mathrm{g}^{-1}\right)$; BD é a densidade do solo $\left(\mathrm{g} \mathrm{cm}^{-3}\right)$; WD é a densidade da água $\left(1,0 \mathrm{~g} \mathrm{~cm}^{-}\right.$ $\left.{ }^{3}\right)$ e PD é a densidade de partícula $\left(2,65 \mathrm{~g} \mathrm{~cm}^{-3}\right)$. 


\subsection{ANÁLISES ESTATÍSTICAS}

Os dados de fluxos de $\mathrm{N}_{2} \mathrm{O}, \mathrm{NO}_{3}{ }^{-}, \mathrm{NH}_{4}{ }^{+}$, temperatura do solo e $\mathrm{N}_{2} \mathrm{O}$ acumulado foram submetidos á análise de variância (ANOVA), e as médias comparadas pelo teste de Tukey HSD $(p=0,05)$. As variáveis do $\mathrm{N}_{2} \mathrm{O}$ e acumulado de $\mathrm{N}_{2} \mathrm{O}$ foram submetidos à análise multivariada (análise de componente principal ACP) a fim de avaliar os fatores de condução (práticas de manejo e variáveis do solo) e fluxos de $\mathrm{N}_{2} \mathrm{O}$. Os coeficientes de correlação (r) entre as variáveis e eixos de ordenação foram considerados significativos apenas quando maiores do que 0,50. As emissões acumuladas de $\mathrm{N}_{2} \mathrm{O}$ foram calculadas por interpolação linear entre as datas de amostragens adjacentes (Allen et al., 2010). Desse modo, as emissões acumuladas foram estimadas plotando-se os valores diários dos fluxos de $\mathrm{N}_{2} \mathrm{O}$ e a escala de tempo em um gráfico e calculando-se a área resultante sob a curva, por integração, utilizando-se o software Sigmaplot@ Versão 10 (Systat Software Inc., Chicago, USA, 2007).

\section{RESULTADOS}

\subsection{SAZONALIDADE PLUVIOMÉTRICA DURANTE DESENVOLVIMENTO DAS CULTURAS NO CERRADO}

A precipitação total de outubro de 2013 a setembro de 2014 foi de $1258 \mathrm{~mm}$ (Fig. 1.4). Desse total, $88 \%$ das precipitações $(1104 \mathrm{~mm})$ ocorreram durante o período chuvoso e $12 \%$ durante o período seco e de forma ocasional (Fig. 1.4).

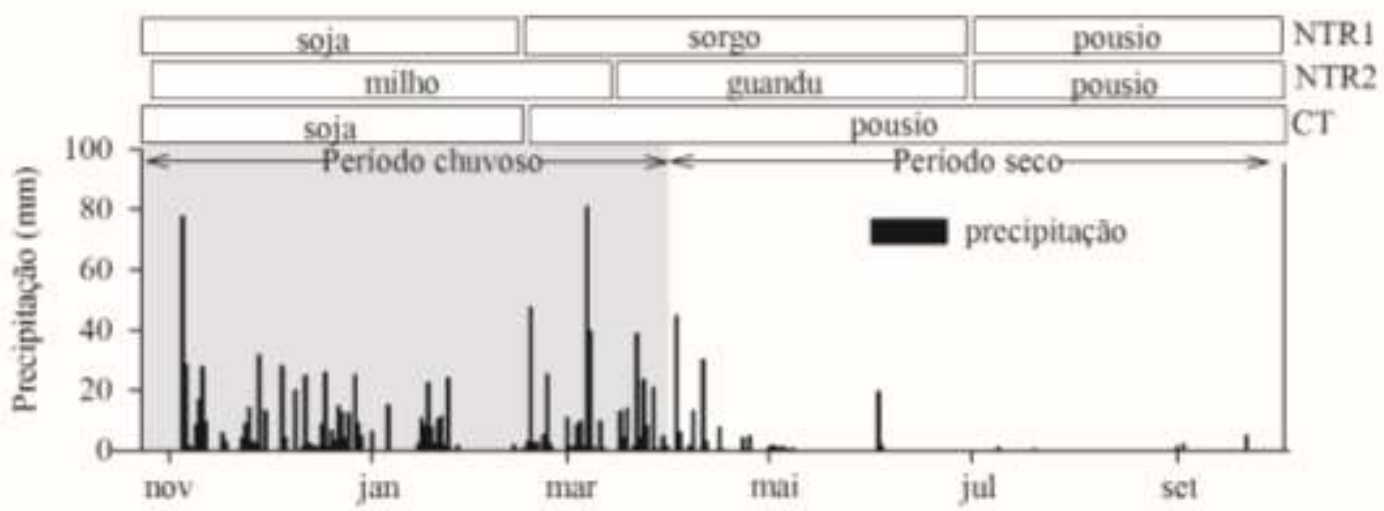

Figura 1.4 Precipitação pluviométrica total na área experimental no período chuvoso e seco, durante o ano agrícola de 2013/2014, Planaltina, DF, Brasil. NTR1 = sistema de manejo plantio direto cultivado com soja e rotação com o sorgo BRS332 (Sorghum bicolor (L.) Moench); NTR2 = sistema de manejo plantio direto com milho e rotação com o guandu (Cajanus cajan); CT = sistema convencional com soja e posterior pousio do solo. 
Durante o período chuvoso, observou-se irregularidades na distribuição do total pluviométrico, com veranicos de duração superior a 4 dias para os meses de novembro, janeiro e fevereiro (Fig. 1.4). Somente no mês de fevereiro, foi observado um intervalo de mais de 17 dias, sem precipitações acima de $3 \mathrm{~mm}$.

Durante o ciclo de desenvolvimento das culturas de soja, milho, sorgo e guandu foram observados totais de precipitações de: $713 \mathrm{~mm}$; $959 \mathrm{~mm} ; 535 \mathrm{~mm}$; e $280 \mathrm{~mm}$, respectivamente.

\subsection{EMISSÕES DIÁRIAS E SAZONAIS DE $\mathrm{N}_{2} \mathrm{O}$ E VARIÁVEIS EDAFOCLIMÁTICAS EM AGROECOSSISTEMAS DO CERRADO}

O Cerrado apresentou os menores pulsos de emissões de $\mathrm{N}_{2} \mathrm{O}$ do solo, sendo que $56 \%$ do total dos pulsos desse sistema estiveram abaixo de $5 \mu \mathrm{g} \mathrm{m}^{-2} \mathrm{~h}^{-1}$, com influxos em algumas medições. Nesse sistema, não foram observadas diferenças de magnitude nas emissões de $\mathrm{N}_{2} \mathrm{O}$ do solo ao longo do período avaliado por efeito da sazonalidade pluviométrica (Fig. 1.5a). 


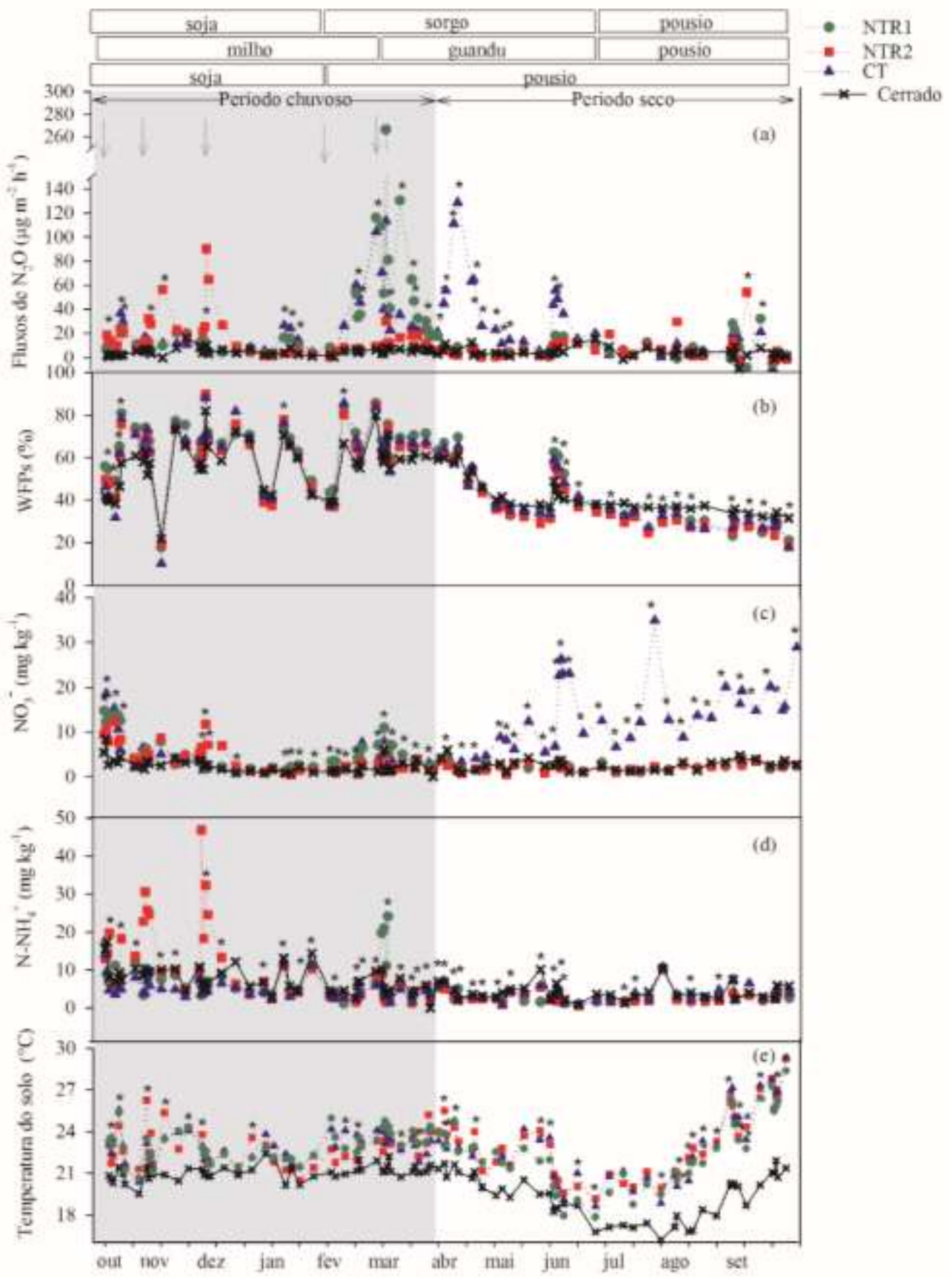

Figura 1.5 Fluxos diários de óxido nitroso (a), espaço poroso saturado com água - WFPS (b), nitrato $\mathrm{NO}_{3}{ }^{-}$(c), amônio $-\mathrm{NH}_{4}{ }^{+}$(d) e temperatura do solo (e) do ano agrícola 2013/2014 sob os sistemas plantio direto (NTR1 e NTR2), convencional (CT) e cerrado nativo, em Latossolo, no período chuvoso e seco, Planaltina, DF, Brasil. As setas indicam eventos de fertilizações nitrogenadas. * Indicativo de diferença significativa, pelo teste de Tukey $(\mathrm{P}<0,05)$, entre os sistemas de manejo no período avaliado.

Diferentemente do Cerrado, ocorreram variações diárias e sazonais nas emissões de $\mathrm{N}_{2} \mathrm{O}$ do solo nos agroecossistemas (Fig. 1.5a). Os fluxos observados nos sistemas de manejo variaram de $266 \mu \mathrm{g} \mathrm{m}^{-2} \mathrm{~h}^{-1}$, no período chuvoso, a valores mínimos de $0,08 \mu \mathrm{g}$ $\mathrm{m}^{-2} \mathrm{~h}^{-1}$, no período seco (Fig. 1.5a). Os maiores fluxos de $\mathrm{N}_{2} \mathrm{O}$ do solo nos sistemas de manejo ocorreram, principalmente, após a adição de fertilizantes nitrogenados e 
elevação nos WFPS durante o período chuvoso. Há indicativos de que no período seco, a ocorrência de precipitação ocasional (>20 $\mathrm{mm}$ em junho) promoveu o reumedecimento do solo (Fig. 1.5b) após prolongados intervalos sem chuva, o que favoreceu as emissões de $\mathrm{N}_{2} \mathrm{O}$ associadas ao aumento dos teores de nitrato e da temperatura do solo (Fig. 1.5a, c, e).

Nove dias após a primeira adubação nitrogenada de cobertura do milho (11/11/2013), no NTR2, os fluxos alcançaram $56 \mu \mathrm{g} \mathrm{m}^{-2} \mathrm{~h}^{-1}$. Nesse mesmo período, os sistemas NTR1 e CT, sob a cultura de soja, emitiram 9 e $11 \mu \mathrm{g} \mathrm{m}^{-2} \mathrm{~h}^{-1}$, respectivamente enquanto o Cerrado nativo, apresentou influxo de $-0,3 \mu \mathrm{g} \mathrm{m} \mathrm{m}^{-2} \mathrm{~h}^{-1}$. Ou seja, a adubação nitrogenada de cobertura no milho promoveu emissões 6,2 vezes superiores, quando comparado aos sistemas cultivados com soja. Após a segunda adubação nitrogenada de cobertura no milho (08/12/2013), o aumento dos fluxos no NTR2 ocorreu quatro dias após a segunda adubação de cobertura com o fertilizante nitrogenado, quando foi observado um pulso de $90,5 \mu \mathrm{g} \mathrm{m}^{-2} \mathrm{~h}^{-1}$, enquanto, nos demais sistemas agrícolas, os valores não ultrapassaram $4 \mu \mathrm{g} \mathrm{m}^{-2} \mathrm{~h}^{-1}$. Também na segunda adubação de cobertura, os fluxos observados na cultura do milho no NTR2 foram 22,5 superiores, quando comparado aos demais tratamentos. No intervalo entre a segunda adubação nitrogenada e a ocorrência do pico de 90,5 $\mu \mathrm{g} \mathrm{m}^{-2} \mathrm{~h}^{-1}$ houve um acúmulo de chuva de $46 \mathrm{~mm}$. No dia que antecedeu essa campanha de campo foram notificados $24 \mathrm{~mm}$ de precipitação pluviométrica e WFPS próximo a 90\%, propiciando condição de anaerobiose e promovendo a desnitrificação (Fig. 1.5b).

No terceiro dia após a colheita do milho e x dias após o plantio do Guandu no NTR2, foi identificado um pico de emissão de $30 \mu \mathrm{g} \mathrm{m}^{-2} \mathrm{~h}^{-1}$, entretanto durante todo o ciclo da cultura não foram observados pulsos maiores que $19 \mu \mathrm{g} \mathrm{m}^{-2} \mathrm{~h}^{-1}$ (Fig. 1.5a). Nesse tratamento ocorreram na entressafra dois picos de 30 e $54 \mu \mathrm{g} \mathrm{m}^{-2} \mathrm{~h}^{-1}$ em 05/08/2014 e 09/09/2014, respectivamente.

Em relação à dinâmica de fluxos nos sistemas de manejo NTR1 e CT, durante o ciclo de desenvolvimento da soja, os maiores fluxos de $\mathrm{N}_{2} \mathrm{O}$ também ocorreram em eventos como o plantio e a colheita. Os maiores fluxos de $\mathrm{N}_{2} \mathrm{O}$ observados no início do desenvolvimento da soja no CT ocorreram dez dias após o plantio, em 30/10/2013, alcançando o valor de $36 \mu \mathrm{g} \mathrm{m}^{-2} \mathrm{~h}^{-1}$, e 18 vezes maior que as emissões encontradas no Cerrado $\left(2 \mu \mathrm{g} \mathrm{m}^{-2} \mathrm{~h}^{-1}\right)$. Nos dias 20 e 23/01/2014 foram registrados picos de $\mathrm{N}_{2} \mathrm{O}$ apenas nos sistemas de manejo que estavam com a cultura da soja (NTR1 e CT). O NTR1 nos dois dias citados emitiu em média $15 \mu \mathrm{g} \mathrm{m}^{-2} \mathrm{~h}^{-1}$ enquanto o CT apresentou fluxos 
médios de $25 \mu \mathrm{g} \mathrm{m}^{-2} \mathrm{~h}^{-1}$, ou seja, $40 \%$ superior ao NTR1. Contudo, os fluxos mais expressivos decorreram do efeito dos resíduos da soja, como pode ser observado no CT e NTR1 nos meses seguintes a sua colheita em 29/01/2014 (Fig. 1.5a).

Durante o pousio do sistema CT, após a colheita da soja, foram observados picos de $\mathrm{N}_{2} \mathrm{O}$ com aumentos nas emissões entre os meses de fevereiro e junho. Nos meses posteriores à colheita da soja foram revelados fluxos médios de 60,113, 128, 23 e $56 \mu \mathrm{g}$ $\mathrm{m}^{-2} \mathrm{~h}^{-1}$, em fevereiro, março, abril, maio e junho, respectivamente. Aos 38 dias após a colheita da soja, os fluxos passaram de $4 \mu \mathrm{g} \mathrm{m}^{-2} \mathrm{~h}^{-1}$, em 03/02/2014, com WFPS em 42\%, para $113 \mu \mathrm{g} \mathrm{m}^{-2} \mathrm{~h}^{-1}$, em 12/03/2014, com elevações do WFPS para $67 \%(\mathrm{P}<0,05)$. Nesse mesmo período foram observadas chuvas regulares que em seis dias totalizaram $136 \mathrm{~mm}$. Foi observado ainda para CT o efeito do reumedecimento do solo em 16/04/2014 (chuva $>7 \mathrm{~mm}$ ) seguido de pulsos de $128 \mu \mathrm{g} \mathrm{m}^{-2} \mathrm{~h}^{-1}$ no dia subsequente. $\mathrm{O}$ efeito do reumedecimento também pode ser observado em 05/06/2014 com 21,2 mm de chuva nos dois dias anteriores, resultando em um pico de $56 \mu \mathrm{g} \mathrm{m} \mathrm{m}^{-2} \mathrm{~h}^{-1}$, o que possivelmente contribuiu para desnitrificação do $\mathrm{N}$ armazenado na forma de $\mathrm{NO}_{3}{ }^{-}$, cujos teores encontrados foram superiores a $25 \mathrm{mg} \mathrm{kg}^{-1}$ (Fig. 3a, c). Ao final do período seco, os teores de $\mathrm{NO}_{3}{ }^{-}$do solo sob plantio direto (NTR1 e NTR2) e Cerrado nativo não ultrapassaram $2,7 \mathrm{mg} \mathrm{kg}^{-1}$, enquanto no CT, foram observados teores de $29 \mathrm{mg} \mathrm{kg}^{-1}$ no mesmo período (Fig. 1.5c).

Após a colheita da soja as emissões de $\mathrm{N}_{2} \mathrm{O}$ foram maiores no NTR1 comparado ao CT. A partir da colheita da soja, no NTR1, as emissões que estavam em $4 \mu \mathrm{g} \mathrm{m}^{-2} \mathrm{~h}^{-1}$ no dia 03/02/2014 se elevaram a $266 \mu \mathrm{g} \mathrm{m}^{-2} \mathrm{~h}^{-1}$ em 12/03/2014, três dias após a adubação de cobertura do sorgo, quando também foi identificado que os teores de $\mathrm{NO}_{3}{ }^{-}$do solo passaram de $7 \mathrm{mg} \mathrm{kg}^{-1}$ para $11 \mathrm{mg} \mathrm{kg}^{-1} \mathrm{e}$, os teores de $\mathrm{NH}_{4}{ }^{+}$de $6 \mathrm{mg} \mathrm{kg}^{-1}$ para $20 \mathrm{mg} \mathrm{kg}^{-}$ ${ }^{1}$ (Fig. 1.5c, d). Esses valores de N mineral observados no sistema NTR1, foram $45 \% \mathrm{e}$ $40 \%$ superiores àqueles obtidos no Cerrado e no CT, respectivamente, no mesmo dia. Excluindo-se o efeito da adubação nitrogenada, realizada no sorgo sob o NTR1, os fluxos de $\mathrm{N}_{2} \mathrm{O}$ nos demais agroecossistemas apresentaram uma variação de 33 a $115 \mu \mathrm{g}$ $\mathrm{m}^{-2} \mathrm{~h}^{-1}$, enquanto que no cerrado variou de $-9,37$ a $16,46 \mu \mathrm{g} \mathrm{m}^{-2} \mathrm{~h}^{-1}$.

\subsection{VARIAÇÕES SAZONAIS DO WFPS, NITROGÊNIO MINERAL $\left(\mathrm{NO}_{3}{ }^{-} \mathrm{E}\right.$ $\mathrm{NH}_{4}^{+}$) E TEMPERATURA DO SOLO}


As diferenças no WFPS, entre os sistemas estudados foram significativas em $22 \%$ das medições $(\mathrm{P}<0.05)$. Durante o período chuvoso o WFPS nos agroecossistemas atingiu $90 \%$ em novembro. No entanto, valores inferiores a $30 \%$ durante veranicos que ocorreram ao longo da estação de crescimento das culturas também foram registrados (Fig. 1.5b). No período seco, a porcentagem mínima de WFPS foi de 18\% (Fig. 1.5b). No início de junho após $19 \mathrm{~mm}$ de precipitação o WFPS chegou a mais de 60\%, valor que foi mantido por 22 dias. Os valores de WPFS de até $18 \%$ observados no período seco foram registrados no final de setembro, somente no CT e, nos demais sistemas (NTR1 e NTR2) a média foi de $20 \%$.

No período chuvoso, pequenas variações de $\mathrm{NO}_{3}{ }^{-}$do solo ocorreram após as práticas de adubação nitrogenada no milho sob o NTR2, chegando a teores de no máximo $12 \mathrm{mg}$ $\mathrm{NO}_{3}{ }^{-} \mathrm{kg}^{-1}$, em 12/12/2013, enquanto nos demais sistemas de manejo, os teores foram inferiores a $2 \mathrm{mg} \mathrm{kg}^{-1}$ no mesmo período. Em geral, os teores de $\mathrm{NO}_{3}{ }^{-}$do solo variaram de 0 a $35 \mathrm{mg} \mathrm{kg}^{-1}$ entre os agroecossistemas e cerrado nativo. Os maiores teores e variações de $\mathrm{NO}_{3}{ }^{-}$foram observados no $\mathrm{CT}$, durante todo período seco (Fig. 1.5c). Apesar dos elevados teores de $\mathrm{NO}_{3}{ }^{-}$do solo no $\mathrm{CT}$ durante todo o período seco, os picos de $\mathrm{N}_{2} \mathrm{O}$ observados nesse período foram limitados à incidência de pequenos volumes de precipitações (<19 mm) ocorridas no mês de junho, e de forma ocasional. A partir de julho, mesmo com o aumento nas concentrações de $\mathrm{NO}_{3}{ }^{-}$do solo no $\mathrm{CT}$, que se estendeu até setembro, não foram observados novos picos de emissão de $\mathrm{N}_{2} \mathrm{O}$ (Fig. 1.5a, c). Para o Cerrado nativo, os teores de $\mathrm{NO}_{3}{ }^{-}$do solo mantiveram-se relativamente baixos e constantes, independente do período sazonal, com teor médio do período chuvoso, semelhante ao período seco de $2,5 \mathrm{mg} \mathrm{kg}^{-1}$ (Fig. 1.5c).

Para os teores de $\mathrm{NH}_{4}{ }^{+}$do solo, entre os sistemas estudados, foram observadas diferenças em $60 \%$ dos dados $(\mathrm{P}<0,05)$. Diferentemente do $\mathrm{NO}_{3}{ }^{-}$, os maiores teores e variações de $\mathrm{NH}_{4}{ }^{+}$do solo ocorreram durante o período chuvoso (Fig. 3d). No NTR2 teores de até $46,8 \mathrm{mg} \mathrm{kg}^{-1}$ de $\mathrm{NH}_{4}{ }^{+}$foram observados no mês de dezembro (Fig. 1.3d). No NTR1, em março, também foi observado aumento nos teores de $\mathrm{NH}_{4}{ }^{+}$do solo. Excetuando-se os eventos após adubação nitrogenada, em todos os agroecossistemas, foram observados valores de $\mathrm{NH}_{4}{ }^{+}$entre 0,5 e $16 \mathrm{mg} \mathrm{kg}^{-1}$. No Cerrado nativo, o teor de $\mathrm{NH}_{4}{ }^{+}$do solo foi 30 e $56 \%$ superiores aos teores de $\mathrm{NO}_{3}{ }^{-}$no período chuvoso e seco, respectivamente (Fig. 1.5d).

A temperatura do solo oscilou entre a mínima de $17^{\circ} \mathrm{C}$, no Cerrado nativo, e a máxima de $29^{\circ} \mathrm{C}$ no CT (Figura $1.5 \mathrm{e}$ ). No período chuvoso, o mês de março foi o que 
apresentou temperaturas do solo mais elevadas nas áreas agrícolas, com média de $24^{\circ} \mathrm{C}$ no NTR1, ou seja, $3^{\circ} \mathrm{C}$ acima da média do Cerrado nativo nesse mês e, os demais sistemas (NTR2 e CT) apresentaram média de $23^{\circ} \mathrm{C}$. No período seco, o mês de julho apresentou as menores temperaturas de solo, em todos os sistemas de manejo e, no mês de setembro, as temperaturas do solo foram mais elevadas (Fig. 1.5e). De maneira geral, o Cerrado nativo apresentou temperatura do solo menor (de 1 a $\left.6^{\circ} \mathrm{C}\right)$ do que os sistemas agrícolas. Nos meses de julho e agosto não foram observadas diferenças significativas nos pulsos de $\mathrm{N}_{2} \mathrm{O}$, assim como, também não foi observada temperatura do solo superior a $21^{\circ} \mathrm{C}$ (Fig. $1.5 \mathrm{e}$ ). Associada aos picos de $\mathrm{N}_{2} \mathrm{O}$ foi constatada temperatura do solo superior a $23^{\circ} \mathrm{C}$ e $19^{\circ} \mathrm{C}$, nos períodos chuvoso e seco, respectivamente (Fig. 1.5a, e). Nas últimas avaliações ao final do período seco, as temperaturas do solo no Cerrado nativo $\left(21^{\circ} \mathrm{C}\right)$ foram $4^{\circ} \mathrm{C}$ inferiores aos demais sistemas de manejo que apresentaram uma média de $29^{\circ} \mathrm{C}$ (Fig. 1.5d). A partir de agosto, foram observados aumentos progressivos na temperatura do solo em todos os sistemas avaliados e aumentos nos teores de $\mathrm{NO}_{3}{ }^{-}$, observados somente no CT.

\subsection{EMISSÕES ACUMULADAS DE $\mathrm{N}_{2} \mathrm{O}$ DOS AGROECOSSISTEMAS EM FUNÇÃO DA SAZONALIDADE PLUVIOMÉTRICA E ROTAÇÃO DE CULTURAS}

As emissões acumuladas de $\mathrm{N}_{2} \mathrm{O}$ do solo foram influenciadas pela sazonalidade das precipitações pluviométricas, sistemas de manejo, rotação cultural, assim como, pelos efeitos interativos desses fatores (Fig. 1.6). Considerando o acumulado anual, as emissões de $\mathrm{N}_{2} \mathrm{O}$ foram agrupadas em CT $\left(1,36 \mathrm{~kg} \mathrm{ha}^{-1}\right)=\operatorname{NTR} 1\left(1,0 \mathrm{~kg} \mathrm{ha}^{-1}\right) \geq$ NTR2 $\left(0,70 \mathrm{~kg} \mathrm{ha}^{-1}\right) \geq$ Cerrado $\left(0,28 \mathrm{~kg} \mathrm{ha}^{-1}\right)$.

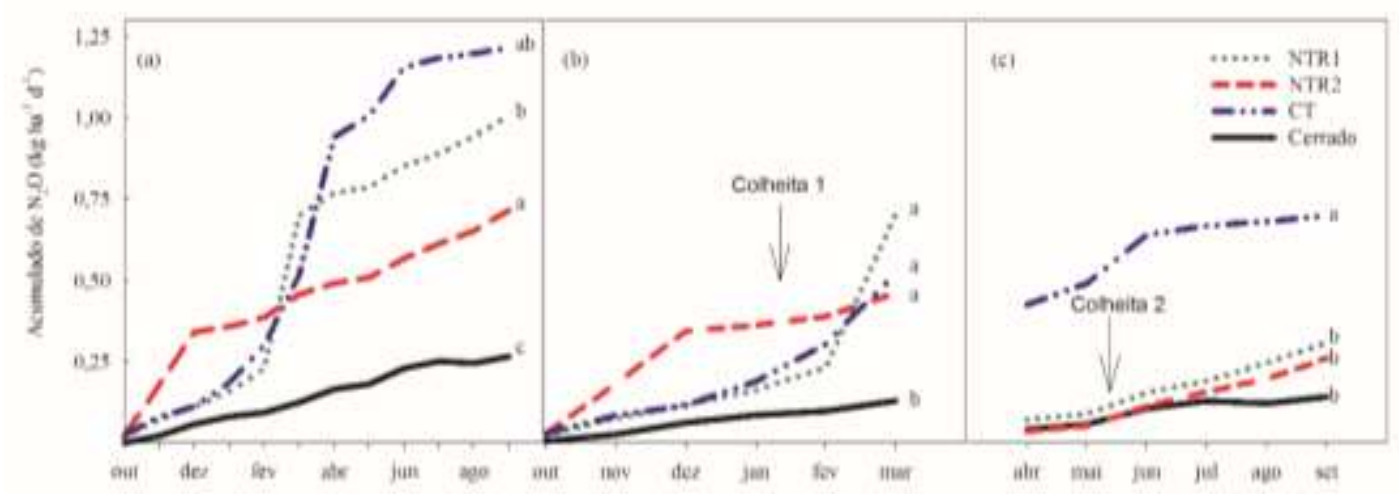

Figura 1.6 Acumulado anual de óxido nitroso do solo (a), no período chuvoso (b) e no período seco (c) sob os sistemas plantio direto (NTR1 e NTR2), convencional (CT) e Cerrado, Planaltina, DF, Brasil. NTR1 = sistema de manejo plantio direto cultivado com soja e rotação com o sorgo BRS332 (Sorghum bicolor (L.) Moench); NTR2 = sistema de manejo plantio direto com milho e rotação com o guandu 
(Cajanus cajan); $\mathrm{CT}=$ sistema convencional com soja e posterior pousio do solo na entressafra. As setas indicam eventos de colheita das leguminosas, soja (Colheita 1) e, guandu (Colheita 2). Médias seguidas de letras iguais não diferem entre si pelo teste de Tukey $(\mathrm{P}<0,05)$.

Durante o período chuvoso, os agroecossistemas apresentaram emissões de $\mathrm{N}_{2} \mathrm{O}$ similares entre si e superiores ao Cerrado nativo, exceto para o NTR2 $(\mathrm{P}<0,05)$. No período seco, o CT promoveu emissão acumulada de $\mathrm{N}_{2} \mathrm{O}$ maior do que os demais sistemas $(\mathrm{P}<0,05)$, não havendo diferenças entre o Cerrado nativo e os sistemas sob plantio direto (NTR1 e NTR2). Do total apresentado de emissão acumulada no CT, aproximadamente, $50 \%$ ocorreu na estação seca e $75 \%$ foi acumulado durante o pousio.

Incrementos nas emissões acumuladas de $\mathrm{N}_{2} \mathrm{O}$ após as colheitas das culturas de primeira e segunda safra dos agroecossistemas foram observados (Fig. 1.6a, b, c). Para a primeira safra, o valor acumulado de $\mathrm{N}_{2} \mathrm{O}$ entre os agroecossistemas variou de 0,23 a 0,48 $\mathrm{kg} \mathrm{ha}^{-1}$. No NTR2 o milho (primeira safra) foi a cultura associada ao sistema de manejo que apresentou maior acumulado de $\mathrm{N}_{2} \mathrm{O}$ com $0,48 \mathrm{~kg} \mathrm{ha}^{-1}$, sendo duas vezes superior quando comparado aos sistemas NTR1 e CT. Já para os cultivos de segunda safra no NTR2 o guandu acumulou apenas $0,15 \mathrm{~kg} \mathrm{ha}^{-1}$ de $\mathrm{N}_{2} \mathrm{O}$, enquanto o sorgo no NTR1 acumulou $0,81 \mathrm{~kg} \mathrm{ha}^{-1}$ de $\mathrm{N}_{2} \mathrm{O}$.

As emissões acumuladas por unidade de produto em cada sistema de manejo, com rotações e intervalos de cultivos (pousios) são apresentadas na Tabela 1.3.

Tabela 1.3 Emissão acumulada de óxido nitroso em função da produtividade das culturas nos diferentes sistemas de manejo do solo.

\begin{tabular}{|c|c|c|c|}
\hline Sistemas ${ }^{*}$ & $\begin{array}{l}\text { Emissão Acumulada } \\
\left(\mathrm{mg} \mathrm{N}_{2} \mathrm{O} \mathrm{m}^{-2}\right)\end{array}$ & $\begin{array}{l}\text { Produtividade dos } \\
\text { grãos/DM } \\
\left(\mathrm{kg} \mathrm{m}^{-2}\right)\end{array}$ & $\begin{array}{l}\text { Emissão por } \\
\text { produtividade/DM } \\
\left(\mathrm{mg} \mathrm{N}_{2} \mathrm{O} \mathrm{m} \mathrm{m}^{-2} \mathrm{~kg}^{-1}\right. \\
\text { grãos/DM) }\end{array}$ \\
\hline NTR1 & $106 \mathrm{ab}$ & 0,67 & $158 \mathrm{~b}$ \\
\hline NTR2 & $63 \mathrm{~b}$ & 1,03 & $62 \mathrm{~b}$ \\
\hline $\mathrm{CT}$ & $136 \mathrm{a}$ & 0,22 & $619 a$ \\
\hline
\end{tabular}

Enquanto os sistemas de manejo sob NTR1 e NTR2 acumularam emissões por unidade de produto de 158 e $62 \mathrm{mg} \mathrm{N}_{2} \mathrm{O} \mathrm{m} \mathrm{kg}^{-1}$ grãos respectivamente, o CT, com apenas uma safra e posterior pousio, emitiu quatro e dez vezes mais do que NTR1 e NTR2, respectivamente $(\mathrm{P}<0.05)$. 
Com base nos resultados de emissão acumulada no período de um ano, foram calculados os potenciais de aquecimento global parcial (pGWP) para os diferentes sistemas de manejo (Fig. 1.7). O CT apresentou maior pGWP (406 $\mathrm{kg} \mathrm{CO}_{2} \mathrm{eq} \mathrm{ha}^{-1}$ ) do que o NTR2 (189 $\mathrm{kg} \mathrm{CO}_{2} \mathrm{eq} \mathrm{ha}^{-1}$ ), enquanto que o NTR1 não se diferenciou dos demais sistemas. Em termos relativos, em um ano de estudo, cada hectare plantado sob sistema de manejo com uma única safra anual de soja (CT) é equivalente a 2,14 há plantados com milho seguido de sorgo (NTR2) em termos de pGWP por emissão de $\mathrm{N}_{2} \mathrm{O}$. Embora nesse curto período de tempo, as diferenças entre o NTR2 e PC não tenham sido estatisticamente significativas pelo rigoroso teste Tukey, verificou-se uma tendência, que pode ou não ser confirmada em longo prazo, de contribuições $30 \%$ maiores em termos de emissão, quando se compara o sistema de produção de soja seguido de uma segunda safra (NTR1) e sem a segunda safra (CT).

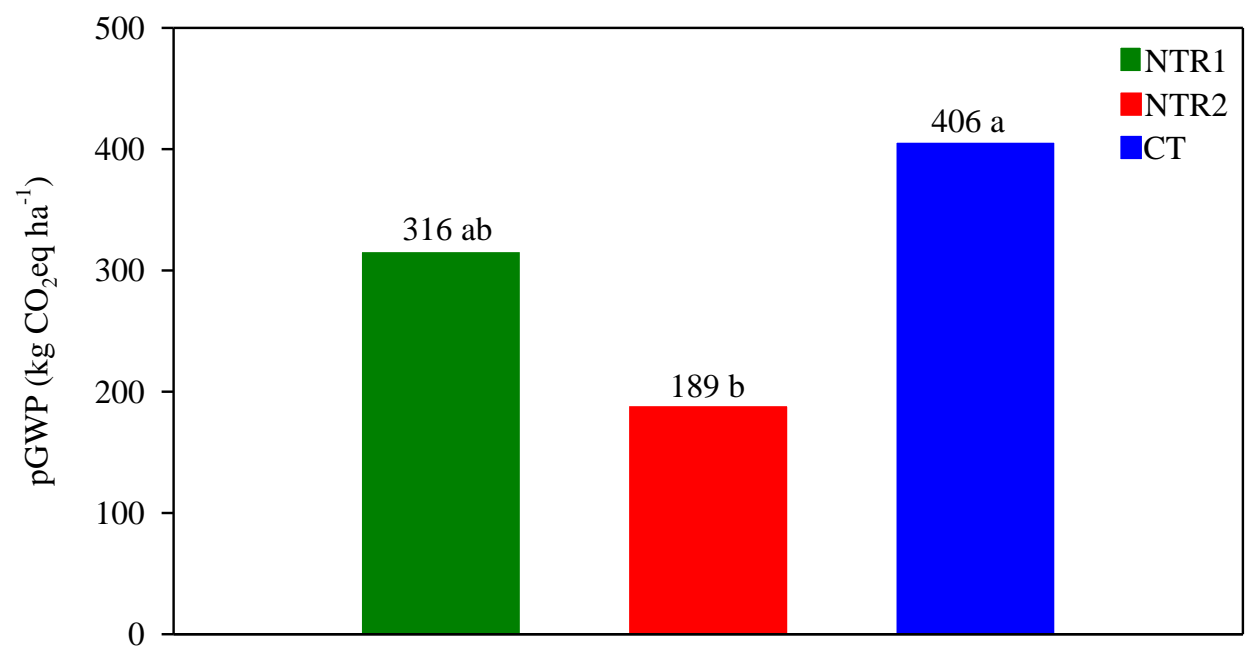

Figura 1.7 Potencial de aquecimento global parcial (pGWP) dos sistemas de manejo de acordo a emissão acumulada de óxido nitroso expressa em equivalente de dióxido de carbono $\left(\mathrm{CO}_{2} \mathrm{eq}\right)$. NTR1= plantio direto com a primeira safra com soybean e a segunda safra com sorghum; NTR2 = plantio direto com a primeira safra com maize e segunda safra com pigeonpea; CT = plantio convencional com a safra de soybean e posterior fallow. Médias seguidas de letras iguais não diferem entre si pelo teste de Tukey (P < $0,05)$.

\subsection{RELAÇÕES ENTRE OS FLUXOS DE $\mathrm{N}_{2} \mathrm{O}$ DO SOLO E VARIÁVEIS EDAFOCLIMÁTICAS DOS SISTEMAS DE MANEJO EM FUNÇÃO DA SAZONALIDADE PLUVIOMÉTRICA}

Dois componentes principais foram gerados (PC1 and PC2) como ferramentas para distinção dos sistemas de manejo, considerando todas as variáveis juntas $\left(\mathrm{NO}_{3}{ }^{-}, \mathrm{NH}_{4}{ }^{+}\right.$, WFPS, Temperatura do Solo and $\mathrm{N}_{2} \mathrm{O}$ ), para o período chuvoso (Fig. 1.8a) e seco (Fig. 
1.8b). As distribuições das variáveis selecionadas apresentaram variação acumulado de $56,16 \%$ e 53,04\% para a soma da PC1 e PC2 para o período chuvoso e seco, respectivamente.
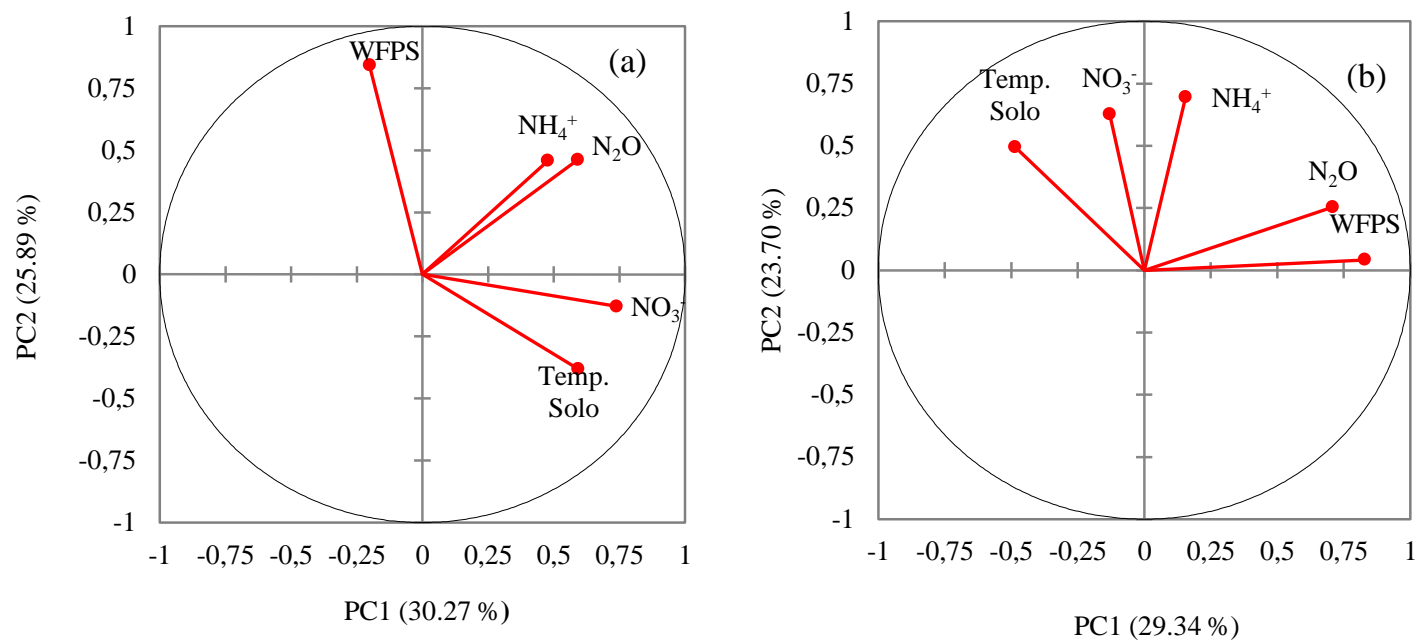

Figura 1.8 Análise de componentes principais (PCA) no período chuvoso (a) e período seco (b) para os fluxos de $\mathrm{N}_{2} \mathrm{O}$ do solo e variáveis edafoclimáticas: nitrato - $\mathrm{NO}_{3}{ }^{-}$, amônio $-\mathrm{NH}_{4}{ }^{+}$, espaço poroso saturado por água - WFPS e temperatura do solo (Temp. Solo) sob diferentes sistemas de manejo e Cerrado nativo durante os seis meses de cada período.

No período chuvoso o componente principal 1 (PC1) apresentou maior correlação com o $\mathrm{N}_{2} \mathrm{O}(0,59)$, teor de $\mathrm{NO}_{3}{ }^{-}(0,74), \mathrm{NH}_{4}{ }^{+}(0,48)$ e temperatura do solo $(0,59)$ (Tabela 1.4). O componente principal 2 (PC2), para o mesmo período, por sua vez, representou melhor a variabilidade do WFPS, com uma relação de 0,84 . Nesse contexto, formaramse dois grupos de correlações positivas no período chuvoso. Um grupo formado a partir do $\mathrm{N}_{2} \mathrm{O}$ e o $\mathrm{NH}_{4}{ }^{+}$do solo e, outro grupo, com a temperatura do solo e de $\mathrm{NO}_{3}{ }^{-}$(Fig. 1.8a). Entretanto, os dois grupos formados no período chuvoso são independentes da variável WFPS, apresentando fraca correlação.

Tabela 1.4 Coeficientes de correlações entre as variáveis edafoclimáticas e os componentes principais (PC1 e PC2), em função da sazonalidade pluviometrica (período chuvoso e seco).

\begin{tabular}{lllll}
\hline \multirow{2}{*}{ Variáveis } & \multicolumn{2}{l}{ Período chuvoso } & Período seco \\
\cline { 2 - 5 } & PC1 & PC2 & PC1 & PC2 \\
\hline Auto valor & 1,51 & 1,29 & 1,47 & 1,18 \\
\% Explicada & 30,27 & 25,89 & 29,34 & 23,70 \\
$\mathrm{~N}_{2} \mathrm{O}$ & 0,59 & 0,46 & 0,71 & 0,25 \\
$\mathrm{NO}_{3}{ }^{-}$ & 0,74 & $-0,13$ & $-0,13$ & 0,63
\end{tabular}




\begin{tabular}{lllll}
$\mathrm{NH}_{4}{ }^{+}$ & 0,48 & 0,46 & 0,16 & 0,70 \\
WFPS & $-0,20$ & 0,84 & 0,83 & 0,04 \\
Temp. Solo & 0,59 & $-0,38$ & $-0,49$ & 0,49 \\
\hline
\end{tabular}

Para o período seco o componente principal 1 (PC1) apresentou maior correlação positiva com o $\mathrm{N}_{2} \mathrm{O}$ e WFPS com coeficientes de correlação (r) de 0,71 e 0,83, respectivamente (Tabela 1.4). E no componente principal 2 (PC2) do período citado anteriormente, foi observado uma relação positiva do $\mathrm{NO}_{3}{ }^{-}(0,63), \mathrm{NH}_{4}{ }^{+}(0,70)$ e temperatura do solo $(0,49)$. De modo contrário ao observado no período chuvoso, no período seco, as emissões de $\mathrm{N}_{2} \mathrm{O}$ mais o WFPS, encontram-se fortemente correlacionados, formando um grupo, e os teores de $\mathrm{NO}_{3}{ }^{-}$e $\mathrm{NH}_{4}{ }^{+}$, juntamente com a temperatura do solo, outro grupo (Fig. 1.8b).

\section{DISCUSSÃO}

\subsection{EFEITOS DA SAZONALIDADE PLUVIOMÉTRICA, DOS SISTEMAS DE MANEJO E DA ROTAÇÃO CULTURAL NOS FLUXOS DE $\mathrm{N}_{2} \mathrm{O}$}

Para o Cerrado nativo o fluxo anual médio de $5 \mu \mathrm{g} \mathrm{N}_{2} \mathrm{O} \mathrm{m} \mathrm{m}^{-2}$, verificado nesse estudo, ficou bem inferior aos valores médios de emissão de $13 \mu \mathrm{g} \mathrm{N}_{2} \mathrm{O} \mathrm{m}^{-2} \mathrm{~h}^{-1}$ observados em outras savanas e ecossistemas de regiões de clima quente (Castaldi et al., 2006; Holtgrieve et al., 2006). Em áreas sob florestas naturais, como na Amazônia os fluxos de $\mathrm{N}_{2} \mathrm{O}$ aumentam durante o período chuvoso e diminuem, no período seco, podendo apresentar diferença cinco vezes superior (Verchot et al., 1999, Erickson et al., 2002; Davidson et al., 2008; Corre et al., 2014; Bai et al., 2014; Petitjean et al., 2015). Em florestas tropicais, no Nordeste da Austrália, foram observados no período chuvoso, pulsos de até $242 \mu \mathrm{g} \mathrm{N} \mathrm{N}_{2} \mathrm{~m}^{-2} \mathrm{~h}^{-1}$, enquanto no período seco, os valores estavam abaixo de $20 \mu \mathrm{g} \mathrm{N}_{2} \mathrm{O} \mathrm{m}^{-2} \mathrm{~h}^{-1}$ (Kiese \& Butterbach-Bahl, 2002). Em geral, nas florestas nativas, com períodos sazonais bem definidos, existe um equilíbrio entre as entradas e saídas de N via decomposição do material orgânico (Bustamante et al., 2009), o que pode tornar as variações nas emissões de $\mathrm{N}_{2} \mathrm{O}$ mais dependentes das variáveis ambientais.

Entretanto, a agricultura é reconhecida como a maior propulsora das emissões globais de $\mathrm{N}_{2} \mathrm{O}$, especialmente quando se utiliza fertilizações nitrogenadas (Baumert et al., 2005). No presente estudo, os agroecossistemas apresentaram variações diárias e 
sazonais maiores em relação às emissões de $\mathrm{N}_{2} \mathrm{O}$ no Cerrado nativo. Entre os sistemas estudados, as taxas de emissão de $\mathrm{N}_{2} \mathrm{O}$ variaram de $0,08 \mu \mathrm{g} \mathrm{m}^{-2} \mathrm{~h}^{-1}$ e máximos de 266 $\mu \mathrm{g} \mathrm{m} \mathrm{m}^{-2} \mathrm{~h}^{-1}$ (Fig. 1.5a). Estes valores foram similares àqueles obtidos por diversos trabalhos $\left(\sim\right.$ 3,5 a $\left.357 \mu \mathrm{g} \mathrm{m}^{-2} \mathrm{~h}^{-1}\right)$ realizados no Brasil (Metay et al., 2007; Jantalia et al., 2008; Gomes et al., 2009; Bayer et al., 2015; Martins et al., 2015).

Durante o período chuvoso, os maiores picos de $\mathrm{N}_{2} \mathrm{O}$ foram verificados após as aplicações de adubo nitrogenado nas gramíneas (milho e sorgo), no entanto, no caso da leguminosa (soja), que não recebeu adubação nitrogenada, as maiores emissões foram verificadas logo após a colheita da cultura, cujos resíduos culturais, ricos em $\mathrm{N}$, foram utilizados pelos microrganismos com consequente liberação de $\mathrm{N}_{2} \mathrm{O}$ para a atmosfera (Fig. 1.5a, c e d). Primeiro o substrato orgânico é decomposto e disponibiliza o $\mathrm{N}$ na forma mineral para a absorção dos vegetais, mas como no caso do CT não foi implantada uma segunda safra após a soja que, sendo leguminosa tem uma relação C:N baixa e nódulos simbióticos prontamente disponíveis para decomposição após a senescência, e no caso do NTR1, o sorgo tinha sido adubado com fonte de N prontamente disponível. Há indicativos que o excesso de $\mathrm{N}$ disponível na forma mineral e orgânico, combinado as condições ambientais de 35 a $60 \%$ de WFPS proporciona processos de decomposição e desnitrificação com redução de compostos nitrogenados a formas gasosas de $\mathrm{N}$, incluindo o $\mathrm{N}_{2} \mathrm{O}$ (Khalil et al., 2004). Próximo à colheita da soja existia um grande volume de folhas senescentes e resíduos culturais sobre o solo e, além disso, a própria senescência dos nódulos radiculares, também pode ter contribuído para o efeito de curto prazo, com maiores picos de $\mathrm{N}_{2} \mathrm{O}$ no sistema CT. Resultados semelhantes com efeitos de curto prazo foram observados por Dyer et al. (2012). No entanto, Bayer et al. (2015) concluíram que a rápida decomposição dos resíduos vegetais não afetou as emissões de $\mathrm{N}_{2} \mathrm{O}$ para o sistema convencional de preparo, o que os autores justificaram como efeito da rotação cultural pode ter promovido uma diluição da mineralização do N na camada arável do solo.

As maiores emissões verificadas nos dois meses subsequentes à colheita da soja, cerca de 1,3 vezes maior no NTR1 quando comparado ao CT podem estar relacionadas às maiores concentrações de $\mathrm{C}$ lábil, produto da senescência nodular, que é consumido e utilizado como substrato para o crescimento das populações microbianas, favorecendo desta maneira aos microrganismos nitrificadores e desnitrificadores do solo (Ciampitti et al., 2005; Dyer et al., 2012; Petitjean et al., 2015). Em condições subtropicais, utilizando rotação de culturas, Bayer et al. (2015) não observaram efeito dos sistemas de 
plantio direto e convencional, no período pós-manejo das culturas, sobre as emissões de $\mathrm{N}_{2} \mathrm{O}$.

Os sistemas de manejo de longa duração afetam a emissão de $\mathrm{N}_{2} \mathrm{O}$ por meio de efeitos de curto e de longo prazos. Por exemplo, ao fornecerem os resíduos orgânicos ao solo, promovem aumentos nas taxas de emissão no curto prazo, voltando posteriormente a fluxos menores (Fig. 1.5a), provavelmente, quando a fração mais lábil dos resíduos já foi decomposta (Baggs et al., 2003). O rápido declínio das emissões após adubação nitrogenada também tem sido observado em vários trabalhos a campo (Martins et al. 2015; Aini et al, 2015; Huang et al. 2013). Isso pode ser consequência da alta demanda de $\mathrm{N}$ pela planta, diminuindo assim as possibilidades de perdas do $\mathrm{N}$ mineral. Porém, as diferentes rotações de cultura ao longo dos anos promovem incrementos em determinados atributos do solo, como os estoques de $\mathrm{C}$ e $\mathrm{N}$ do solo, já observados por Baggs et al. (2006) e Gomes et al. (2009) em condições tropicais e subtropicais, respectivamente.

\subsection{VARIÁVEIS EDAFOCLIMÁTICAS}

A dinâmica temporal das emissões de $\mathrm{N}_{2} \mathrm{O}$ pode ser atribuída às diferenças entre os sistemas de manejo e suas condições edafoclimáticas. Durante o período chuvoso, o WFPS manteve-se entre 50-70\%, com grande variação diária, de modo que tanto a nitrificação e como a desnitrificação podem ter regulado as emissões de $\mathrm{N}_{2} \mathrm{O}$, situação semelhante foi observada por Ball et al. (2014) para dois anos de estudo com a utilização de rotação cultural. O WFPS controla as emissões de $\mathrm{N}_{2} \mathrm{O}$ através do seu efeito sobre os processos de nitrificação e desnitrificação e o transporte de gás no interior do solo (Burger et al., 2005; Neil et al., 2005). Muitos estudos têm demonstrado que a umidade do solo, expressa pelo WFPS, a temperatura do solo e o teor de $\mathrm{N}$ mineral são as principais variáveis que controlam as emissões de $\mathrm{N}_{2} \mathrm{O}$ (Ball et al., 2014; Yang et al., 2015; Bayer et al., 2015; Petitjean et al., 2015).

No presente estudo, a correlação entre os fluxos de $\mathrm{N}_{2} \mathrm{O}$ com a precipitação pluviométrica pode ser explicada pelo curto intervalo de tempo com que a água chega ao solo, preenchendo os espaços vazios, gerando condições anaeróbias, que estimulam as bactérias desnitrificantes (Butterbach-Bahl et al. 2013). Como a difusibilidade do $\mathrm{N}_{2} \mathrm{O}$ é baixa em solos com grande volume de microporos (Eickenscheidt and Brumme, 2013), característica de solos argilosos, as maiores emissões são registradas apenas depois de algumas horas ou dias, após a ocorrência de chuva (Dick et al., 2001). Na 
época seca, os mecanismos que regem esses fluxos ainda não estão completamente esclarecidos, pode ser que as condições secas de solo melhorem a difusão do $\mathrm{N}_{2} \mathrm{O}$ proveniente da atmosfera para dentro do solo, sob limitada disponibilidade de $\mathrm{N}$ inorgânico, e o $\mathrm{N}_{2} \mathrm{O}$ atmosférico é reduzido para $\mathrm{N}_{2}$ por bactérias desnitrificantes (Dijkstra et al., 2013), reduzindo assim as emissões $\mathrm{N}_{2} \mathrm{O}$ no período seco.

Observando o efeito da sazonalidade (Fig. 1.4), alguns fluxos de $\mathrm{N}_{2} \mathrm{O}$ no solo ocorreram durante o período seco, resultado esse que pode ser consequência do efeito que acontece em eventos de secagem/reumedecimento, nos quais o reumedecimento após longo período de seca promove altas taxas de decomposição vegetal e rápida mineralização no solo, declinando a intensidade com o tempo após o reumedecimento (Birch, 1964, Jarvis et al., 2007, Petitjean et al., 2015). Esse comportamento é característico da região, com chuvas ocasionais durante um longo período de seca, que pode chegar a 5 meses, promovendo uma intensa resposta na atividade da microbiota. A adição de água aumenta rapidamente a população e o metabolismo dos microrganismos no solo (Jarvis et al., 2007), podendo explicar esta relação entre reumedecimento e emissões de $\mathrm{N}_{2} \mathrm{O}$ no solo. De forma semelhante, Pelster et al. (2011) ao estudarem o cultivo de alfafa e soja em plantio direto e plantio convencional observaram os maiores picos de $\mathrm{N}_{2} \mathrm{O}$ após eventos de reumedecimento do solo.

A ocorrência de baixos fluxos de $\mathrm{N}_{2} \mathrm{O}$ do solo sob vegetação natural de Cerrado verificado no presente estudo, independente do período sazonal, também pode ser explicado por características do solo, como a alta drenabilidade, elevada acidez (Castaldi et al., 2006; Martins et al., 2015) e baixa disponibilidade de N (Bustamante et al., 2009). De fato, o Cerrado nativo apresentou pequena variação nos teores de $\mathrm{NO}_{3}{ }^{-} \mathrm{e}$ $\mathrm{NH}_{4}{ }^{+}$, cujos valores estavam abaixo de $10 \mathrm{mg} \mathrm{kg}^{-1}$ durante a maior parte período estudado, o que pode justificar essas baixas emissões de $\mathrm{N}_{2} \mathrm{O}$ (Fig. 1.5a, c, d). Na primeira semana de junho os maiores fluxos de $\mathrm{N}_{2} \mathrm{O}$ observados no CT comparado aos demais sistemas estão associados aos elevados teores de $\mathrm{NO}_{3}{ }^{-}$em torno de $26 \mathrm{mg} \mathrm{kg}^{-1}$, na presença de água no solo, com WFPS por volta de 59\%. Nessa situação, as condições para ocorrência da desnitrificação foram ideais, uma vez que tem sido reportado que valores acima de $10 \mathrm{mg} \mathrm{kg}^{-1}$ de $\mathrm{NO}_{3}{ }^{-}$inibem a conversão de $\mathrm{N}_{2} \mathrm{O}$ em $\mathrm{N}_{2}$, já que há preferência do $\mathrm{NO}_{3}{ }^{-}$em relação ao $\mathrm{N}_{2} \mathrm{O}$ como aceptor final de elétrons (Chapuis-lardy et al. 2007, Cameron et al., 2013).

As diferenças significativas entre os sistemas de manejo em $66 \%$ dos dados de temperatura do solo, verificadas no presente estudo, são similares aos resultados obtidos 
por outros autores, que observaram efeitos diretos da temperatura do solo sobre as emissões de $\mathrm{N}_{2} \mathrm{O}$ (Smith et al., 1998; Wang et al., 2005; Li et al., 2012; Yang et al., 2015). No entanto, deve-se ressaltar que as emissões são resultado de efeitos combinados da temperatura com as demais variáveis como WFPS e N mineral. Chirinda et al. (2010) ressaltam que normalmente o período de temperaturas mais altas $\left(\mathrm{T}<25^{\circ} \mathrm{C}\right)$ coincide com eventos como plantio e adubações, que podem confundir o efeito isolado da temperatura.

\subsection{EMISSÕES ACUMULADAS E POTENCIAL DE AQUECIMENTO GLOBAL PARCIAL}

As emissões acumuladas de $\mathrm{N}_{2} \mathrm{O}$ foram influenciadas pela sazonalidade climática, pelos sistemas de manejo, rotação de cultura e pelo sinergismo desses fatores. Essa interação de fatores ajuda a definir a magnitude dessas emissões (Aini et al. 2015). Independe do período avaliado (seco ou chuvoso) o NTR2 promoveu emissões semelhantes ao Cerrado nativo. Portanto, o não revolvimento do solo associado à rotação do milho com uma leguminosa (guandu) representa uma alternativa de manejo sustentável para o Cerrado.

As taxas de emissão do presente estudo de 106, 63 e $136 \mathrm{mg} \mathrm{N}_{2} \mathrm{O} \mathrm{m}^{-2}$ (Tabela 1.3) verificados no NTR1, NTR2 e CT, respectivamente, estão dentro dos limites obtidos por Bayer et al. (2015). O CT apresentou valores elevados para as condições do Cerrado, podendo estar associado a uma decomposição mais rápida dos resíduos culturais, decorrentes de baixos valores da razão C/N (Huang et al., 2004) e da qualidade dos resíduos (Garcia-Ruiz \& Baggs, 2007), associado ao efeito do revolvimento do solo (Jantalia et al., 2008) promovendo maior emissão de $\mathrm{N}_{2} \mathrm{O}$. De acordo com Bayer et al. (2015) o período pós manejo no sistema convencional cultivado com leguminosagramínea respondeu em cerca de $90 \%$ pela emissão de $\mathrm{N}_{2} \mathrm{O}$.

Para o CT aproximadamente $75 \%$ do pGWP decorreu do efeito sazonal e da prática agrícola do manejo (pousio) (Fig. 1.6b, c e 1.7). Situação semelhante foi observada por Bayer et al. (2014) em condições de clima subúmido, no Sul do Brasil, no presente estudo o NTR2 resultou em menor pGWP do que o CT. A ruptura de agregados e a exposição do $\mathrm{C}$ orgânico antes protegido da decomposição por microrganismos do solo, possivelmente, intensificou as atividades dos desnitrificadores que aliado a deposição dos resíduos pós-colheita, resultaram em aumento das emissões de $\mathrm{N}_{2} \mathrm{O}$. Estudos 
indicam que a mudança de preparo convencional para sistemas conservacionistas de uso do solo tem sido condição fundamental para mudança dos sistemas agrícolas de emissores para mitigadores dos GEE (Moiser et al., 2005; Robertson et al., 2000).

Quando considerado o PAG total, Adviento-Borbe et al. (2007), nos EUA, verificaram que tanto os sistemas de monocultura do milho quanto de sucessão sojamilho, agiram como fonte de GEE, com os sistemas milho-milho e soja-milho

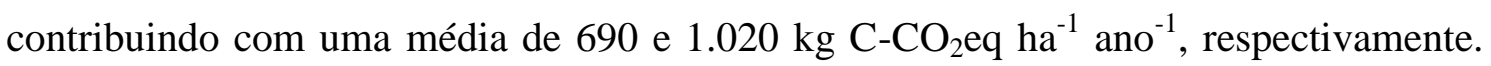
Nesse mesmo estudo, os autores atribuíram que as menores emissões pelos sistemas de monocultura do milho ao maior sequestro de $\mathrm{C}$, mesmo que esses sistemas tenham apresentado maiores emissões de $\mathrm{N}_{2} \mathrm{O}$ e maiores custos relacionados a utilização de fertilizantes nitrogenados. Já Robertson et al. (2000), relataram que sistemas perenes de Alfafa e Floresta de Álamo (Populus sp.) apresentaram PAG de -200 e -1050 kg C$\mathrm{CO}_{2} \mathrm{eq} \mathrm{ha}{ }^{-1}$ ano $^{-1}$, respectivamente, enquanto o sistema em plantio direto com rotação milho-trigo-soja, apresentaram um PAG positivo, com uma média de $140 \mathrm{~kg} \mathrm{CCO}_{2}$ eqha $^{-}$

${ }^{1}$ ano $^{-1}$, porém menores que o sistema de preparo convencional do solo $(1.140 \mathrm{~kg}$ $\mathrm{CCO}_{2}$ eq ha ${ }^{-1}$ ano $^{-1}$ ). A escolha de sistemas de manejo adequados torna possível elevar os estoques de carbono no solo e, ao mesmo tempo, diminuir as emissões em equivalente de $\mathrm{CO}_{2}$, reduzindo assim o pGWP. O acompanhamento dos ciclos de rotação, além de identificar quais culturas e sistemas de manejo melhor se adequam as nossas condições edafoclimáticas possibilita reduzir as emissões acumuladas de $\mathrm{N}_{2} \mathrm{O}$ e, através do pGWP, avaliar o potencial das práticas agrícolas em reduzir os impactos da agricultura (Wang et al., 2016). Além das práticas de preparo do solo, o controle dos demais fatores indutores (drivers) de emissão é de fundamental importância. Nesse sentido, vários estudos buscam estratégias de mitigação das emissões de $\mathrm{N}_{2} \mathrm{O}$ focados principalmente em otimizar as quantidades e as taxas de aplicação de fertilizantes nitrogenados (Soares et al., 2015; Martins et al., 2015).

\subsection{EFEITO INTERATIVO DA SAZONALIDADE PLUVIOMÉTRICA COM AS EMISSÕES DE $\mathrm{N}_{2} \mathrm{O}$ DO SOLO E AS VARIÁVEIS EDAFOCLIMÁTICAS}

As avaliações dos fluxos diários, com diferenças significativas entre os agroecossistemas, mostraram que os maiores fluxos não decorreram de um efeito isolado e sim da interação de efeitos. 
As relações estabelecidas entre as variáveis temperatura do solo, WFPS e $\mathrm{NO}_{3}{ }^{-} \mathrm{com}$ os fluxos de $\mathrm{N}_{2} \mathrm{O}$ do solo, durante as duas estações climáticas, indicam que a produção de $\mathrm{N}_{2} \mathrm{O}$ foi favorecida, principalmente, pelos altos valores de WFPS, após o incremento da umidade do solo (Zhu et al., 2013). Normalmente, junto com o aumento dos WFPS há também o consumo do $\mathrm{O}_{2}$ do solo por atividades microbianas com a oxidação de $\mathrm{C}$ orgânico lábil e consequente formação de sítios de anaerobiose (Khalil \& Baggs, 2005). Pimentel et al. (2015) observaram maiores emissões de $\mathrm{N}_{2} \mathrm{O}$ com WFPS a partir de $70 \%$ sob condições de laboratório. E em experimento sob condições de campo, resultados semelhantes foram observados por Escobar et al. (2010), em condições subtropicais, e por Martins et al. (2015), em condições tropicais, no Cerrado brasileiro.

Outro fator a se destacar, comum às duas estações sazonais climáticas estudadas, que sugere uma interferência na ocorrência de maiores fluxos de $\mathrm{N}_{2} \mathrm{O}$ é a contribuição de elevadas temperaturas do solo juntamente com o aumento da umidade do solo. Liu et al. (2013) justificaram a fraca relação estabelecida entre as emissões de $\mathrm{N}_{2} \mathrm{O}$ com a temperatura do solo devido às alterações provocadas pela baixa umidade do solo observada, com formação de WFPS inferiores a 50\%. Em solos com o WFPS entre 70$90 \%$ as emissões de $\mathrm{N}_{2} \mathrm{O}$ do solo são, preferencialmente, por desnitrificação (Granli \& Bøckman, 1994; Davidson et al., 2000). Do mesmo modo que, na estação seca o umedecimento dos solos, em concentrações ideias de compostos mineralizados, aceleram as atividades microbianas e, consequentemente, também aumentarão as emissões de $\mathrm{N}_{2} \mathrm{O}$ (Davidson et al., 1992).

O tempo de implantação dos sistemas de manejo, nas condições climáticas tropicais, também deve ser considerado para validar os dados de emissões de $\mathrm{N}_{2} \mathrm{O}$. Estudos realizados por Six et al. (2004) em regiões de clima úmido, afirmam que as emissões de $\mathrm{N}_{2} \mathrm{O}$ são menores no sistema plantio direto de longa duração com mais de dez anos. Observou-se que sob condições de clima tropical, os sistemas plantios diretos (NTR1 e NTR2) apresentaram diferenças entre si, relacionadas às rotações culturais desenvolvidas em cada plantio direto, refletindo as emissões de curto prazo em função do manejo. Entretanto, o sistema convencional, com monocultivo de leguminosa apresentou grandes oscilações e fluxos mais elevados, principalmente, quando a umidade do solo aumentava. 


\section{CONCLUSÕES}

Os nossos resultados indicam que sob condições naturais o Cerrado é um sistema conservador em termos de $\mathrm{N}$, já que as emissões de $\mathrm{N}_{2} \mathrm{O}$ do solo não foram influenciadas pelas diferenças sazonais ou eventos de chuva. Entre os agroecossistemas estudados as emissões acumuladas de $\mathrm{N}_{2} \mathrm{O}$ do solo foram influenciadas pela sazonalidade das precipitações pluviométricas, sistemas de manejo, rotação de culturas, assim como, pela interação entre esses fatores. Os sistemas integrados sob PD, quando comparados ao monocultivo de soja sob PC, contribuíram para a mitigação de emissões de $\mathrm{N}_{2} \mathrm{O}$, tanto por área plantada como por produtividade de grãos. A definição do NT como um sistema mitigador das emissões de $\mathrm{N}_{2} \mathrm{O}$ é dependente da rotação de culturas adotada. A rotação de culturas utilizada no NTR2 (milho-guandu) foi mais eficiente, com pulsos de emissão menores quando comparados ao NTR1 (soja-sorgo). Portanto a definição de um sistema mitigador das emissões de $\mathrm{N}_{2} \mathrm{O}$ deverá se basear no tipo de cultura (gramínea/leguminosa) a ser utilizada na rotação de culturas e no máximo aproveitamento do $\mathrm{N}$ disponível no sistema.

\section{REFERÊNCIAS}

ABDALlA, M.; OSBORNE, B.; OSBORNE, G.; OSBORNE, D.; OSBORNE, M.; OSBORNE, P.; OSBORNE, M.B. Conservation tillage systems: a review of its consequences for greenhouse gas emissions. Soil Use and Management, v. 29, p. 199209, 2013.

ALLEN, D. E.; KINGSTON, G.; RENNENBERG, H.; DALAL, R. C.; SCHMIDT, S. Effect of nitrogen fertilizer management and waterlogging on nitrous oxide emission from subtropical sugarcane soils. Agriculture, Ecosystems and Environment, v. 136, p. 209-217, 2010.

ALVES, B. J. R.; JANTALIA, C. P.; MADARI, E. B.; MACHADO, P. L. O. A.; FRANCHINI, J. C.; SANTOS, H. P.; BODDEY, R. M.; URQUIAGA, S. Emissões de óxido nitroso de solos pelo uso de fertilizantes nitrogenados em áreas agrícolas. Seropédica: RJ, 2010. 6 p. Embrapa Agrobiologia. (Comunicado Técnico, 126).

ALVES, B. J. R.; SMITH, K. A.; FLORES, R. A.; CARDOSO, A. S.; OLIVEIRA, W. R. D.; JANTALIA, C. P.; URQUIAGA S.; BODDEY, R. M. Selection of the most suitable sampling time for static chambers for the estimation of daily mean $\mathrm{N}_{2} \mathrm{O}$ flux from soils. Soil Biology and Biochemistry, v. 46, p. 129-135, 2012.

BAI, Z.; YANG, G.; CHEN,; ZHU, Q.; CHEN, L. Y.; WANG, X.; WU, Z.; ZHOU, G.; PENG, C. Nitrous oxide fluxes from three forest types of the tropical mountain 
rainforests on Hainan Island, China. Atmospheric Environment, v. 92, p. 469-477, 2014.

BALL, B. C.; GRIFFITHS, B. S.; TOPP, C. F. E.; WHEATLEY, R.; WALKER, R. L.; REES, R. M.; WATSON, C. A.; GORDON, H.; HALLETT, P. D.; MCKENZIE, B. M.; NEVISON, I. M. Seasonal nitrous oxide emissions from field soils under reduced tillage, compost application or organic farming. Agriculture, Ecosystems and Environment, v. 189, p. 171-180, 2014.

BAYER, C.; COSTA, F. S.; PEDROSO, G. M.; ZSCHORNACK, T.; CAMARGO, E. S.; LIMA, M. A.; FRIGHETO, R. T. S.; GOMES, J.; MARCOLIN, E.; MACEDO, V. R. M. Yield-scaled greenhouse gas emissions from flood irrigated rice under long-term conventional tillage and no-till systems in a Humid Subtropical climate. Field Crops Research, v. 162, p. 60-69, 2014.

BAYER, C.; ZSCHORNACK, T.; PEDROSO, G. M.; ROSA, C. M.; CAMARGO, E. S.; BOENI, M.; MARCOLIN, E.; REIS, C. E. S.; SANTOS, D. C. A seven-year study on the effects of fall soil tillage on yield-scaled greenhouse gas emission from flood irrigated rice in a humid subtropical climate. Soil \& Tillage Research, v. 145, p. 118$125,2015$.

BENOIT, M.; GARNIER, J.; BIÇÇEN, G. Temperature dependence of nitrous oxide production of a luvisolic soil in batch experiments. Process Biochemistry, v. 50, p. 70$85,2015$.

BUSTAMANTE, M. M. C.; VORBEELS, M.; SCOBEL, M.; ROSCOE, R. Soil carbon and sequestration potential in the Cerrado Region of Brazil, 2006. in: Lal, R., Cerri, C.C., Bernoux, M., Etchevers, J., Cerri C.E.P. (Eds.), Carbon sequestration in soils of Latin America. 1. ed. New York: Food Product Press, cap. 14, pp. 285-304.

BUSTAMANTE, M. M. C.; NARDOTO, G. B.; PINTO, A. S.; RESENDE, J. C. F.; TAKAHASHI, F. S. C.; VIEIRA, L. C. G. Potential impacts of climate change on biogeochemical functioning of Cerrado Ecosystems. Brazilian Journal of Biology, v. 72, p. 655-671, 2012.

BUSTAMANTE, M. M. C.; MARTINELLI, L. A.; OMETTO, J. P. H. B.; CARMO, J. B.; JARAMILLO, V.; GAVITO, M. E.; ARAUJO, P. I.; AUSTIN, A. T.; PÉREZ, T.; MARQUINA, S. Innovations for a sustainable future: rising to the challenge of nitrogen greenhouse gas management it in Latin America. Current Opinion Environmental Sustainability, v. 9, p. 73-81, 2014.

BUTTERBACH-BAHL，K.; BAGGS，E. M.; DANNENMANN， M.; KIESE，R.; ZECHMEISTER-BOLTENSTERN, S. Nitrous oxide emissions from soils: how well do we understand the processes and their controls? Philosophical Transactions of the Royal Society Biological Science, v. 368, p. 1- 3, 2013.

CARDOSO, A. N.; SAMINEZ, T. C.; VARGAS, M. A. Fluxo de gases-traço de efeito estufa na interface solo/atmosfera em solos de cerrado. Planaltina: DF, 2001. 23 p. Embrapa Cerrados. (Boletim de Pesquisa e Desenvolvimento, 17). 
CARVALHO, A. M.; BUSTAMANTE, M. M. C.; KOZOVITS, A. R.; MIRANDA, L. N.; VIVALDI, L. J. V.; SOUSA, D. M. Emissão de óxidos de nitrogênio associada à aplicação de uréia sob plantio convencional e direto. Pesquisa Agropecuária Brasileira, Brasília, v. 41, n. 4, p. 679-685, 2006.

CARVALHO, J. L. N.; CERRI, C. E. P.; FEIGL, B. J.; PICOLLO, M. C.; GODINHO, V. P.; CERRI, C.C. Carbon sequestration in agricultural soils in the Cerrado region of the Brazilian Amazon. Soil \&Tillage Research, n. 103, p. 342-349, 2009.

CARVALHO, J. L. N.; AVANZI, J. C.; SILVA, M. L. N.; MELLO, C. R.; CERRI, C. E. P. Potencial de sequestro de carbono em diferentes biomas do Brasil. Revista Brasileira de Ciência do Solo, v. 34, p. 277-289, 2010.

CARVALHO, A. M.; COELHO, M. C.; DANTAS, R. A.; FONSECA , O. P.; JÚNIOR, R. G.; FIGUEIREDO, C. C. Chemical composition of cover plants and its effect on maize yield in no-tillage systems in the Brazilian savanna. Crop \& Pasture Science, v. 63, p. 1075-1081, 2012.

CARVALHO, M. T. M.; MADARI, B. E.; LEAL, G. O.; COSTA, A. R.; MACHADO, P. L. O. A.; SILVEIRA, P. M.; MOREIRA, J. A.; HEINEMANN, A. B. Nitrogen fluxes from irrigated common-bean as affected by mulching and mineral fertilization. Pesquisa Agropecuária Brasileira, v. 48, p. 478-486, 2013.

CARVALHO, A. M.; COSER, T. R.; REIN, T. A.; DANTAS, R. A.; SILVA, R. R.; SOUZA, K. W. Manejo de plantas de cobertura na floração e na maturação fisiológica e seu efeito na produtividade do milho. Pesquisa Agropecuária Brasileira, v. 50, n. 7, p. 551-561, 2015.

CASTALDI, S.; ERMICE, A.; STRUMIA, S. Fluxes of $\mathrm{N}_{2} \mathrm{O}$ and $\mathrm{CH}_{4}$ from soils of savannas and seasonally dry ecosystems. Journal Biogeography, v. 33, p. 401-415, 2006.

COMPANHIA NACIONAL DE ABASTECIMENTO - CONAB, 2015. Acompanhamento da safra brasileira: grãos safra 2014/2015: oitavo levantamento: maio de 2015. Brasília: Conab, 2015. Disponível em: <http://www.conab.gov.br/OlalaCMS/uploads/arquivos/15_05_13_08_46_55_boletim_ graos_maio_2015.pdf> Acesso em: 10 de maio 2015.

CORRE, M. D.; SUETA, J. P.; VELDKAMP, E. Nitrogen-oxide emissions from tropical forest soils exposed to elevated nitrogen input strongly interact with rainfall quantity and seasonality. Biogeochemistry, v. 118, p. 103-120, 2014.

CHAPUIS-LARDY, L.; WRAGE, N.; METAY, A.; CHOTTE, J.L.; BERNOUX, M. Soils, a sink for $\mathrm{N}_{2} \mathrm{O}$ ? A review. Global Change Biology, v. 13, n. 1, p. 1-17, 2007.

CRUVINEL, E. B. F.; BUSTAMANTE, M. M. C.; KOZOVITS, A. R.; ZEPP, R. G. Soil emissions of $\mathrm{NO}, \mathrm{N}_{2} \mathrm{O}$ and $\mathrm{CO}_{2}$ from croplands in the savanna region of central Brazil. Agriculture, Ecosystems and Environment, v. 144, p. 29-40, 2011. 
DAVIDSON , E. A.; FIRESTONE, M. K.; HART, S. C. Internal cycling of nitrate in soils of a mature coniferous forest, Ecology, v. 73, p. 1148-1156, 1992.

DAVIDSON, E.; KELLER, M.; ERICKSON, H.; VERCHOT, L.; VELDKAMP, E. Testing a conceptual model of soil emissions of nitrous and nitric oxides. Bioscience, $v$. 50, p. 667-680, 2000.

DAVIDSON, E. A.; BUSTAMANTE, M. M. C.; PINTO, A. S. Emissions of Nitrous Oxide and Nitric Oxide from Soils of Native and Exotic Ecosystems of the Amazon and Cerrado Regions of Brazil. The Science World Journal, v. 1, p. 312-319, 2001.

DAVIDSON, E. A.; SÁ, T. D. A.; CARVALHO, C. J. R.; FIGUEIREDO, R. O.; KATO, M. S. A.; KATO, O. R.; ISHIDA, F. Y. An integrated greenhouse gas assessment of an alternative to slash-and-burn agriculture in eastern Amazonia. Global Change Biology, v. 14, n. 5, p. 998-1007, 2008.

DENG, Q.; HUI, D.; WANG, J.; IWUOZO, S.; YU, C. L.; JIMA, T.; SMART, D.; REDDY, C.; DENNIS, S. Corn yield and soil nitrous oxide emission under different fertilizer and soil management: A three-year field experiment in middle Tennessee. Plos One, v. 10, p. 2-14, 2015.

DOBBIE, K. E.; MCTAGGART, I. P.; SMITH, K. A. Nitrous oxide emissions from intensive agricultural systems: variations between crops and seasons, key driving variables, and mean emission factors. Journal of Geophysical Research, v. 104, p. 26891-26899, 1999.

ESCOBAR, L. F.; AMADO, T. J. C.; BAYER, C.; CHÁVEZ, L. F.; ZANATTA, J. A.; FIORIN, J. Emissões de curto prazo de óxido nitroso em sistemas de manejo do solo no Rio Grande do Sul. In: XVII Reunião Brasileira de Manejo e Conservação do Solo e da Água, 2008, Rio de Janeiro.

ESCOBAR, L. F.; AMADO, T. J. C.; BAYER, C.; CHAVEZ, L. F.; ZANATTA, J. A.; FIORIN, J. E. Postharvest nitrous oxide emissions from a subtropical oxisol as influenced by summer crop residues and their management. Revista Brasileira de Ciência do Solo, v. 34, p. 507-516, 2010.

FUB, R.; RUTH, B.; SCHILLING, R.; SCHERB, H.; MUNCH, J. C. Pulse emissions of $\mathrm{N}_{2} \mathrm{O}$ and $\mathrm{CO}_{2}$ from an arable field depending on fertilization and tillage practice. Agriculture, Ecosystems and Environment, v. 144, p. 61-68, 2011.

GELFAND, I.; CUI, M.; TANG, J.; ROBERTSON, G. P. Short-term drought response of $\mathrm{N}_{2} \mathrm{O}$ and $\mathrm{CO}_{2}$ emissions from mesic agricultural soils in the US Midwest. Agriculture, Ecosystems and Environment, v. 212, p. 127-133, 2015.

GOMES, J.; BAYER, C.; COSTA, F. S.; PICCOLO, M. C.; ZANATTA, J. A.; VIEIRA, F. C. B.; SIX, J. Soil nitrous oxide emissions in long-term cover crops based rotations under subtropical climate. Soil \& Tillage Research, v. 106, p. 36-44, 2009.

GRANLI, T.; BØCKMAN, O. C. Nitrous oxide from agriculture, Norw. Journal of Agricultural Science, v. 12, p. 1-128, 1994. 
HAMILTON, C.E.; BEVER, J.D.; LABBÉ, J.; YANG, X.; YIN, H. Mitigating climate change through managing constructed-microbial communities in Agriculture. Agriculture, Ecosystems and Environment, v. 216, p. 304-308, 2016.

HARRISON-KIRK, T.; BEARE, M. H.; MEENKEN, E. D.; CONDRON, L. M. Soil organic matter and texture affect responses to dry/wet cycles: Effects on carbon dioxide and nitrous oxide emissions. Soil Biology and Biochemistry, v. 57, p. 43-55, 2013.

HAYASHI, K.; TOKIDA, T.; KAJIURA, M.; YANAI, Y.; YANO, M. Cropland soilplant systems control production and consumption of methane and nitrous oxide and their emissions to the atmosphere. Soil Science and Plant Nutrition, v. 61, p. 2-33, 2015.

HUANG, Y.; ZOU, J.; ZHENG, X.; WANG, Y.; XU, X. Nitrous oxide emissions as influenced by amendment of plant residues with different $C: N$ ratios. Soil Biology and Biochemistry, v. 36, n. 6, p. 973-981, 2004.

HUANG, T.; GAO, B.; CHRISTIE, P.; JU, X. Net global warming potential and greenhouse gas intensity in a double-cropping cereal rotation as affected by nitrogen and straw management. Biogeosciences, v. 10, p. 7897-7911, 2013.

HUANG, M.; LIANG, T.; WANG, L. Nitrous oxide emissions in a winter wheat summer maize double cropping system under different tillage and fertilizer management. Soil Use and Management, v. 31, p. 98-105, 2015.

INTERGOVERNMENTAL PANEL ON CLINTERGOVERNMENTAL PANEL ON CLIMATE CHANGE - IMATE CHANGE - IPCC. Climate Change, 2013: The Physical Science Basis: Working Group I Contribution to the Fifth Assessment Report of the Intergovernmental Panel on Climate Change. Cambridge University Press, UK.

JANTALIA, C. P.; SANTOS, H. P.; URQUIAGA, S.; BODDEY, R. M.; ALVES, B. J. R. Fluxes of nitrous oxide from soil under different crop rotations and tillage systems in the South of Brazil. Nutrient Cycling in Agroecosystems, v. 82, p. 161-173, 2008.

JERECKI, M. K.; LAL, R. Compost and mulch effects on gaseous flux from an alfisol in Ohio. Soil Science, v. 171, p. 249-260, 2006.

KIESE, R.; BUTTERBACH-BAHL, K. $\mathrm{N}_{2} \mathrm{O}$ and $\mathrm{CO}_{2}$ emissions from three different tropical forest sites in the wet tropics of Queensland, Australia. Soil Biology and Biochemistry, v. 34, n. 7, p. 975-987, 2002.

KLINK, C. A.; MACHADO, R. B. A conservação do Cerrado brasileiro. Megadiversidade, Belo Horizonte, v. 1, p. 147-155, 2005.

KHALIL, M. I.; BAGGS, E. M. $\mathrm{CH}_{4}$ oxidation and $\mathrm{N}_{2} \mathrm{O}$ emissions at varied soil waterfilled pore spaces and headspace $\mathrm{CH}_{4}$ concentrations. Soil Biology and Biochemistry, v. 37, p. 1785-1794, 2005. 
KHALIL, K.; MARY, B.; RENAULT, P. Nitrous oxide production by nitrification and denitrification in soil aggregates as affected by $\mathrm{O}_{2}$ concentration. Soil Biology and Biochemistry, v. 36, n. 4, p. 687-699, 2004.

KONG, A. Y. Y.; HRISTOVA, K.; SCOWB, K. M.; SIX, J. Impacts of different N management regimes on nitrifier and denitrifier communities and $\mathrm{N}$ cycling in soil microenvironments. Soil Biology and Biochemistry, v. 42, p. 1523-1533, 2010.

LAMMEL, D. R.; NÜSSLEIN, K.; TSAI, S. M.; CERRI, C. C. Land use, soil and litter chemistry drive bacterial community structures in samples of the rainforest and Cerrado (Brazilian Savannah) biomes in Southern Amazonia. European Journal of Soil Biology, v. 66, p. 32-39, 2015.

LAPOLA, D. M.; MARTINELli, L. A.; PERES, C. A.; OMETTO, J. P. H. B.; FERREIRA, M. E.; NOBRE, C. A.; AGUIAR, A. P. D.; BUSTAMANTE, M. M. C.; CARDOSO, M. F.; COSTA, M. H.; JOLY, C. A.; LEITE, C. C.; MOUTINHO, P.; SAMPAIO, G.; STRASSBURG, B. B. N.; VIEIRA, I. C. G. Pervasive transition of the Brazilian land-use system. Nature Climate Change, v. 4, p. 27-35, 2014.

LIU, X. J.; MOSIER, A. R.; HALVORSON, A. D.; REULE, C. A.; ZHANG, F. S. Dinitrogen and $\mathrm{N}_{2} \mathrm{O}$ emissions in arable soils: Effect of tillage, $\mathrm{N}$ source and soil moisture. Soil Biology and Biochemistry, v. 39, p. 2362-2370, 2007.

LIU, Z. J.; YANG, X. G.; CHEN, F.; WANG, E. L. The effects of past climate change on the northern limits of maize planting in Northeast China. Nature Climate Change, v. 117 , p. 891-902, 2013.

LIU, C.; YAO, Z.; WANG, K.; ZHENG, X. Three-year measurements of nitrous oxide emissions from cotton and wheat-maize rotational cropping systems. Atmospheric Environment, v. 96, p. 201-208, 2014.

LUO, G. J.; KIESE, R.; WOLF, B.; BUTTERBACH-BAH, K. Effects of soil temperature and moisture on methane uptake and nitrous oxide emissions across three different ecosystem types. Biogeosciences, v. 10, p. 3205-3219, 2013.

MARTINS, M. R.; JANTALIA, C. P.; POLIDORO, J. C.; BATISTA, J. N.; ALVES, B. J. R.; BODDEY, R. M.; URQUIAGA, S. Nitrous oxide and ammonia emissions from N fertilization of maize crop under no-till in a Cerrado soil. Soil \& Tillage Research, v. 151, p. 75-81, 2015.

METAY, A.; OLIVER, R.; SCOPEL, E.; DOUZET, J. M.; MOREIRA, J. A. A.; MARAUX, F.; FEIGL, B. J.; FELLER, C. $\mathrm{N}_{2} \mathrm{O}$ and $\mathrm{CH}_{4}$ emissions from soils under conventional and no-till management practices in Goiânia (Cerrados, Brazil). Geoderma, v. 141, p. 78-88, 2007.

MINISTÉRIO DA CIÊNCIA, TECNOLOGIA E INOVAÇÃO - MCTI. Sumário Executivo, 2014. Estimativas anuais de emissões de gases de feito estufa no Brasil. $2^{\text {a }}$ ed. Brasília, Brasil, 80 p., 2014. 
MILLER, M. N.; ZEBARTH, B. J.; DANDIE, C. E.; BURTON, D. L.; GOYER, C.; TREVORS, J. T. Crop residue influence on denitrification, $\mathrm{N}_{2} \mathrm{O}$ emissions and denitrifier community abundance in soil. Soil Biology and Biochemistry, v. 40, p. 2553-2562, 2008.

MOSIER, A. R. Chamber and isotope techniques. In: Andreae MO, Schimel DS (eds) Exchange of trace gases between terrestrial ecosystems and the atmosphere. Wiley, Chichester, p. 175-187, 1989.

NARDOTO, G.B.; BUSTAMANTE, M.M.C. Effects of fire on soil nitrogen dynamics and microbial biomass in savannas of Central Brazil. Pesquisa Agropecuária Brasileira, v. 38, n. 8, p. 955-962, 2003.

PETITJEAN, C.; HÉNAULT, C.; PERRIN, A.-S.; PONTET, C.; METAY, BERNOUX, A.; M.; JEHANNO, T.; VIARD, A.; ROGGY, J.-C. Soil $\mathrm{N}_{2} \mathrm{O}$ emissions in French Guiana after the conversion of tropical forest to agriculture with the chop-and-mulch method. Agriculture, Ecosystems and Environment, v. 208, p. 64-74, 2015.

PIMENTEL, L. G.; WEILER, D. A.; PEDROSO, G. M.; BAYER, C. Soil $\mathrm{N}_{2} \mathrm{O}$ emissions following cover-crop residues application under two soil moisture conditions. Journal of Plant Nutrition and Soil Science, v. 15, p. 1-10, 2015.

PRAMANIK, P.; HAQUE, M. D. M.; KIM, S. Y.; KIM, P. J. C and N accumulations in soil aggregates determine nitrous oxide emissions from cover crop treated rice paddy soils during fallow season. Science of theTotal Environment, v. 490, p. 622-628, 2014.

RAUT, N.; SITAULA, B. K.; BAKKEN, L. R.; BAJRACHARYA, R. M.; DÖRSCH, P. Higher $\mathrm{N}_{2} \mathrm{O}$ emission by intensified crop production in South Asia. Global Ecology and Conservation, v. 4, p. 176-184, 2015.

REATTO, A.; BRUAND, A.; SILVA, E. M.; MARTINS, E. S.; BROSSARD, M. Hydraulic properties of the diagnostic horizon of Latosols of a regional toposequence across the Brazilian Central Plateau. Geoderma, v. 139, p. 51-59, 2007.

SIGNOR, D.; CERRI, C. E. P. Nitrous oxide emissions in agricultural soils: a review. Pesquisa Agropecuária Tropical, v. 43, p. 322-338, 2013.

SILVA, F. A. M.; EVANGELISTA, B. A.; MALAQUIAS, J. V. Normal climatológica de 1974 a 2003 da estação principal da Embrapa Cerrados. Planaltina: DF, 2014. 98 p. Embrapa Cerrados. (Documento, 321).

SIQUEIRA NETO, M.; PICCOLO, M. C. JUNIOR, C. C.; CERRI, C. C.; BERNOUX, M. Emissão de gases do efeito estufa em diferentes usos da terra no bioma Cerrado. Revista Brasileira de Ciência do Solo, v. 35, p. 63-76, 2011.

SOARES, J. R.; CANTARELLA, H.; VARGAS, V. P.; CARMO, J. B.; MARTINS, A. A.; SOUSA, R. M.; ANDRADE, C. A. Enhanced-efficiency fertilizers in nitrous oxide emissions from urea applied to sugarcane. Journal of Environmental Quality, v. 44, p. 423-430, 2015. 
SMITH, K. A.; THOMSON, P. E.; CLAYTON, I. P.; MCTAGGART, H.; CONEN, F. Effects of temperature, water content and nitrogen fertilisation on emissions of nitrous oxide by soils. Atmospheric Environment, v. 32, n. 19, p. 3301-3309, 1998.

SOIL SURVEY STAFF. Keys to Soil Taxonomy. 8 ed. 2006. United States Department of Agriculture, Natural Resources Conservation Service, Washington.

SCHWENKE, G. D.; HERRIDGE, D.F.; SCHEER, C.; ROWLINGS, D. W.; HAIGH, B. M.; MCMULLEN, K. G. Soil $\mathrm{N}_{2} \mathrm{O}$ emissions under $\mathrm{N}_{2}$-fixing legumes and $\mathrm{N}$ fertilised canola: A reappraisal of emissions factor calculations. Agriculture, Ecosystems and Environment, v. 201, p. 232-242, 2015.

TATTI, E.; GOYER, C.; CHANTIGNY, M.; WERTZ, S.; ZEBARTH, B. J.; BURTON, D. L.; FILION, M. Influences of over winter conditions on denitrification and nitrous oxide-producing microorganism abundance and structure in an agricultural soil amended with different nitrogen sources. Agriculture, Ecosystems and Environment, v. 183, p. 47-59, 2014.

UCHIDA, Y.; CLOUGH, T.; KELLIHER F.; HUNT, J.; SHERLOCK, R. Effects of bovine urine, plants and temperature on $\mathrm{N}_{2} \mathrm{O}$ and $\mathrm{CO}_{2}$ emissions from a subtropical soil. Plant and Soil, v. 345, p. 171-186, 2011.

URQUIAGA, S.; ALVES, B. J. R.; JANTALIA, C. P.; BODDEY, R. M. Variações nos estoques de carbono e emissões de gases de efeito estufa em solos das regiões tropicais e subtropicais do Brasil: uma análise crítica. Seropédica: RJ, 2010. 11 p. Embrapa Agrobiologia. (Documento, 130).

USSIRI, D. A. N.; LAL, R.; JARECKI, M. K. Nitrous oxide and methane emissions from long-term tillage under a continuous corn cropping system in Ohio. Soil \& Tillage Research, v. 104, p. 247-255, 2009.

WANG, Y.; XUE, M.; ZHENG, X.; JI, B.; DU, R.; WANG, Y. Effects of environmental factors on $\mathrm{N}_{2} \mathrm{O}$ emission from and $\mathrm{CH}_{4}$ uptake by the typical grasslands in the Inner Mongolia. Chemosphere, v. 58, n. 2, p. 205-2015, 2005.

WANG, W.; DALAL, R. C.; REEVES, S. H.; BUTTERBACH-BAHL, K.; KIESE, R. Greenhouse gas fluxes from an Australian subtropical cropland under long-term contrasting management regimes. Global Change Biology, v. 17, n. 10, p. 3089-3101, 2011.

YAO, Z.; ZHEN, X.; WANG, R.; XIE, B.; BUTTERBACH-BAHL, K.; ZHU, J. Nitrous oxide and methane fluxes from a rice-wheat crop rotation under wheat residue incorporation and no-tillage practices. Atmospheric Environment, v. 79, p. 641-649, 2013.

YANO, M.; TOYODA, S.; TOKIDA, T.; HAYASHI, K.; HASEGAWA, T.; MAKABE, A.; KOBA, K.; YOSHIDA, N. Isotopomer analysis of production, consumption and soil-to-atmosphere emission processes of $\mathrm{N} 2 \mathrm{O}$ at the beginning of paddy field irrigation. Soil Biology and Biochemistry, v. 70, p. 66-78, 2014. 
ZHANG, L.; ZHENG, J.; CHEN, L.; SHEN, M.; ZHANG, X.; ZHANG, M.; BIAN, X.; ZHANG, J.; ZHANG, W. Integrative effects of soil tillage and straw management on crop yields and greenhouse gas emissions in a rice-wheat cropping system. European Journal of Agronomy, v. 63, p. 47-54, 2015a.

ZHANG, N.; WAN, S.; GUO, J.; HAN, G.; GUTKNECHT, J.; SCHMID, B.; YU, L.; LIU, W.; BI, J.; WANG, Z.; MA, K. Precipitation modifies the effects of warming and nitrogen addition on soil microbial communities in northern Chinese grasslands. Soil Biology and Biochemistry, v. 89, p. 12-23, 2015c.

ZHANG, Y.; SHEN, J.; WANG, Z.; CHEN, L.; ZHENG, J. Nitrous oxide and methane emissions from a Chinese wheat-rice cropping system under different tillage practices during the wheat-growing season. Soil \& Tillage Research, v. 146, p. 261-269, 2015 b.

ZHU, X.; BURGER, M.; DOANE, T. A.; HORWATH, W. R. Ammonia oxidation pathways and nitrifier denitrification are significant sources of $\mathrm{N}_{2} \mathrm{O}$ and $\mathrm{NO}$ under low oxygen availability. Proceeding of the National Academy of Sciences, v. 110, p. 6328-6333, 2013. 
CAPÍTULO II

COMPARTIMENTOS DA MATÉRIA ORGÂNICA DO SOLO E EMISSÃO DE ÓXIDO NITROSO EM AGROECOSSISTEMAS NO CERRADO BRASILEIRO 


\section{RESUMO}

\section{COMPARTIMENTOS DA MATÉRIA ORGÂNICA DO SOLO E EMISSÃO DE ÓXIDO NITROSO EM AGROECOSSISTEMAS NO CERRADO BRASILEIRO}

A adoção de agroecossistemas com rotações culturais tem sido proposta como uma estratégia para mitigar as mudanças climáticas decorrentes da agricultura através das reduções das emissões de $\mathrm{N}_{2} \mathrm{O}$. No entanto, ainda não está clara a relação entre o acúmulo de matéria orgânica e a emissão de $\mathrm{N}_{2} \mathrm{O}$ do solo submetido a diferentes agroecossistemas. A hipótese do nosso trabalho é que a adoção de agroecossistemas conservacionistas promove acúmulo de frações lábeis e estáveis da MOS com redução das emissões de óxido nitroso para a atmosfera. Este estudo avaliou os efeitos de agroecossistemas conduzidos por dezoito anos, baseado nas rotações de culturas: 1) nos estoques de carbono e nitrogênio e nas frações lábeis e estáveis da MOS; 2) na emissão acumulada de $\mathrm{N}_{2} \mathrm{O}$; e 3) nas relações entre frações da MOS e emissões de $\mathrm{N}_{2} \mathrm{O}$ em Latossolo, no Cerrado brasileiro. Os sistemas agrícolas utilizados incluíram: (I) plantio direto, com uma safra de soja, seguida por uma segunda safra de sorgo (NT1); (II) plantio direto, com uma safra de milho e posterior, segunda safra de guandu (NT2); (III) sistema convencional, com uma safra de soja seguida de pousio do solo (CT); (IV) e o cerrado nativo (CER). A adoção do CT por 18 anos, após a supressão do cerrado nativo, reduziu o estoque de $\mathrm{C}$ do solo, na profundidade de $0-100 \mathrm{~cm}$, em 1,5 $\mathrm{t} \mathrm{ha}^{-1} \mathrm{ano}^{-1}$. Os sistemas conservacionistas (NT1 e NT2) foram mais eficientes em acumular frações lábeis e estáveis de $\mathrm{C}$ com valores próximos aos observados sob o CER sendo diretamente relacionados a menores emissões de $\mathrm{N}_{2} \mathrm{O}$ do solo. $\mathrm{O}$ fluxo acumulado de $\mathrm{N}_{2} \mathrm{O}$ foi relacionado aos sistemas de manejo e às seguintes frações da matéria orgânica do solo: carbono da biomassa microbiana (CBM), carbono oxidado com permanganato de potássio $\left(\mathrm{C}-\mathrm{KMnO}_{4}\right)$, carbono orgânico particulado (COP), carbono inerte $(\mathrm{CI})$, ácido húmico $(\mathrm{AH})$, ácido fúlvico (AF) e humina (HUM). Com base na análise de componentes principais, de maneira geral, observou-se uma separação do CT dos demais sistemas de uso do solo formando um grupo juntamente com as emissões de $\mathrm{N}_{2} \mathrm{O}$, sendo esse grupo formado associado, aos baixos teores de $\mathrm{C}$ nas diversas frações da MOS.

Palavras-chave: Carbono orgânico do solo, sistemas de manejo do solo, rotação de cultura, mudanças climáticas.

\section{ABSTRACT \\ SOIL ORGANIC MATTER POOLS AND NITROUS OXIDE EMISSIONS IN AGROECOSYSTEMS IN THE BRAZILIAN CERRADO}

The adoption of agro-ecosystems with crop rotation has been proposed as a strategy to mitigate climate change arising from agriculture through reductions in $\mathrm{N}_{2} \mathrm{O}$ emissions. However, the relationship is not clear between the accumulation of soil organic matter (SOM) and $\mathrm{N}_{2} \mathrm{O}$ emissions from soil submitted to different agroecosystems. The 
hypothesis of our work is that the adoption of conservation agriculture promotes a balanced accumulation of labile and stable fractions of SOM with a reduction in nitrous oxide emissions to the atmosphere. This study evaluated the effects of agro-ecosystems conducted for eighteen years, based on crop rotations: 1) on $\mathrm{C}$ and $\mathrm{N}$ stocks and the labile and stable fractions of SOM; 2) the accumulated emission of $\mathrm{N}_{2} \mathrm{O}$; and 3) the relationship between fractions of SOM and $\mathrm{N}_{2} \mathrm{O}$ emissions in Oxisol in the Brazilian Cerrado. The utilized agricultural systems included: (I) no-tillage soybean in the main and sorghum in the late growing season (NT1); (II) no-tillage maize in the main and pigeon pea in the late growing season (NT2); (III) soybean in the main and fallow in the late growing season under conventional tillage (CT); (IV) and native Cerrado (CER). The adoption of CT for 18 years after the suppression of native vegetation, reduced the stock of soil $\mathrm{C}$ in $1.5 \mathrm{t} \mathrm{ha}^{-1} \mathrm{yr}^{-1}$. Conservation agriculture based crop rotations (NT1 and NT2) were more efficient in accumulating labile and stable fractions of $\mathrm{C}$ with values close to those observed under the CER is directly related to lower emissions of $\mathrm{N}_{2} \mathrm{O}$ soil. The cumulative flow of $\mathrm{N}_{2} \mathrm{O}$ was related to management systems and the following fractions of soil organic matter: microbial biomass carbon (MBC), oxidized carbon with potassium permanganate $\left(\mathrm{C}-\mathrm{KMnO}_{4}\right)$, particulate organic carbon (POC), inert carbon (CI), humic acid (HA), fulvic acid (FA), humin (HUM) and carbon associated with minerals (COM). Based on the principal component analysis, in general, there was a separation of CT of other land use systems, this separation was due to higher $\mathrm{N}_{2} \mathrm{O}$ emissions in this system associated with low carbon content in the various fractions of SOM.

Keywords: Soil organic carbon, tillage, climate change.

\section{INTRODUÇÃO}

A agricultura contribui significativamente com as emissões de $\mathrm{N}_{2} \mathrm{O}$ para atmosfera mas os efeitos do tipo de manejo do solo sobre as emissões desse gás são complexos, e, em muitos casos, inconsistentes (Smith et al., 1998). Entre os diversos fatores que interferem nas emissões de $\mathrm{N}_{2} \mathrm{O}$ de solos agrícolas, a quantidade e a qualidade da matéria orgânica do solo (MOS) têm merecido destaque em pesquisas recentes (Sheehy et al., 2015). A análise de dados globais sobre emissões de $\mathrm{N}_{2} \mathrm{O}$ de áreas agrícolas sugere que as emissões aumentam com a elevação dos teores de carbono orgânico do solo (Stehfest e Bouwman, 2006). No entanto, os efeitos do acúmulo de carbono orgânico por longo prazo em solos agrícolas nas emissões de $\mathrm{N}_{2} \mathrm{O}$ ainda são pouco compreendidos (Jäger et al., 2011). E por esse motivo, há incertezas sobre a relação existente entre o acúmulo de frações da matéria orgânica do solo em agroecossistemas de longa duração e a mitigação de $\mathrm{N}_{2} \mathrm{O}$ (Wu et al., 2016).

A adoção de rotações culturais, com disponibilidade diferenciada de $\mathrm{N}$, tem sido proposta como uma estratégia para mitigar as mudanças climáticas decorrentes da agricultura, por meio das reduções das emissões de $\mathrm{N}_{2} \mathrm{O}$ (Marie et al., 2015; Zhang et 
al., 2015; Gupta et al., 2016; Turner et al., 2016). A adição de compostos orgânicos com baixa relação $\mathrm{C}: \mathrm{N}$, por exemplo, resultou em maiores acúmulos de $\mathrm{C}$ e maiores emissões de $\mathrm{N}_{2} \mathrm{O}$, em pastagens na Califórnia, USA (Ryals et al., 2015). Gupta et al. (2016) relataram que no cultivo do trigo a aplicação de resíduos de arroz, que apresenta uma elevada relação $\mathrm{C}: \mathrm{N}$, sob sistema plantio direto (PD), foi capaz de reduzir em até $12,8 \%$ as emissões de $\mathrm{N}_{2} \mathrm{O}$ no sul da Ásia. Do mesmo modo, Vaughan et al. (2011) também observaram reduções nas emissões de $\mathrm{N}_{2} \mathrm{O}$ de até $30 \%$ a partir da aplicação de compostos orgânicos de elevada relação C:N. Diferentemente, Iqbal et al. (2015) observaram que não existe um efeito positivo dos resíduo orgânicos, oriundos de plantas de cobertura de elevada relação $\mathrm{C}: \mathrm{N}$, nas emissões de $\mathrm{N}_{2} \mathrm{O}$ nos solos agrícolas. Sob condições subtropicais do Brasil, Bayer et al. (2015), observaram que as emissões de $\mathrm{N}_{2} \mathrm{O}$ no sistema convencional de preparo do solo foram semelhantes entre os cultivos em rotação de gramíneas e leguminosas, enquanto no plantio direto (PD) cultivado com leguminosas, as emissões foram extremamente elevadas. Apesar desses avanços nas pesquisas, ainda não está totalmente esclarecido o fato de sistemas sob vegetação natural e conservacionistas apresentarem altos teores de $\mathrm{C}$ e baixas emissões de $\mathrm{N}_{2} \mathrm{O}$ do solo, como no caso do Cerrado brasileiro (Martins et al., 2015).

A deterioração da estrutura do solo, causada por alguns sistemas convencionais de preparo do solo, reduz os estoques de $\mathrm{C}$ e $\mathrm{N}$ totais, impactando, sobretudo, as frações lábeis da matéria orgânica do solo (MOS) (Figueiredo et al., 2013; Corbeels et al., 2016). Por outro lado, o PD é conhecido por aumentar os teores tanto de frações humificadas quanto de lábeis da MOS, como a biomassa microbiana do solo e o C lábil (Piccoli et al., 2016).

As interações existentes entre MOS e emissões de $\mathrm{N}_{2} \mathrm{O}$ normalmente são decorrentes da maior proporção de frações lábeis na MOS, com grande fornecimento de $\mathrm{N}$ derivado de resíduos de culturas (Chirinda et al., 2010; Henderson et al., 2010; Wu et al., 2016) ou fertilizantes nitrogenados (Iqbal et al., 2015; Martins et al., 2015; Venterea \& Coulter, 2015; Jain et al., 2016; Wang et al., 2016). Outro aspecto ainda pouco explicado é a forma de proteção da MOS promovida pelos sistemas de manejo do solo e sua relação com a emissão de $\mathrm{N}_{2} \mathrm{O}$. Sistemas de manejo que favorecem a formação de agregados estáveis, apresentam maior acúmulo de $\mathrm{C}$ e $\mathrm{N}$, como resultado da proteção física da MOS contra a oxidação microbiana (Andruschkewitsch et al., 2014; Tivet et al., 2013). Além disso, a forte interação organomineral de frações da MOS associada aos minerais, que predominam em solos intemperizados de regiões tropicais, podem 
contribuir com a estabilização da MOS e assim explicar as reduzidas emissões $\mathrm{N}_{2} \mathrm{O}$ em solos de savanas sob vegetação natural (Martins et al., 2015).

A hipótese do nosso trabalho é que a adoção de agroecossistemas conservacionistas promova um acúmulo balanceado de frações lábeis e estáveis da MOS com redução das emissões de óxido nitroso para a atmosfera. O objetivo deste estudo foi determinar os efeitos de agroecossistemas de longa duração, baseados na rotação de culturas: 1) nas frações lábeis e estáveis da MOS; 2) na emissão acumulada de $\mathrm{N}_{2} \mathrm{O}$; e 3) nas relações entre frações da MOS e emissões de $\mathrm{N}_{2} \mathrm{O}$ do solo.

\section{MATERIAL E MÉTODOS}

\subsection{CARACTERIZAÇÃO DA ÁREA EXPERIMENTAL}

A caracterização da área experimental, as informações do clima local, histórico, atributos químicos e físicos do solo encontram-se descritos no Capítulo I nas seções 2.1 e 2.2 .

\subsection{AMOSTRAGEM DO SOLO E DETERMINAÇÕES DOS ESTOQUES DE CARBONO E NITROGÊNIO, DA AGREGAÇÃO DO SOLO E DAS FRAÇÕES DA MOS}

\subsubsection{Teores e estoques de carbono e nitrogênio do solo}

Para a determinação dos estoques totais de C (EstC) e N (EstN) do solo em cada sistema de manejo foram coletadas quatro amostras simples em pontos aleatórios da parcela para formar uma amostra composta, nas seguintes profundidades: 0-5, 5-10, 1020, 20-40, 40-60, 60-80, 80-100 cm realizadas no início do período chuvoso, em outubro de 2013 e analisadas na Embrapa Cerrados. Nessas amostras compostas foram avaliados os teores de $\mathrm{C}$ totais (COT) em analisador elementar modelo vario Macro cube. Os teores de $\mathrm{N}$ totais (NOT) foram determinados pela digestão do solo com ácido sulfúrico e água oxigenada, seguida de destilação a vapor (Kjeldahl) com hidróxido de sódio e titulação do coletado com ácido bórico. Os estoques de C (EstC) e nitrogênio (EstN) foram determinados pelo método da camada equivalente (Ferreira et al., 2016a) conforme a equação 1 . 
em que o EstC ou EstN é o estoques de carbono ou nitrogênio $\left(\mathrm{Mg} \mathrm{ha}^{-1}\right)$; $\mathrm{C}$ ou $\mathrm{N}$ é o teor de carbono ou nitrogênio $\left(\mathrm{g} \mathrm{kg}^{-1}\right)$; DS é a densidade do solo $\left(\mathrm{g} \mathrm{cm}^{-3}\right)$ determinada pela umidade volumétrica e segundo Embrapa (1997); p é a profundidade da camada do solo $(\mathrm{cm})$.

\subsubsection{Agregação e teor de carbono em agregados do solo}

Para a determinação da agregação do solo e dos teores de $\mathrm{C}$ em macro e microagregados, monolitos de solo foram coletados em abril de 2014 no período de floração das culturas, na profundidade de $0-20 \mathrm{~cm}$.

Para tanto foram abertas mini-trincheiras em três pontos da parcela experimental. Após a coleta, ainda no campo, o solo foi cuidadosamente passado por peneira de 19 mm de malha e armazenado em caixas plásticas para manutenção da estrutura do solo (Fig. A3). No laboratório as amostras foram subdivididas em quatro subamostras que foram submetidas à oscilação em aparelho de Yoder. Cada subamostra foi colocada em um conjunto de peneiras de: $2 \mathrm{~mm} ; 1 \mathrm{~mm} ; 0,5 \mathrm{~mm} ; 0,25 \mathrm{~mm}$; e $0,106 \mathrm{~mm}$, segundo metodologia proposta pela Embrapa (1997). Os agregados menores que 0,106 mm foram obtidos após secagem do solo armazenado que restou no recipiente de oscilação. Após a secagem dos agregados, foi determinado o diâmetro médio ponderado (DMP) dos agregados (Kemper \& Rosenau, 1986) conforme equação 2.

$D M P=\sum_{i=l}^{n}\left(x_{i x} w_{i}\right)$

em que DMP é o diâmetro médio ponderado $(\mathrm{mm})$; xi = diâmetro médio das classes; wi $=$ proporção de cada classe em relação ao total.

O C foi determinado nas classes de macroagregados (CMAC >0,25 mm) e microagregados (CMIC <0,25 mm), obtidos pela junção das classes intermediárias (Fig. 2.1). 


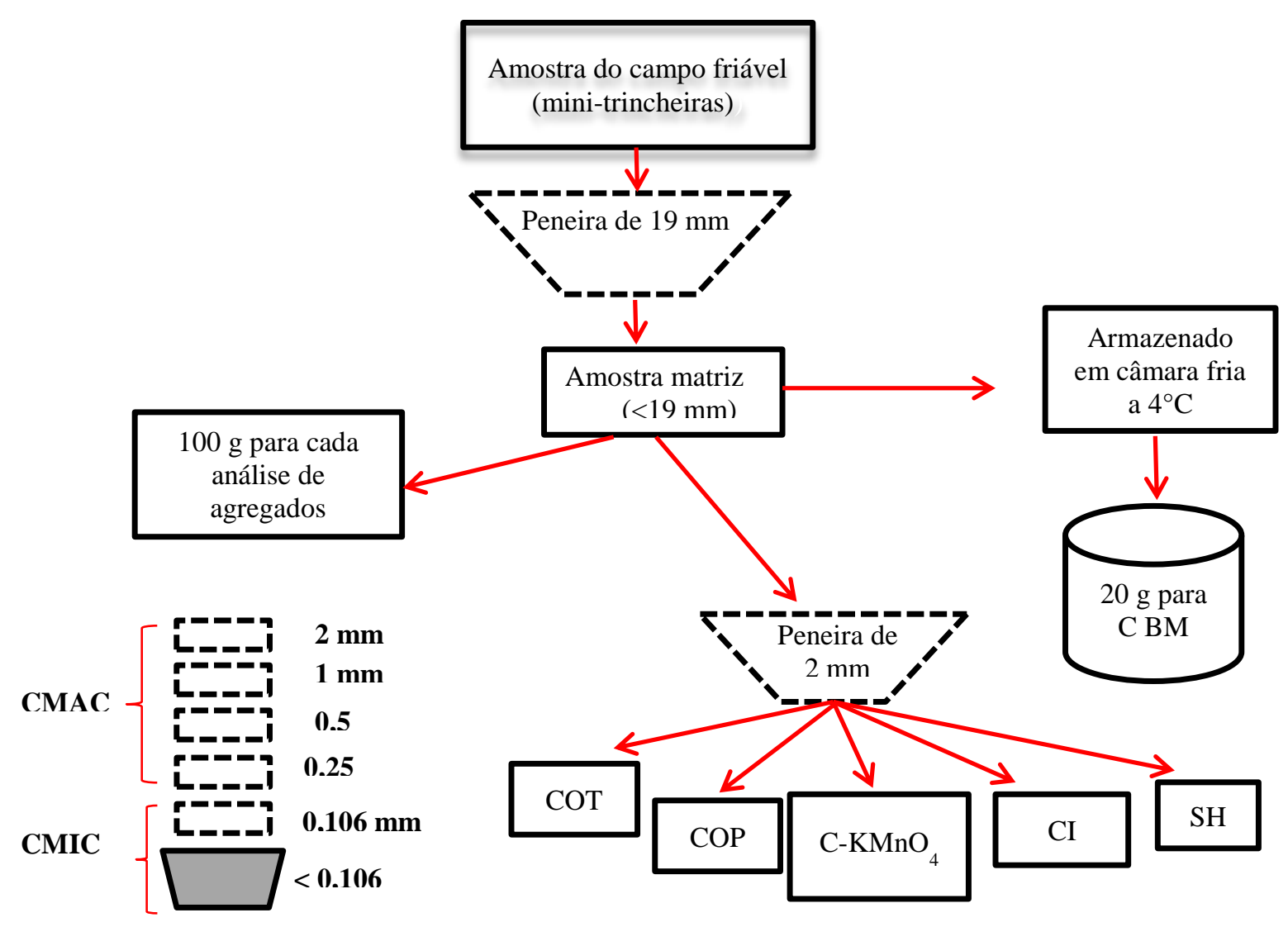

Figura. 2.1. Esquema de amostragem do solo em campo e separação das amostras para determinação das frações orgânicas do solo.

\subsubsection{Frações da matéria orgânica do solo}

Amostras de solo foram coletadas em mini-trincheiras conforme procedimento apresentado no item 2.2.2. Essas amostras foram secas ao ar e passadas em peneira de 2,00 mm para compor a terra fina seca ao ar (TFSA).

O fracionamento químico da matéria orgânica foi realizado e as substâncias húmicas (SH) foram determinadas utilizando a técnica de solubilidade diferencial (Swift, 1996). A partir desse fracionamento foram obtidas as frações ácido fúlvico (AF), ácido húmico (AH) e humina (HU).

Para quantificação do carbono inerte $(\mathrm{CI})$ foi utilizada a metodologia proposta por Jackson (1958) que identifica este C como parte do compartimento estável da matéria orgânica. Foi utilizado ainda o fracionamento físico-granulométrico da MOS. De acordo com este procedimento, carbono orgânico particulado (COP) foi determinado, utilizando o hexametafosfato de sódio como dispersante, conforme descrito por Cambardella \& Elliott (1992). O carbono orgânico associado aos minerais (COM) foi obtido pela diferença entre as frações de COT e COP. 
O carbono oxidável em permanganato de potássio $\left(\mathrm{C}-\mathrm{KMnO}_{4}\right)$ foi determinado segundo procedimento descrito por Blair et al. (1995), adaptado por Shang \& Tiessen (1997). A leitura das amostras foi realizada em espectrofotômetro em comprimento de onda de $565 \mathrm{~nm}$. Para a construção da curva, foi assumido que $1 \mathrm{mM}$ de $\mathrm{MnO}_{4}$ é consumido (MnVII + MnII) na oxidação de 0,75 mmol ou 9 mg de carbono, e assim, quantificado o teor de carbono oxidável.

O carbono da biomassa microbiana (CBM) foi determinado pelo método de irradiação-extração, conforme Islam \& Weil (1998), utilizando o forno micro-ondas, que tem por base o rompimento das células e a liberação de compostos intracelulares dos microrganismos eliminados. A solução extratora do $\mathrm{CBM}$ foi $\mathrm{K}_{2} \mathrm{SO}_{4} 0,5 \mathrm{~mol} \mathrm{~L}^{-1}$. Foram retiradas alíquotas de $10 \mathrm{ml}$ dos extratos filtrados acrescentando-se $2 \mathrm{ml}$ de $\mathrm{K}_{2} \mathrm{Cr}_{2} \mathrm{O}_{7}$ 0,066 mol L ${ }^{-1}$ e $10 \mathrm{ml} \mathrm{de} \mathrm{H}_{2} \mathrm{SO}_{4}$ em erlenmeyers de $250 \mathrm{ml}$. Diluíram-se as soluções com $50 \mathrm{ml}$ de água destilada. O residual do dicromato foi quantificado por titulação com solução de sulfato ferroso amoniacal [Fe( $\left(\mathrm{NH}_{4}\right)_{2}\left(\mathrm{SO}_{4}\right)_{2} 6 \mathrm{H}_{2} \mathrm{O}$ ] em $\mathrm{H}_{2} \mathrm{SO}_{4}$ concentrado, na presença de solução indicadora composta por fenantrolina e sulfato ferroso (Ferroin). Foram realizadas provas em branco. A quantidade de CBM foi determinada pela diferença entre o $\mathrm{C}$ extraído das amostras irradiadas e não irradiadas.

Os teores de C nas frações COP, CI, CMAC, CMIC foram determinados em analisador elementar Perkin Elmer Series II CHNS/O 2400.

\subsection{EMISSÃO DE ÓXIDO NITROSO ACUMULADO}

Em cada parcela experimental foram instaladas três câmaras estáticas fechadas, formando nove câmaras por tratamento e medidos os fluxos de $\mathrm{N}_{2} \mathrm{O}$ do solo em intervalos médios de 3 dias consecutivos, entre 09:00 e 11:00 horas (Alves et al., 2012), de outubro de 2013 a setembro de 2014. Amostras de ar do interior da câmara foram coletadas nos tempos 0,15 e 30 minutos após o fechamento das câmeras. Os fluxos de $\mathrm{N}_{2} \mathrm{O}$ foram então determinados por regressão linear da concentração de $\mathrm{N}_{2} \mathrm{O}$ em função do tempo de amostragem (Livingston \& Hutchinson, 1995). Posteriormente, as emissões acumuladas de $\mathrm{N}_{2} \mathrm{O}$ foram determinadas a partir da interpolação linear dos valores diários de emissão de $\mathrm{N}_{2} \mathrm{O}$ do solo (Dobbie et al., 1999; Allen et al., 2010; Bayer et al., 2015). 


\subsection{ANÁLISES ESTATÍSTICAS}

Após aplicação do teste de normalidade, os dados foram submetidos à análise de variância e as médias comparadas pelo teste de Tukey a 5\% de significância $(\mathrm{P}<0,05)$. As análises estatísticas foram realizadas com o auxílio do software estatístico SAS ${ }^{\circledR}$, versão 8.02 .

Os dados de emissão acumulada de $\mathrm{N}_{2} \mathrm{O}$ e das frações da MOS foram submetidos a análise de componentes principais (ACP). Emissões acumuladas foram calculadas por interpolação entre datas de amostragem adjacentes (Allen et al., 2010). As emissões acumuladas foram estimadas plotando-se os valores diários dos fluxos de $\mathrm{N}_{2} \mathrm{O}$ e a escala de tempo em um gráfico e calculando-se a área resultante sob a curva, por integração, utilizando-se o software Sigmaplot ${ }^{\circledR}$ Versão 10 (Systat Software Inc., Chicago, USA, 2007).

\section{RESULTADOS E DISCUSSÃO}

\subsection{TEORES E ESTOQUES DE CARBONO E NITROGÊNIO DO SOLO}

Os agroecossistemas não se diferenciaram quanto aos teores de COT e NOT nas diferentes profundidades avaliadas $(\mathrm{P}<0,05)$. Reduções nos teores de COT e NOT foram observadas, em algumas profundidades, quando os agroecossistemas foram comparados ao Cerrado nativo (Fig. 2.1). Quanto aos teores de COT, na profundidade 0-5 cm o CER teve maior teor do que o CT, e nas profundidades $60-80 \mathrm{~cm}$ e $80-100 \mathrm{~cm}$, o CER foi superior ao NT2 $(\mathrm{P}<0,05)$. Em relação aos teores de NOT, o CER foi superior ao NT2 na profundidade de 10-20 cm, ao CT na profundidade de 20-40 cm, e ao NT1 e NT2 em 60-80 cm. Geraei et al. (2016) atribuíram as concentrações de COT e NOT superiores observadas sob floresta, quando comparada aos demais sistemas avaliados, à adição em maior quantidade de MOS, que permanece no solo devido a ausência de qualquer perturbação, como a remoção repetida de biomassa. Diferentemente do que foi observado por Sá et al. (2015), nesse estudo os teores totais de C e N não foram capazes de expressar as diferenças do manejo entre os agroecossistemas. Os resultados sugerem que os teores totais de $\mathrm{C}$ e $\mathrm{N}$ apresentaram baixa sensibilidade para refletir as alterações do manejo para esses sistemas de longo prazo (Geraei et al., 2016). 


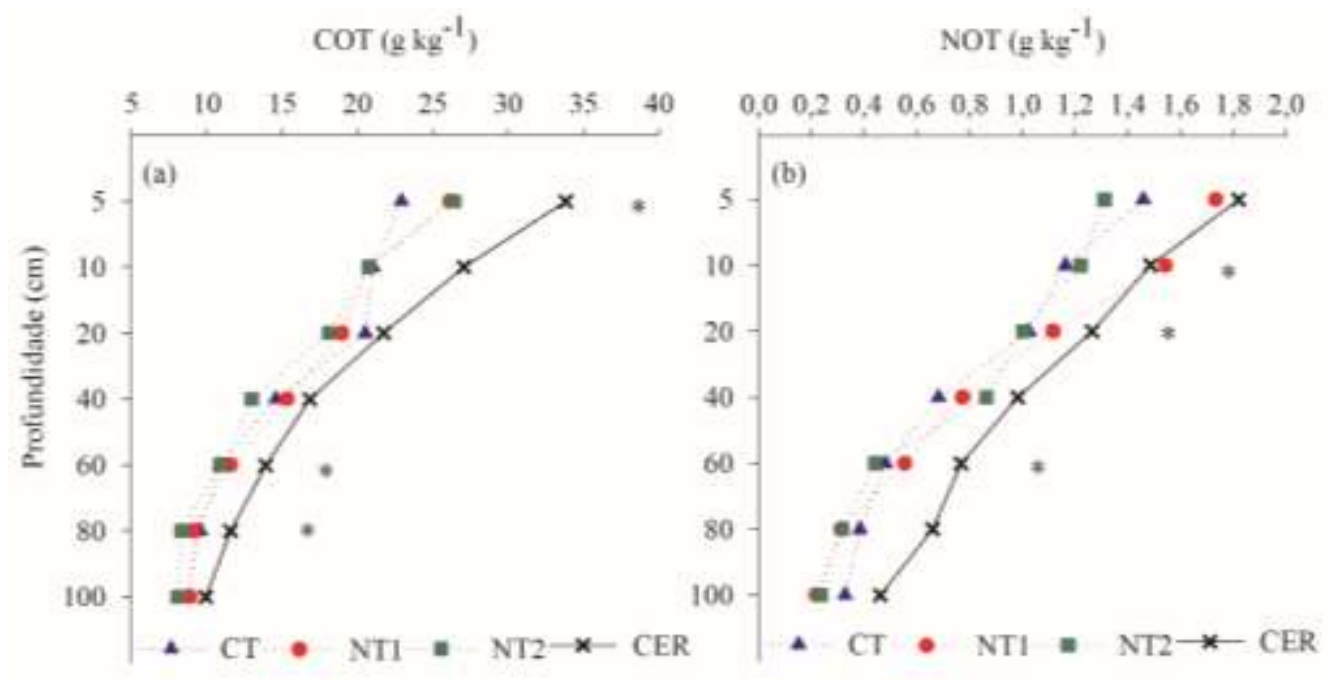

Figura 2. 1 Carbono orgânico total - COT (a) e nitrogênio orgânico total - NOT (b) no perfil do solo da área estudada. * indica que há diferença estatística entre os sistemas de manejo de acordo com o teste de Tukey $(\mathrm{P}<0,05)$.

Em todos os sistemas avaliados, os teores de COT e NOT foram reduzidos com o aumento da profundidade (Fig. 2.1). Sob o CER, por exemplo, os teores de COT e NOT foram, respectivamente, $33,9 \mathrm{~g} \mathrm{C} \mathrm{kg}^{-1}$ e $1,82 \mathrm{~g} \mathrm{~N} \mathrm{~kg}^{-1}$ na profundidade de $0-5 \mathrm{~cm}$, em comparação com 9,9 $\mathrm{g} \mathrm{C} \mathrm{kg}^{-1}$ e $0,46 \mathrm{~g} \mathrm{~N} \mathrm{~kg}^{-1}$ na profundidade de $80-100 \mathrm{~cm}$. As reduções nos teores de COT a partir de $20 \mathrm{~cm}$ de profundidade até $100 \mathrm{~cm}$, quando comparados os sistemas agrícolas ao CER, foram de 42\%, 43\% e 47\% para o NT1, NT2 e CT, respectivamente. Ainda nesse intervalo de profundidade, a redução nos teores de NOT no plantio direto (NT1 e NT2), em média, foi de 31\%, com redução ainda maior no CT, de 54\%, quando comparados ao CER. Comportamento similar foi observado por diversos autores em trabalhos com Latossolos do Cerrado (D'Andréa et al., 2004; Figueiredo et al., 2013; Sá et al., 2014; Corbeels et al., 2016; Ferreira et al., 2016a). Weller et al. (2016) também observaram elevadas reduções nos conteúdos de COT e NOT, em condições tropicais, mesmo sob sistemas de manejo com rotações culturais. Assim como, Lozano-García \& Parras-Alcántara (2013), sob Cambissolo no mediterrâneo europeu, também constataram que a substituição da vegetação nativa por sistemas agrícolas causam elevadas reduções nos teores totais de $\mathrm{C}$ e $\mathrm{N}$ do solo em profundidade.

Em relação ao cerrado nativo, o CT foi o sistema que promoveu as maiores perdas de COT e NOT, principalmente nas profundidades superficiais. Plaza-Bonilla et al. (2016) observaram que o sistema convencional proporciona perdas significativas de COT e que as rotações com leguminosas reduzem o impacto que o sistema convencional causa ao 
perturbar as estruturas do solo e expor a MOS fisicamente protegida. Do mesmo modo, Mazzoncini et al. (2016), sob condições do Mediterrâneo, também observaram que o CT reduziu os teores de NOT ao longo de 28 anos de experimento ao NT.

Os agroecossistemas também não se diferenciaram quanto aos estoques de carbono e nitrogênio (EstC e EstN) (Tabela 2.1). Contudo, os sistemas sob plantio direto (NT1 e NT2) apresentaram valores similares ao CER e o uso de sistema convencional promoveu redução no EstC em relação à mata nativa. De forma similar ao EstC, o EstN foi reduzido quando da incorporação do CER para agricultura. Sob CT e NT2 houve redução do EstN em relação ao CER, enquanto o NT1 apresentou valor de EstN similar à área nativa. Diferente dos resultados do presente trabalho, normalmente, o uso de leguminosas na sucessão de culturas promove aumento do EstN (Veras et al., 2016). De acordo com Santos et al. (2014) a composição química da leguminosa guandu, com elevadas quantidades de lignina (média de $50 \mathrm{~g} \mathrm{~kg}^{-1}$ ) e alta relação lignina/ $\mathrm{N}$ (Veras et al., 2016), comparada a outras plantas de coberturas (Carvalho et al., 2012), apresenta lenta taxa de mineralização, e pode justificar a baixa contribuição dessa cultura para o aumento do EstN verificado no NT2.

Também foi observado que o EstC de $175 \mathrm{Mg} \mathrm{ha}^{-1}$ no CER é maior do que os valores normalmente obtidos para solos da região, como aqueles apresentados por Sá et al. (2015) e Ferreira et al. (2016a). O elevado teor de argila do solo no presente estudo, possivelmente, justifique os maiores estoques de $\mathrm{C}$ encontrados, conforme destacado por Lozano-García \& Parras-Alcántara (2013) e Geraei et al. (2016).

Tabela 2.1 Estoques de carbono (EstC), nitrogênio (EstN) e relação $\mathrm{C} / \mathrm{N}$ do solo na profundidade de $0-100 \mathrm{~cm}$ sob sistemas de manejo e cerrado nativo.

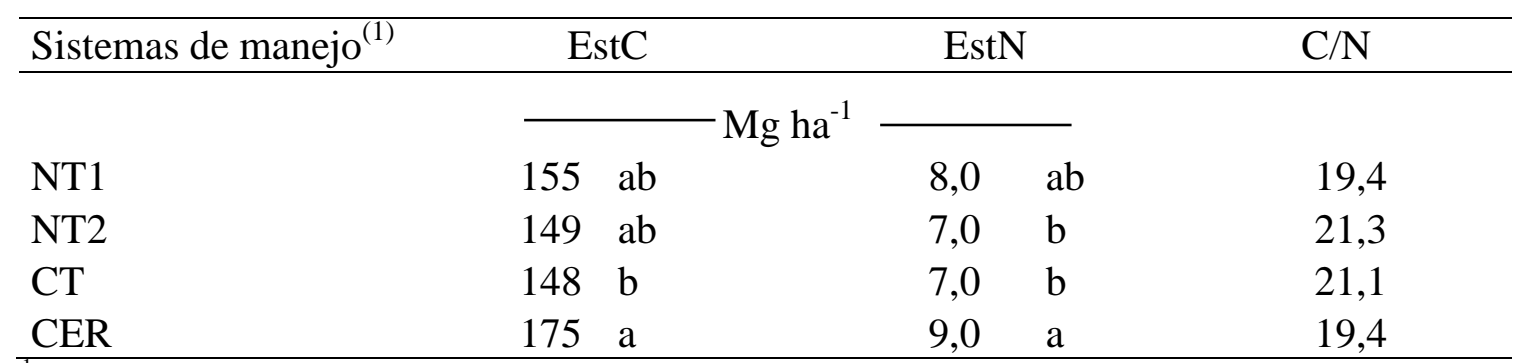

${ }^{1}$ NT1 e NT2 = sistema plantio direto; $\mathrm{CT}$ = sistema convencional; CER = cerrado. Médias seguidas de letras iguais não diferem entre si pelo teste de Tukey $(\mathrm{P}<0,05)$

O CT em 18 anos de cultivo reduziram os estoques de C em 15\%, quando comparados ao CER, sendo que, as reduções sob plantio direto (NT1 e NT2) não foram significativas. Em relação ao EstN, as reduções foram ainda maiores, de $22 \%$ e $22 \%$ no 
CT e NT2 respectivamente, comparado ao CER (Tabela 2.1). Geraei et al. (2016) no semiárido do Iran, destacam que o impacto da conversão da floresta para áreas agrícolas, sem o manejo adequado, pode reduzir os estoques EstC e EstN em 53\% e $66 \%$, respectivamente. Assim como já confirmado por Jantalia et al (2007) e Ferreira et al. (2016a), em experimentos de longa duração nas condições do cerrado brasileiro, a introdução de sistemas agrícolas reduzem os EstC mesmo com a utilização de rotações culturais. Contudo, à semelhança dos resultados observados por Sá et al. (2015), as maiores perdas e reduções do EstC são observadas em sistemas convencionais de uso do solo. A adoção do CT por 18 anos, após a supressão do cerrado nativo, reduziu seu EstC em 1,5 t ha ${ }^{-1}$ ano $^{-1}$ (Tabela 2.1), mesmo com a utilização do descanso do solo (pousio) até o próximo cultivo e sucessão bienal entre leguminosas/gramíneas. Sob as condições edafoclimáticas do cerrado, o uso de grade pesada promoveu maior taxa de decomposição da MOS, superior à entrada de C no solo (Ferreira et al., 2016b). Taxas mais elevadas de mineralização da MOS com sua diluição no perfil do solo sob CT, devido, o uso contínuo de implementos agrícolas, foram relatadas por Mazzoncini et al. (2016) como responsável por diminuir o EstC e $\mathrm{N}$ em 3\% e 5\%, respectivamente, ao passo que, no NT ocorreram incrementos de $22 \%$ na profundidade de $0-30 \mathrm{~cm}$.

Quando comparados o NT1 e NT2 ao CER, em relação aos EstC, o NT1 foi o sistema de manejo que proporcionou menores perdas de $\mathrm{C}$ nos 18 anos de experimento, com $1,1 \mathrm{t} \mathrm{ha}^{-1}$ ano $^{-1}$ versus $1,4 \mathrm{t} \mathrm{ha}^{-1}$ ano $^{-1}$, respectivamente. Nesse contexto, a proteção física, química e bioquímica, decorrente das rotações culturais (soja/sorgo) e práticas de manejo do NT1, conferiram uma maior estabilidade ao EstC, assim como, também observado no resultado do EstN sob esse mesmo sistema de manejo. Sendo assim, o NT2 mesmo sob cultivo do milho em rotação com uma leguminosa de cobertura (guandu), não elevou o EstC e EstN como descrito e recomendado por outros trabalhos em diferentes regiões brasileiras (Calonego \& Rosolem, 2008; Ferreira et al., 2016b).

No CER o estado de equilíbrio entre entrada e saída de C e N, a decomposição radicular em profundidade das plantas arbóreas, com manutenção das estruturas físicas do solo são responsáveis pelos maiores valores de EstC e EstN observados nessa pesquisa e, similarmente a outros trabalhos realizados nesse bioma (Bustamante et al., 2006; Assad et al., 2013; Figueiredo et al., 2013;; Ferreira et al., 2016a; Oliveira et al., 2016). Assim, como também se observou que a conversão de áreas nativas em terras agrícolas reduziu os estoques de N (Franco et al., 2015; Oliveira et al., 2016). A 
limitação do $\mathrm{N}$ no solo inibe o sequestro de $\mathrm{C}$ no solo, uma vez que há correlação positiva entre EstN e EstC (Sá et al., 2014; Cherubin et al., 2015).

\subsection{EFEITO DOS SISTEMAS DE MANEJO NAS FRAÇÕES DA MATÉRIA ORGÂNICA DO SOLO}

\subsubsection{Frações lábeis da matéria orgânica do solo}

Nas frações lábeis da matéria orgânica que, normalmente, são mais sensíveis ao manejo do solo (Figueiredo et al., 2013; Prasad et al., 2016; Geraei et al., 2016), foram observadas as maiores diferenças entre os sistemas avaliados (Fig. 2.2). Todos os sistemas de uso do solo se diferenciaram quanto aos teores de carbono da biomassa microbiana $(\mathrm{CBM})(\mathrm{P}<0,05)$. Em ordem decrescente, os sistemas apresentaram os seguintes teores de CBM: CER $\left(436 \mathrm{mg} \mathrm{kg}^{-1}\right)>\mathrm{NT} 2\left(308 \mathrm{mg} \mathrm{kg}^{-1}\right)>\mathrm{NT} 1\left(227 \mathrm{mg} \mathrm{kg}^{-}\right.$ 1) > CT (154 $\left.\mathrm{mg} \mathrm{kg}^{-1}\right)$. 

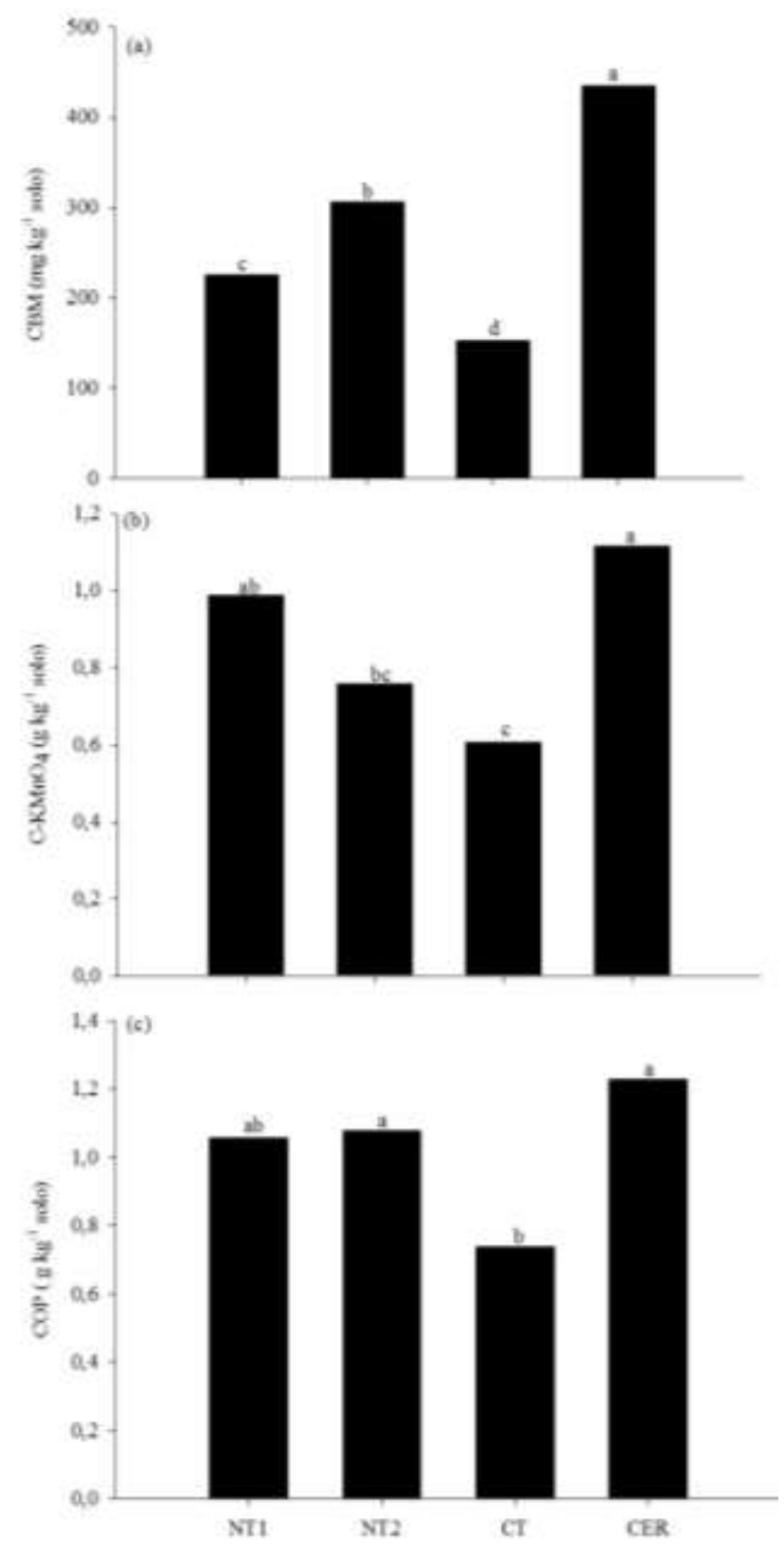

Figura 2.2 Carbono da biomassa microbiana - CBM (a), carbono oxidado por permanganato de potássio $\mathrm{C}_{-} \mathrm{KMnO}_{4}$ (b) e orgânico particulado - COP (c) em 0-20 cm de profundidade dos sistemas de manejo convencional (CT), plantios direto (NT1 e NT2) e cerrado nativo (CER). Médias seguidas de letras iguais não diferem entre si pelo teste de Tukey $(\mathrm{P}<0,05)$.

O CER teve maiores teores de $\mathrm{C}$ oxidável em permanganato de potássio $\left(\mathrm{C}-\mathrm{KMnO}_{4}\right)$ do que os sistemas CT e NT2 e o sistema NT1 foi o único agroecossistema que apresentou teor de $\mathrm{C}-\mathrm{KMnO}_{4}$ similar ao $\mathrm{CER}(\mathrm{p}<0,05)$. Entre os agroecossistemas, os sistemas sob plantio direto não se diferenciaram quanto aos teores de $\mathrm{C}-\mathrm{KMnO}_{4}$ e o NT1 acumulou maior C- $\mathrm{KMnO}_{4}$ do que o CT (Figura 2.2b).

Assim como verificado para as demais frações lábeis, o sistema CT reduziu os teores de COP em relação ao CER e ao NT2, não se diferenciando do NT1 (Fig. 2.2c). Os 
sistemas com rotações culturais sob plantio direto (NT1 e NT2) tiveram teores de COP similares ao do cerrado nativo. As similaridades observadas no COP entre o NT1 e CT, possivelmente, são decorrentes do uso da mesma cultura (soja) no mesmo período de cultivo. A menor produção de biomassa desta cultura pode ter limitado o acúmulo de matéria orgânica particulada nesses sistemas. Além disso, segundo Bayer et al. (2011), a soja possui elevada exportação de $\mathrm{N}$ para os grãos onde sistemas com sucessão soja/gramíneas tem limitada capacidade de sequestro de $\mathrm{C}$, que levam a um déficit de $\mathrm{C}$ e N lábil.

As reduções nas concentrações dessas frações lábeis na conversão do CER para o CT foram elevadas, chegando a $65 \%$ para o $\mathrm{CBM}, 46 \%$ para o $\mathrm{C}-\mathrm{KMnO}_{4}$ e $40 \%$ para o COP. Ao passo que, nos sistemas conservacionistas NT1 e NT2, as diferenças de concentrações das frações lábeis foram menores: $48 \%$ e $29 \%$ para o CBM, $13 \%$ e $37 \%$ para o C- $\mathrm{KMnO}_{4}$ e $14 \%$ e $12 \%$ para o $\mathrm{COP}$, respectivamente. A dominância relativa de cada mecanismo de proteção da MOS em um ano agrícola é impulsionada pela interação entre processos como taxa de decomposição do $\mathrm{C}$, fatores edafoclimáticos (Tivet et al., 2013), disponibilidade do N (Six \& Paustian, 2014) e sistema de preparo do solo (Sá et al., 2014). Assim como observado por Sá et al. (2014), os resultados das frações lábeis da MOS no NT, demonstraram que a deposição contínua de biomassa de $\mathrm{C}$ e $\mathrm{N}$ na superfície do solo e a preservação da estrutura do solo, pela ausência de revolvimento, elevam o potencial de sistemas conservacionistas para o acúmulo de $\mathrm{C}$ no solo em diferentes compartimentos da MOS. Como consequência, a maior concentração de frações lábeis pode aumentar a formação de agregados e proteger o carbono orgânico do solo (Tivet et al., 2013), já que em curto prazo, a estabilidade estrutural do solo também se correlaciona positivamente tanto com a densidade de bactérias quanto de fungos, necessários à formação de agregados no solo e proteção física do C no NT (Lienhard et al., 2013).

\subsubsection{Frações estáveis da matéria orgânica do solo}

O NT1 e NT2 não diferiram do CER em todas as frações orgânicas estáveis avaliadas (Fig. 2.3). O CT também não diferiu do NT2, na fração humina (HUM) e nem em relação ao NT1 e CER, no carbono inerte $(\mathrm{CI})(\mathrm{P}<0,05)$. Não foram observadas diferenças para o ácido fúlvico (AF) entre os sistemas avaliados (Fig. 2.3a). 


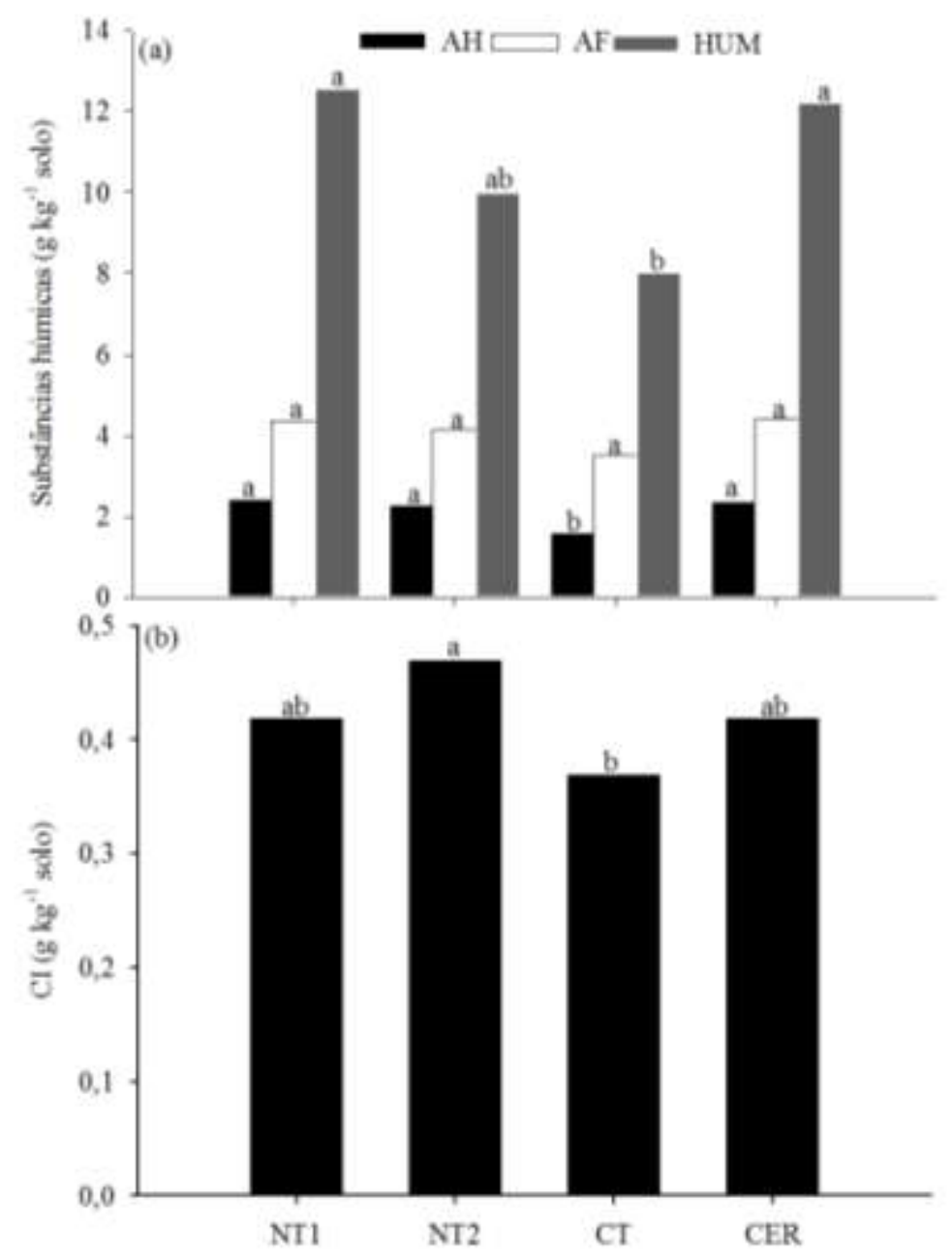

Figura 2.3 Carbono nas frações ácido húmico - AH, ácido fúlvico - AF, humina - HUM (a) e inerte -CI (b) em 0-20 cm de profundidade dos sistemas de manejo convencional (CT), plantios direto (NT1 e NT2) e cerrado nativo (CER). Médias seguidas de letras iguais não diferem entre si pelo teste de Tukey $(\mathrm{P}<$ $0,05)$.

No presente estudo, os sistemas acumularam carbono em substâncias com maior grau de humificação, como a HUM. Porém, mesmo nesta fração, menos sujeita a variações pelo manejo do solo, verificou-se, uma redução promovida pelo sistema convencional de cultivo $(\mathrm{P}<0,05)$, representando uma importante fonte de $\mathrm{C}$ para as emissões de $\mathrm{CO}_{2}$ para atmosfera. Ainda considerando o ambiente natural (CER) como referência, os sistemas conservacionistas foram capazes de manter os teores de $\mathrm{C}$ em todas as frações húmicas da matéria orgânica do solo. Em relação às diferenças ocasionadas pelo manejo, observou-se que no $\mathrm{CT}$, o uso de grade pesada, associada à monocultura da soja, pode explicar os níveis mais baixos das frações húmicas do solo (AH e HUM).

Nesse sistema, cuidados especiais são necessários, considerando a reduzida quantidade de $\mathrm{C}$ nessas frações estáveis, devido a rápida decomposição dos resíduos 
orgânicos lábeis (Fig. 2.2a, b, e c), com a quebra dos agregados que contribuem para formação de um depósito frágil de C no solo (Figueiredo et al., 2013). Das frações estáveis, o CI foi o único compartimento que não sofreu redução pela incorporação de áreas nativas do Cerrado para atividades agrícolas. Jantalia et al. (2007) entretanto, obtiveram redução de $35 \%$ no teor de CI com a adoção de agroecossistemas (média de sistemas convencionais e conservacionistas) no Cerrado.

A elevada concentração de lignina nos resíduos sorgo e guandu, utilizados nas rotações do NT1 e NT2, pode ter contribuído para a formação de frações húmicas estáveis como o ácido húmico e a humina. Portanto, entre os agroecossistemas, observou-se que sob NT ocorreram maiores teores de C em frações estáveis, sendo um importante mecanismo de sequestro de C no solo. De acordo com Santos et al. (2014), além de maiores acúmulos de C nessas frações, a formação de COP sob NT, similar ao CER, também é um indicador de uma MOS com maior qualidade.

\subsubsection{Agregação do solo e C em macro e microagregados}

Os agroecossistemas promoveram ruptura e redução do DMP de agregados (Fig. 2.4a). Em comparação ao CER, os agroecossistemas apresentaram uma redução média de $36 \%$ no DMP. Esses resultados demonstram que a quebra de agregados promovida pela incorporação do Cerrado para agricultura é tão intensa que mesmo a adoção do sistema plantio direto por 18 anos não foi capaz de retornar o nível de agregação superior ao da área sob vegetação nativa. No caso do CT os valores mostram um impacto típico das operações de preparo com grade pesada com quebra dos agregados estáveis, conforme relatado por vários autores (Marchão et al., 2007; Figueiredo et al., 2013). Esses resultados demonstram ainda que nas condições edafoclimáticas do Cerrado o solo apresenta uma característica mais lenta na formação de agregados estáveis, com dificuldades de sequestrar $\mathrm{C}$, necessitando de maior entrada de biomassa vegetal. Segundo Lal (2009) a capacidade de formar agregados estáveis é um dos fatores que afetam a taxa de sequestro de $\mathrm{C}$ no solo. 


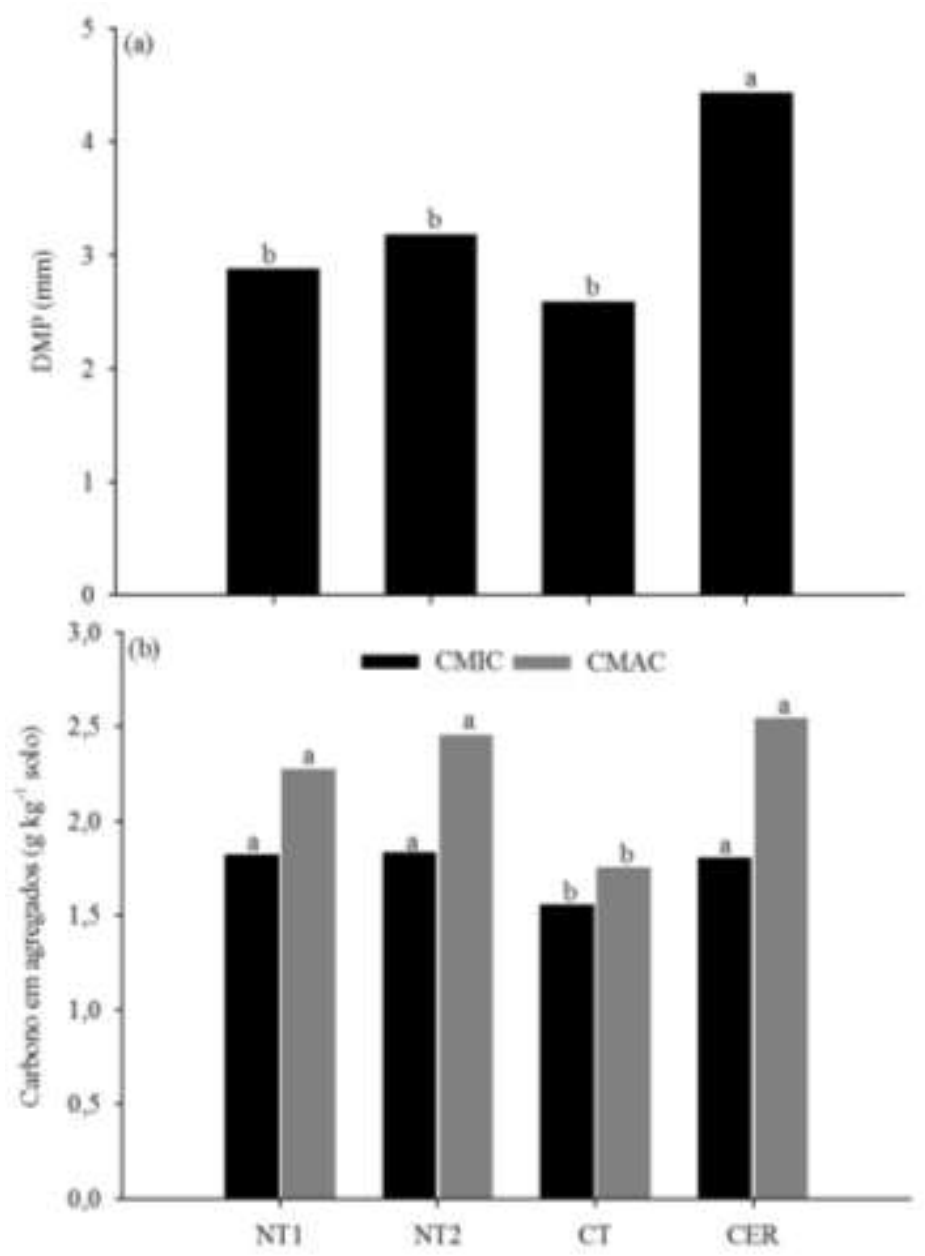

Figura 2.9 Diâmetro médio ponderado - DMP (a), carbono em macroagregados - CMAC e em microagregados - CMIC estáveis em água (b) na profundidade de $0-20 \mathrm{~cm}$ nos sistemas de manejo convencional (CT), plantios direto (NT1 e NT2) e cerrado nativo (CER). Médias seguidas de letras iguais não diferem entre si pelo teste de Tukey $(\mathrm{P}<0,05)$.

Sob plantio direto (NT1 e NT2) o solo apresentou acúmulo de C em macro e microagregados semelhantes $(\mathrm{P}<0,05)$ ao solo sob vegetação natural (CER) (Fig. 2.4b). Portanto, após a implantação do plantio direto ocorre uma maior formação de macro e microagregados ricos em C (Sá et al., 2014). O CT teve os menores teores de C tanto em macro e quanto em microagregados. As perturbações físicas à estrutura do solo, causadas por grade pesada ou outros implementos agrícolas, diretamente aceleram a decomposição da MOS e impedem o acúmulo e a proteção do $\mathrm{C}$ em agregados do solo. Dessa forma expõe a comunidade microbiana do solo aos processos de rápido umedecimento e secagem (Davidson et al., 1992), que contribuem para maiores emissões de C para a atmosfera em sistemas convencionais de preparo do solo. Assim, contrário ao que foi observado por Andruschkewitsch et al. (2014) que sugeriram aumento da estabilização do COS em macroagregados por translocação e incorporação de resíduos orgânicos a partir do uso de grade no CT, no presente trabalho, os resultados 
indicam que o efeito da grade sobre a estrutura física do solo reduziu a proteção da MOS em agregados. Além desses fatores, o cultivo em rotação no NT1 e NT2 possibilitou o uso de espécies com sistemas radiculares mais profundos, a exemplo da gramínea sorgo e leguminosa guandu, que além de serem mais resistentes à seca (Magalhães et al., 2000; Burle et al., 2006), proporcionam em profundidade maiores deposições de $\mathrm{C}$ que, ao mesmo tempo, contribui para a proteção da MOS em agregados do solo.

Como não foi verificada diferença entre os agroecossistemas quanto ao DMP, o maior acúmulo de $\mathrm{C}$ em agregados verificado nos sistemas conservacionistas (NT1 e NT2) podem ser decorrentes de outros mecanismos de proteção do C. De acordo com John et al. (2005), as explicações para a maior proteção de C e N no solo vão além das proteções físicas. Adicionado ao mecanismo físico de proteção da MOS a proteção química, com formação de estruturas complexas e aromáticas também ocorrem de modo a garantir maior estabilidade dos compostos orgânicos formados sob os NT nesse Latossolo ao longo desses 18 anos.

A utilização de gramíneas nas rotações dos NT como o milho e sorgo, por exemplo, são capazes de produzir uma quantidade elevada de exsudados que aumentam a agregação e contribuem para uma maior e mais contínua rizodeposição de $\mathrm{C}$ no solo (Ghimire et al., 2014).

\subsection{EMISSÕES ACUMULADAS DE $\mathrm{N}_{2} \mathrm{O}$ EM SOLOS SOB SISTEMAS DE MANEJO DO SOLO}

As emissões acumuladas de $\mathrm{N}_{2} \mathrm{O}$ do solo foram influenciadas pelos diferentes sistemas de manejo e rotação cultural (Fig. 2.5). Em relação ao cerrado nativo nos sistemas CT e NT1 houve aumento das emissões de $\mathrm{N}_{2} \mathrm{O}$ e sob NT2 a emissão desse gás foi similar ao CER. Os sistemas sob plantio direto (NT1 e NT2) não se diferenciaram nas emissões de $\mathrm{N}_{2} \mathrm{O}$ do solo. 


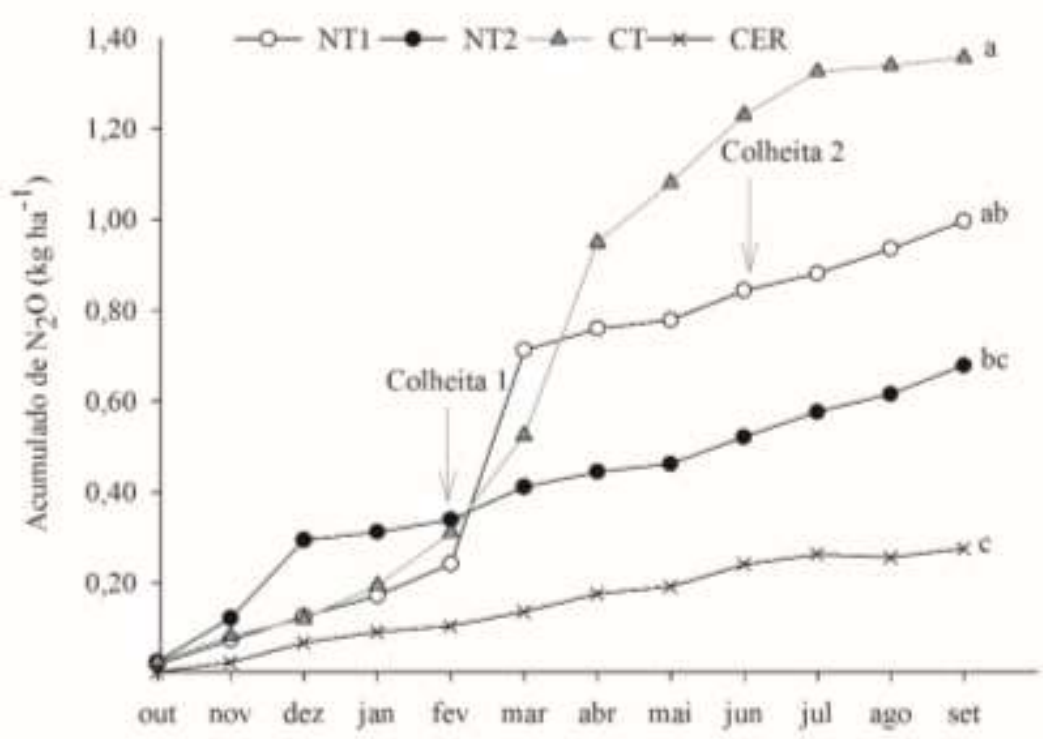

Figura 2.5 Óxido nitroso acumulado total nos sistemas de manejo convencional (CT), plantios direto (NT1 e NT2) e cerrado nativo (CER) medido de outubro de 2013 a setembro de 2014. As setas indicam eventos de colheita da soja no CT e NT1 (Colheita 1) e guandu no NT2 (Colheita 2). Médias seguidas de letras iguais não diferem entre si pelo teste de Tukey $(\mathrm{P}<0,05)$.

Após a colheita da soja (29/01/2014) foi observado um intenso aumento nas emissões de $\mathrm{N}_{2} \mathrm{O}$ no $\mathrm{CT}$ (Fig. 2.5). Os resíduos da soja, ricos em $\mathrm{N}$, possivelmente, foram utilizados pelos microrganismos com consequente liberação de $\mathrm{N}_{2} \mathrm{O}$ para a atmosfera. $\mathrm{O}$ estímulo da comunidade microbiana com a a dição de resíduos no solo se reflete nas camadas adjacentes a superfície do solo em reposta a liberação dos compostos orgânicos solúveis liberados pela mineralização / decomposição da liteira. Esse estímulo provado por compostos solúveis possivelmente reduz a concentração de oxigênio na rede de poros do solo e conduz a um ambiente favorável a desnitrificação (Dieng et al., 2015). Como não foi instalada segunda safra no CT, o uso de uma leguminosa com relação $\mathrm{C}: \mathrm{N}$ baixa e grande número de nódulos radiculares (soja) combinado a fatores edafoclimáticos (Butterbach-Ball et al., 2013; Ball et al., 2014; Bayer et al., 2015; Aini et al., 2015), a redução da proteção física do C, ocasionada pelo revolvimento (Jantalia et al., 2007), propiciaram a decomposição da MOS e a desnitrificação que resultaram em perdas de $\mathrm{N}_{2} \mathrm{O}$.

O NT2 foi o único agroecossistema que apresentou emissão de $\mathrm{N}_{2} \mathrm{O}$ similar ao CER $(\mathrm{P}<0,05)$. Comparado ao NT1, o NT2 apresentou maior biomassa microbiana, o que pode favorecer maior quantidade de $\mathrm{N}$ imobilizado por microrganismos e, consequentemente, favorecido menores emissões de $\mathrm{N}_{2} \mathrm{O}$ ao longo do ano avaliado. Além disso, a elevada relação $\mathrm{C}: \mathrm{N}$ de algumas culturas tem sido relacionadas com a 
baixa emissão de $\mathrm{N}_{2} \mathrm{O}$ (Vaughan et al., 2011; Gupta et al., 2016). No presente estudo, a alta relação $\mathrm{C}: \mathrm{N}$ dos resíduos do milho no NT2, provavelmente, favoreceu a imobilização do $\mathrm{N}$, resultando em baixa disponibilidade de substrato para os processos de nitrificação e desnitrificação, assim como as condições ambientais.

\subsection{RELAÇÕES ENTRE AS FRAÇÕES DA MATÉRIA ORGÂNICA DO SOLO E AS EMISSÕES DE $\mathrm{N}_{2} \mathrm{O}$}

Dois componentes principais foram gerados (PC1 e PC2) como ferramentas para a distinção dos sistemas de manejo (NT1, NT e CT), considerando todos os atributos juntos (COT, NOT, CBM, C-KMnO 4 , COP, AH, AF, HUM, CI, CMIC, CMAC e $\mathrm{N}_{2} \mathrm{O}$ acumulado) e analisados sem (Fig. 2.6a) e com o CER (Fig. 2.6b). A distribuição das variáveis selecionadas apresentou variação acumulada de $81 \%$ e $77 \%$ para a soma dos componentes principais PC1 e PC2 na avaliação realizada somente com os agroecossistemas sem o CER e com o cerrado nativo, respectivamente. 

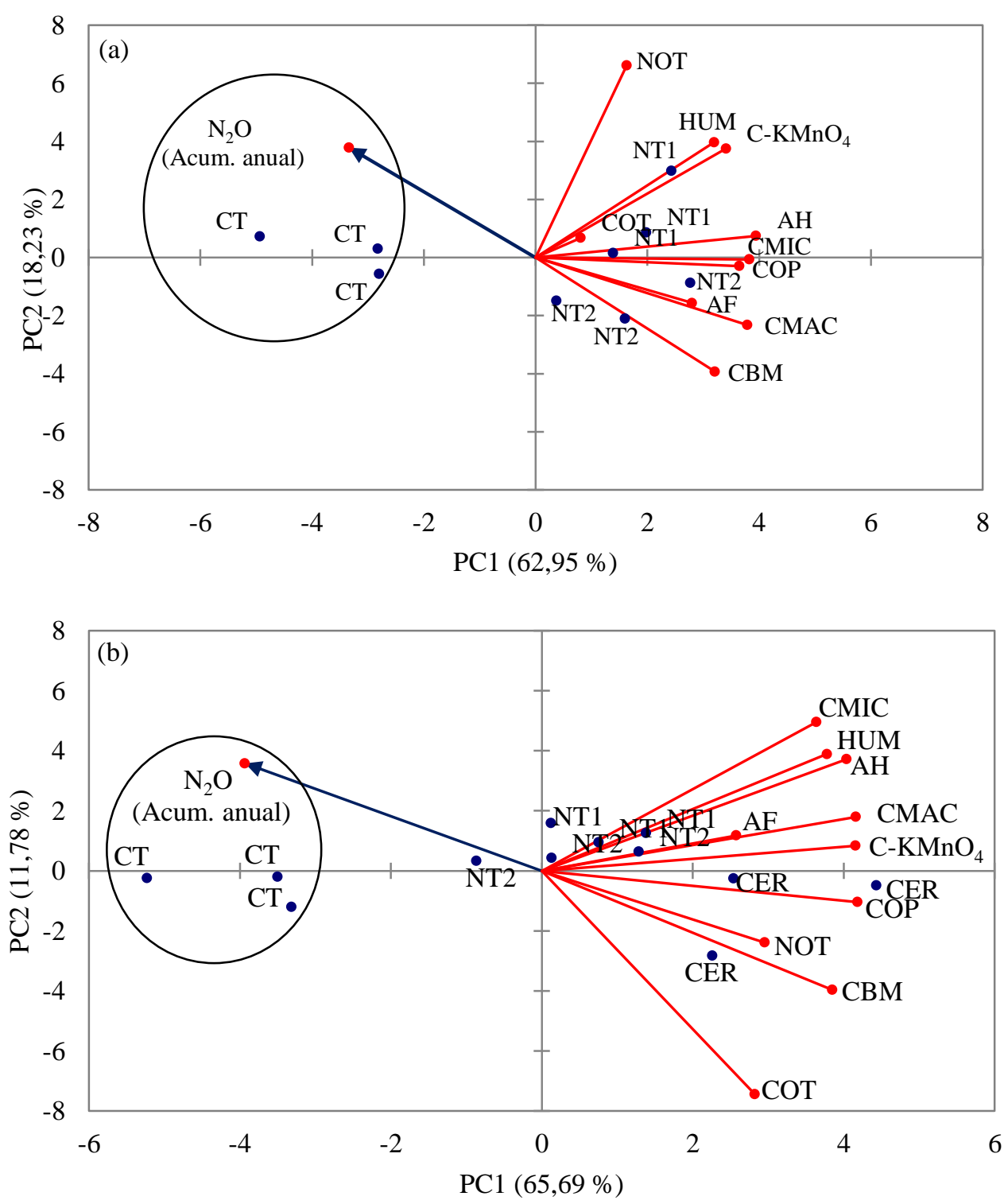

Figura 2.6 Análise de componentes principais - ACP somente para os agroecossistemas sob preparo convencional - CT e plantios diretos - NT1 e NT2 (a), e agroecossistemas mais o CER (b). Emissão acumulada de $\mathrm{N}_{2} \mathrm{O}$ do solo - $\mathrm{N}_{2} \mathrm{O}$ Acum. anual; carbono orgânico total - COT; nitrogênio total - NOT; carbono da biomassa microbiana - $\mathrm{CBM}$, carbono oxidável em permanganato - $\mathrm{C}-\mathrm{KMnO}_{4}$, ácido fúlvico $\mathrm{AF}$, ácido húmico - $\mathrm{AH}$, humina - HUM, carbono orgânico particulado - COP, carbono em microagregados - CMIC, carbono em macroagregados - CMAC durante o período avaliado.

A análise de interação mostrou um efeito integrado não só entre os sistemas de manejo, resíduos culturais, rotações, frações orgânicas de $\mathrm{C}$ e, no ano das avaliações, mas, principalmente, uma relação direta entre as práticas dos sistemas de manejo e acumulado de $\mathrm{N}_{2} \mathrm{O}$ (Fig. 2.6). Nas duas ACPs o $\mathrm{N}_{2} \mathrm{O}$ está inversamente proporcional ao 
CBM e COP, o que permite assumir que os solos com elevada concentração de CBM necessariamente apresentarão menor emissão de $\mathrm{N}_{2} \mathrm{O}$.

De maneira geral observou-se uma separação do CT dos demais sistemas de uso do solo. Essa separação é resultado da maior emissão acumulada de $\mathrm{N}_{2} \mathrm{O}$ nesse sistema aliada aos baixos teores de $\mathrm{C}$ nas diversas frações da MOS. Esses resultados demonstram que o acúmulo de resíduos das culturas após a colheita, sem quebra da estrutura física do solo, por gradagem, pode melhorar tanto as propriedades físicas, químicas e biológicas do solo como favorecer o acúmulo de MOS em suas diversas frações. Esse acúmulo de MOS de forma protegida nos agregados pode explicar a redução das emissões de $\mathrm{N}_{2} \mathrm{O}$ em sistemas naturais e conservacionistas de uso do solo no Cerrado.

Ao passo que, a quebra de agregados por revolvimento do solo, como observado no CT, com a exposição do C orgânico antes protegido da decomposição por microrganismos do solo, possivelmente, intensificou as atividades dos desnitrificadores, que aliado a deposição dos resíduos pós-colheita, resultaram em aumento das emissões de $\mathrm{N}_{2} \mathrm{O}$. Desse modo, para as condições de cerrado brasileiro, a ruptura dos agregados e a exposição da matéria orgânica protegida física e quimicamente da ação microbiana pelo preparo mecânico do solo, além de reduzir as quantidades das frações orgânicas lábeis e estáveis, favorecem os processos de desnitrificação.

De modo geral, a redução das frações orgânicas lábeis e estáveis, observada no CT, contribuíram, de acordo com resultados das análises, para as maiores emissões de $\mathrm{N}_{2} \mathrm{O}$ observadas nesse sistema haja vista, as menores porcentagens observadas nesse sistema, quando comparado aos sistemas conservacionistas.

\section{CONCLUSÕES}

Os agroecossistemas alteraram os estoques de $\mathrm{C}$ e $\mathrm{N}$ e o acúmulo de $\mathrm{C}$ em diferentes frações da MOS. Em relação ao cerrado nativo, as maiores reduções dos teores de C foram promovidas pelo sistema convencional de uso do solo, verificadas principalmente nas frações mais lábeis da MOS e nos agregados do solo. Além disso, o uso do solo sob sistema convencional no Cerrado também promoveu maior emissão de $\mathrm{N}_{2} \mathrm{O}$ do solo. Os sistemas sob plantio direto apresentaram valores de acúmulo de $\mathrm{C}$ e de emissão de $\mathrm{N}_{2} \mathrm{O}$ mais próximos da área nativa, representando uma importante estratégia para o manejo do solo em regiões tropicais. Os nossos resultados indicam que sistemas de manejo do 
solo que incrementam $\mathrm{C}$ de forma equilibrada entre frações lábeis e estáveis, além de mecanismos de proteção desse $\mathrm{C}$ em agregados apresentam baixa emissão de $\mathrm{N}_{2} \mathrm{O}$ do solo.

\section{REFERÊNCIAS}

AINI, F. K.; HERGOUALC'H, K.; SMITH, J. U.; VERCHOT, L. Nitrous oxide emissions along a gradient of tropical forest disturbance on mineral soils in Sumatra. Agriculture, Ecosystems and Environment, n. 214, p. 107 - 117, 2015.

ALLEN, D. E.; KINGSTON, G.; RENNENBERG, H.; DALAL, R. C.; SCHMIDT, S. Effect of nitrogen fertilizer management and waterlogging on nitrous oxide emission from subtropical sugarcane soils. Agriculture, Ecosystems and Environment, n. 136, p. $209-217,2010$.

ALVES, B. J. R.; SMITH, K. A.; FLORES, R. A.; CARDOSO, A. S.; OLIVEIRA, W. R. D.; JANTALIA, C. P.; URQUIAGA S.; BODDEY, R. M. Selection of the most suitable sampling time for static chambers for the estimation of daily mean $\mathrm{N}_{2} \mathrm{O}$ flux from soils. Soil Biology and Biochemistry, n. 46, p. 129-135, 2012.

ANDRUSCHKEWITSCH, R.; KOCH, H. J.; LUDWIG, B. Effect of long-term tillage treatments on the temporal dynamics of water-stable aggregates and on macro-aggregate turnover at three German sites. Geoderma, p. 57-64, 2014.

ASSAD, E. D.; PINTO, H. S.; MARTINS, J. D.; GROPPO, J. D.; SALGADO, P. R.; EVANGELISTA, B.; VASCONCELLOS, E.; SANO, E. E.; PAVÃO, E.; LUNA, R.; CAMARGO, P. B.; MARTINELLI, L. A. Changes in soil carbon stocks in Brazil due to land use: paired site comparisons and a regional pasture soil survey. Biogeosciences, $v$. 10, p. 6141- 2013, 2013.

BAYER, C.; AMADO, T. J. C.; TORNQUIST, C. G.; CERRI, C. E. C.; DIECKOW, J.; ZANATTA, J. A.; NICOLOSO, R. S. Estabilização do carbono no solo e mitigação das emissões de gases de efeito estufa na agricultura conservacionista. Tópicos em Ciência do Solo, n. 7, p. 55 - 118, 2011.

BAYER, C.; GOMES, J.; ZANATTA, J. A.; VIEIRA, F. C. B.; PICCOLO, M. C.; DIECKOW, J.; SIX, J. Soil nitrous oxide emissions as affected by long-term tillage, cropping systems and nitrogen fertilization in Southern Brazil. Soil and Tillage Research, n. 146, p. 213 - 222, 2015.

BALL, B. C.; GRIFFITHS, B. S.; TOPP, C. F. E.; WHEATLEY, R.; WALKER, R. L.; REES, R. M.; WATSON, C. A.; GORDON H.; HALLETT, P. D.; MCKENZIE, B. M.; NEVISON, I. M., 2014. Seasonal nitrous oxide emissions from field soils under reduced tillage, compost application or organic farming. Agriculture, Ecosystems \& Environment, n. 189, p. 171-180, 2014. 
BUSTAMANTE, M. M. C.; VORBEELS, M.; SCOBEL, M.; ROSCOE, R. Soil carbon and sequestration potential in the Cerrado Region of Brazil. In: Lal, R., Cerri, C. C., Bernoux, M., Etchevers, J., Cerri C.E.P. (Eds.), Carbon sequestration in soils of Latin America. 1. ed. New York: Food Product Press, cap. 14, pp. 285-304, 2006.

BUTTERBACH-BAHL, K.; BAGGS, E. M.; DANNENMANN, M.; KIESE, R.; ZECHMEISTER-BOLTENSTERN, S. Nitrous oxide emissions from soils: how well do we understand the processes and their controls? Philosophical Transaction of the Royal Society B: Biological, n. 368, p. 1- 3, 2013.

BURLE, M. L.; CARVALHO, A. M.; AMABILE, R. F.; PEREIRA, J. Caracterização de espécies de adubo verde. In: CARVALHO, A. M.; AMABILE, R. F., eds. Cerrado: Adubação verde. Planaltina, Embrapa Cerrados, 2006. p. 71-142.

CALONEGO, J. C.; ROSOLEM, C. A. Estabilidade de agregados do solo após manejo com rotações de culturas e escarificação. Revista Brasileira de Ciência do Solo, v. 32, p. 1399-1407, 2008.

CAMBARDELLA, C. A.; ELLIOTT, E. T. Particulate soil organic matter changes across a grassland cultivation sequence. Soil Science Society of America Journal, n. 56, p. 777-783, 1992.

CARVAlHO, A. M.; COELHO, M. C.; DANTAS, R. A.; FONSECA, O. P.; GUIMARÃES JÚNIOR, R.; FIGUEIREDO, C. C. Chemical composition of cover plants and its effect on maize yield in no-tillage systems in the Brazilian savanna. Crop and Pasture Science, v. 63, p. 1075 - 1081, 2012.

CORBEELS, M.; MARCHÃO, R. L.; SIQUEIRA NETO, M.; FERREIRA; E. G.; MADARI; B. E.; SCOPEL, E.; BRITO, O. R. Evidence of limited carbono sequestration in soils under no-tillage systems in the Cerrado of Brazil. Scientific Reports, v. 6, n. 21450, 2016.

CHERUBIN, M. R.; FRANCO, A.; CERRI, C. E. P.; CERRI, C. C. Sugarcane expansion in Brazilian tropical soils-effects of land use change on soil chemical attributes. Agriculture, Ecosystems and Environment, n. 211, p. 173-184, 2015.

CHIRINDA, N.; OLESEN, J. E.; PORTER, J. R.; SCHJONNING, P. Soil properties, crop production and greenhouse gas emissions from organic and inorganic fertilizerbased arable cropping systems. Agriculture, Ecosystems and Environment, n. 139, p. 584-594, 2010.

DAVIDSON , E. A.; FIRESTONE, M. K.; HART, S. C. Internal cycling of nitrate in soils of a mature coniferous forest, Ecology, v. 73, p. 1148-1156, 1992.

D’ANDRÉA, A. F.; SILVA, M. L. N.; CURI, N.; GUILHERME, L. R. G. Estoque de carbono e nitrogênio e formas de nitrogênio mineral em um solo submetido a diferentes sistemas de manejo. Pesquisa Agropecuária Brasileira, v. 39, n. 2, p. 179-186, 2004.

DIENG, A.; BAUDOIN, E.; THIOULOUSE, J.; BRUNET, D.; TOUCET, J.; SYLIA, S. N.; BRAUMAN, A. Soil organic matter quality, structure and activity of the 
denitrifiers community as influenced by decaying mulched crop residues. Applied Ecology and environmental research, n. 13, v. 3, p. 655-675, 2015.

DOBBIE, K. E.; MCTAGGART, I. P.; SMITH, K. A. Nitrous oxide emissions from intensive agricultural systems: variations between crops and seasons, key driving variables, and mean emission factors. Journal of Geophysical Research, n. 104, p. 26891-26899, 1999.

EMBRAPA. Centro Nacional de Pesquisa de Solos. Manual de métodos de análise de solos. 2. ed. Rio de Janeiro, 1997. 212 p.

FERREIRA, E.A.B.; BUSTAMANTE, M.M.C.; RESCK, D.V.S.; FIGUEIREDO, C.C,; PINTO, A.S.; MALAQUIAS, J.V. Carbon stocks in compartments of soil organic matter 31 years after substitution of native cerrado vegetation by agroecosystems. Revista Brasileira de Ciência do Solo, v. 40, p. 1-15, 2016 a.

FERREIRA, A.O.; AMADO, T.; RICE, C.W.; DIAZ, D.A.R.; KELLER, C.; INAGAKI, T.M. Can no-till grain production restore soil organic carbon to levels natural grass in a subtropical Oxisol? Agriculture, Ecosystems and Environment, n. 229, p. 13-20, 2016 b.

FIGUEIREDO, C. C.; RESCK, D. V. S.; CARNEIRO, M. A. C.; RAMOS, M. L. G.; SÁ J. C. M. Stratification ratio of organic matter pools influenced by management systems in a weathered Oxisol from a tropical agro-ecoregion in Brazil. Soil Research, v. 51, p. 133-141, 2013.

FRANCO, A. L. C.; CHERUBIN, M. R.; PAVINATO, P. S.; CERRI, C. E. P.; SIX, J.; DAVIES, C. A.; CERRI, C. C. Soil carbon, nitrogen and phosphorus changes under sugarcane expansion in Brazil. Science Total Environment, n. 515, p. 30-38, 2015.

GERAEI, D. S.; HOJATI, S.; LANDI, A.; CANO, A. F. Total and labile forms of soil organic carbon as affected by land use change in southwestern Iran. Geoderma Regional, n. 7, p. 29-37, 2016.

GUPTA, D. K.; BHATIA, A.; KUMAR, A.; DAS, T. K.; JAIN, N.; TOMER, R.; MALYAN, S. K.; FAGODIYA, R. K.; DUBEY, R.; PATHAK, H. Mitigation of greenhouse gas emission from rice-wheat system of the Indo-Gangetic plains: Through tillage, irrigation and fertilizer management. Agriculture Ecosystems and Environment, n. 230, p. 1-9, 2016.

GHIMIRE, R.; NORTON, J. B.; PENDALL, E. Alfalfa-grass biomass, soil organic carbon, and total nitrogen under different management approaches in an irrigated agroecosystems. Plant Soil, n. 374, p. 173-184, 2014.

HENDERSON, S. L.; DANDIE, C. E.; PATTEN, C. L.; ZEBARTH, B. J.; BURTON D. L.; TREVORS, J. T.; GOYER, C. Changes in Denitrifier Abundance, Denitrification Gene mRNA Levels, Nitrous Oxide Emissions, and Denitrification in Anoxic Soil Microcosms Amended with Glucose and Plant Residues. Applied and Environmental Microbiology, v. 76, p. 2155-2164, 2010. 
ISLAM, K.; WEIL, R. Microwave irradiation of soil for routine measurement of microbial biomass carbon. Biology and Fertility of Soils, v. 27, n. 4 p. 408-416, 1998.

IQBAL, J.; MITCHELL, D. C.; BARKER, D. W.; MIGUEZ, F.; SAWYER, J. E.; PANTOJA, J.; CASTELlANO, M. J. Does Nitrogen Fertilizer Application Rate to Corn Affect Nitrous Oxide Emissions from the Rotated Soybean Crop? Journal of Environmental Quality, n. 44, p. 711-719, 2015.

JÄGER, N.; STANGE, C. F.; LUDWIG, B.; FLESSA, H. Emission rates of $\mathrm{N}_{2} \mathrm{O}$ and $\mathrm{CO}_{2}$ from soils with different organic matter content from three long-term fertilization experiments-a laboratory study. Biology and Fertility of Soils, v. 47, p. 483-494, 2011.

JAIN, N.; ARORA, P.; TOMER, R.; MISHRA, S. V.; BHATIA, A.; PATHAK, H.; CHAKRABORTY, D.; KUMAR, V.; DUBEY, D. S.; HARIT, R. C.; SINGH, J. P. Greenhouse gases emission from soils under major crops in Northwest India. Science of the Total Environment, n. 542, p. 551-561, 2016.

JANTALIA, C. P.; RESCK, D. V. S.; ALVES, B. J. R.; ZOTARELLI, L.; URQUIAGA, S.; BODDEY, R. M. Tillage effect on C stocks of a clayey Oxisol under a soybean-based crop rotation in the Brazilian Cerrado region. Soil and Tillage Research, n. 95, p. 97-109, 2007.

JOHN, B.; YAMASHITA, T.; LUDWIG, B.; FLESSA, H. Storage of organic carbon in aggregate and density fractions of silty soils under different types of land use. Geoderma, n. 128, p. 63-79, 2005.

LAL, R. Challenges and opportunities in soil organic matter research. European Journal of Soil Science, n. 60, p. 158-169, 2009.

LIENHARD, P.; TIVET, F. ; CHABANNE, A.; DEQUIEDT, S.; LELIÈVRE, M.; SAYPHOUMMIE, S.; LEUDPHANANE, B.; PRÉVOST-BOURÉ, N.C.; SÉGUY, L.; MARON, P.; RANJARD, L. No-till and cover crops shift soil microbial abundance and diversity in Laos tropical grasslands. Agronomy for Sustainable Development, v. 33, n. 2, p. 375-384, 2013.

LIVINGSTON, G.P.; HUTCHINSON, G.L. Enclosure-based measurement of trace gas exchange: applications and sources of error. Cap. 2. In: Biogenic Trace Gases: measuring Emissions form soil and Water. P.A. MATSON; R.C. HARRISS JOHN WILEY, 408 p., 1995.

LOZANO-GARCÍA, B.; PARRAS-ALCÁNTARA, L. Land use and management effects on carbon and nitrogen in Mediterranean Cambisols. Agriculture, Ecosystems and Environment, n. 179, p. 208-214, 2013.

MAZZONCINI, M.; ANTICHI, D.; DI BENE, C.; RISALITI, R.; PETRI, M.; BONARI, E. Soil carbon and nitrogen changes after 28 years of no-tillage management under Mediterranean conditions. European Journal of Agronomy, n. 77, p. 156-165, 2016. 
MARIE, B.; JOSETTE, G.; GILLES, B.; JULIEN, T.; ERIC, G.; BRUNO, M. Nitrous oxide emissions and nitrate leaching in an organic and a conventional cropping system (Seine basin, France). Agriculture, Ecosystems and Environment, n. 213, p. 131 $141,2015$.

MARCHÃO, R. L.; BALBINO, L. C.; SILVA, E. M.; SANTOS JÚNIOR, J. D. G.; SÁ, M. A. C.; VILELA, L.; BECQUER, T. Qualidade física de um Latossolo Vermelho sob sistemas de integração lavoura-pecuária no Cerrado. Pesquisa Agropecuária Brasileira, v. 42, p. 873-882, 2007.

MARTINS, M. R.; JANTALIA, C. P.; POLIDORO, J. C.; BATISTA, J. N.; ALVES, B. J. R.; BODDEY, R. M.; URQUIAGA, S. Nitrous oxide and ammonia emissions from N fertilization of maize crop under no-till in a Cerrado soil. Soil and Tillage Research, $\mathrm{n}$. 151, p. 75-81, 2015.

OLIVEIRA, D. M. S.; PAUSTIAN, K.; DAVIES, C. A.; CHERUBIN, M. R.; FRANCO, A. L. C.; CERRI, C. C.; CERRI, C. E. P. Soil carbon changes in areas undergoing expansion of sugarcane into pastures in south-central Brazil. Agriculture, Ecosystems and Environment, n. 228, p. 38-48, 2016.

PICCOLI, I.; CHIARINI, F.; CARLETTI, P.; FURLAN, L.; LAZZARO, B.; NARDI, S.; BERTI, A.; SARTORI, L.; DALCONI, M. C.; MORARI, F. Disentangling the effects of conservation agriculture practices on the vertical distribution of soil organic carbon. Evidence of poor carbon sequestration in North-Eastern Italy. Agriculture, Ecosystems and Environment, n. 230, p. 68-78, 2016.

PLAZA-BONILLA, D.; NOLOT, J. M.; PASSOT, S.; RAFFAILLAC, D.; JUSTES, E. Grain legume-based rotations managed under conventional tillage need cover crops to mitigate soil organic matter losses. Soil and Tillage Research, n. 156, p. 33-43, 2016.

PRASAD, J. V. N. S.; RAO, C. S.; SRINIVAS, K.; JYOTHI, C. N.; VENKATESWARLU, B.; RAMACHANDRAPPA, B. K.; DHANAPAL, G. N.; RAVICHANDRA, K.; MISHRA, P. K. Effect of ten years of reduced tillage and recycling of organic matter on crop yields, soil organic carbon and its fractions in Alfisols of semi arid tropics of southern India. Soil and Tillage Research, n. 156, p. 131-139, 2016.

RYALS, R.; HARTMAN, M. D.; PARTON, W. J.; MARCIA S. DELONGE, WHENDEE L. SILVER. Long-term climate change mitigation potential with organic matter management on grasslands. Ecological Applications, v. 25, n. 2, p. 531-545, 2015.

SÁ, J.C.M.; TIVET, F.; LAL, R.; BRIEDIS, C.; HARTMAN, D.C., SANTOS, J.Z., SANTOS, J.B. Long-term tillage systems impacts on soil C dynamics, soil resilience and agronomic productivity of a Brazilian Oxisol. Soil \& Tillage Research, n. 136, p. 38-50, 2014.

SÁ, J.C.M.; SÉGUY, L.; TIVET, F.; LAL, R.; BOUZINAC; S.; BORSZOWSKEI; P.R.; BRIEDIS, C.; SANTOS, J.B.; HARTMAN, D.C.; BERTOLONI, C.G.; ROSA, J.; FRIEDRICH, T. Carbon depletion by plowing and its restoration by no-till cropping 
systems in oxisols of subtropical and tropical agro-ecoregions in brazil. Land Degradation \& Development. n. 26, p. 531-543, 2015.

SANTOS, I. L; CAIXETA, C. F.; SOUSA, A. A. T. C.; FIGUEIREDO, C. C.; RAMOS, M. L. G.; CARVALHO, A. M. Cover plants and mineral nitrogen: effects on organic matter fractions in an oxisol under no-tillage in the Cerrado. Revista Brasileira de Ciência do Solo, v. 38, p. 1874-1881, 2014.

SIX, J.; PAUSTIAN, K. Aggregate-associated soil organic matter as an ecosystem property and a measurement tool. Soil Biology and Biochemistry, n. 68, p. 44-49, 2014.

SHEEHY, J.; REGINA, K.; ALAKUKKU, L.; SIX, J. Impact of no-till and reduced tillage on aggregation and aggregate-associated carbon in Northern European agroecosystems. Soil and Tillage Research, n. 150, p. 107-113, 2015.

SMITH, K. A.; THOMSON, P. E.; CLAYTON, I. P.; MCTAGGART, H.; CONEN, F. Effects of temperature, water content and nitrogen fertilisation on emissions of nitrous oxide by soils. Atmospheric Environment, v. 32, n. 19, p. 3301-3309, 1998.

STEHFEST, E; BOUWMAN, L. $\mathrm{N}_{2} \mathrm{O}$ and $\mathrm{NO}$ emission from agricultural fields and soils under natural vegetation: summarizing available measurement data and modeling of global annual emission. Nutrient Cycling in Agroecosystems, v. 74, p. 207-228. 2006.

TIVET, F.; SÁ, J. C. M.; LAL, R.; BORSZOWSKEI, P. R.; BRIEDIS, C.; SANTOS, J. B.; SÁ, M. F. M.; HARTMAN, D. C.; EURICH, G.; FARIAS, A.; BOUZINAC, S.; SÉGUY, L. Aggregate $\mathrm{C}$ depletion by plowing and its restoration by diverse biomass-C inputs under no-till in sub-tropical and tropical regions of Brazil. Geoderma, n. 209, p. 214-225, 2013.

TURNER, P. A.; BAKER, J. M.; GRIFFIS, T. J.; VENTEREA, R. T. Impact of Kura Clover Living Mulch on Nitrous Oxide Emissions in a Corn-Soybean System. Journal of Environmental Quality, n. 36, 2016.

VAUGHAN, S. M.; DALAL, R. C.; HARPER, S. M.; MENZIES, N. W. Effect of fresh green waste and green waste compost on mineral nitrogen, nitrous oxide and carbon dioxide from a Vertisol. Waste Management, n. 31, p. 1720-1728, 2011.

VERAS, M. S.; RAMOS, M. L. G.; OLIVEIRA, D. N. S.; FIGUEIREDO, C. C.; CARVALHO, A. M.; PULROLNIK, K.; SOUSA, K. W. Cover Crops and nitrogen fertilization effects on nitrogen soil fractions under corn cultivation in a no-tillage system. Revista Brasileira de Ciência do Solo, v. 40, p. 1-12, 2016.

VENTEREA, R. T.; COULTER, J. A. Split application of urea does not decrease and may increase nitrous oxide emissions in rainfed corn. Agronomy, Soil and Environmental Quality, n. 107, p. 337-348, 2015. 
WANG, B.; LI , Y.; WAN, Y.; QIN, X.; GAO, Q.; LIU, S.; LI, J. Modifying nitrogen fertilizer can reduce greenhouse gas emissions from a Chinese double rice cropping system. Agriculture, Ecosystems and Environment, n. 215, p. 100-109, 2016.

WELLER, S.; JANZ, B.; CORG, L.J.; KRAUS, D.; RACELA, H. S. U.; WASSMANN, R.; BUTTERBACH-BAHL, K.; KIESE, R. Greenhouse gas emissions and global warming potential of traditional and diversified tropical rice rotation systems. Global Change Biology, v. 16, n. 22, p. 432-448, 2016.

WU, Y.; LIN, S.; LIU, T.; WAN, T.; HU, R. Effect of crop residue returns on $\mathrm{N}_{2} \mathrm{O}$ emissions from red soil in China. Soil Use and Management, v. 32, p. 80-88, 2016.

ZHANG, Y., SHEN, J., WANG, Z., CHEN, L., ZHENG, J. Nitrous oxide and methane emissions from a Chinese wheat-rice cropping system under different tillage practices during the wheat-growing season. Soil and Tillage Research, n. 146, p. 261-269, 2015. 


\begin{tabular}{|c|c|c|c|c|}
\hline \multicolumn{5}{|c|}{ ANEXOS } \\
\hline \multicolumn{5}{|c|}{$\begin{array}{l}\text { Tabela A1. Histórico completo da área experimental com dinâmicas de sistemas de } \\
\text { preparo do solo e rotações de culturas dos tratamentos utilizados desde } 1995 \text {. }\end{array}$} \\
\hline \multirow{2}{*}{ Ano } & \multirow{2}{*}{ Safra } & \multicolumn{3}{|c|}{ Sistemas de manejo* } \\
\hline & & CT & NT1 & NT2 \\
\hline 1 & $1995 / 96$ & \multicolumn{3}{|c|}{$\begin{array}{l}\text { Inventário da vegetação nativa, caracterização inicial do solo, desmatamento e } \\
\text { plantio de arroz }\end{array}$} \\
\hline 2 & $1996 / 97$ & GP-L & ADL-G1 & ADG-L1 \\
\hline 3 & $1997 / 98$ & GP-L & ADL-G1 & ADG-L1 \\
\hline 4 & $1998 / 99$ & GP-G & AVG-L1 & AVL-G1 \\
\hline 5 & $1999 / 00$ & GP-G & AVG-L1 & AVL-G1 \\
\hline 6 & $2000 / 01$ & GP-L & PDL-G1 & PDG-L1 \\
\hline 7 & $2001 / 02$ & GP-L & PDL-G1 & PDG-L1 \\
\hline 8 & $2002 / 03$ & GP-G & PDG-L1 & PDL-G1 \\
\hline 9 & $2003 / 04$ & GP-G & PDG-L1 & PDL-G1 \\
\hline 10 & $2004 / 05$ & GP-L & PDL-G1 & PDG-L1 \\
\hline 11 & $2005 / 06$ & GP-L & PDL-G1 & PDG-L1 \\
\hline 12 & $2006 / 07$ & GP-G & PDG-L1 & PDL-G1 \\
\hline 13 & $2007 / 08$ & GP-G & PDG-L1 & PDL-G1 \\
\hline 14 & $2008 / 09$ & GP-L & PDL-G1 & PDG-L1 \\
\hline 15 & $2009 / 10$ & GP-L & PDL-G1 & PDG-L1 \\
\hline 16 & $2010 / 11$ & GP-G & PDG-L1 & PDL-G1 \\
\hline 17 & $2011 / 12$ & GP-G & PDG-L1 & PDL-G1 \\
\hline 18 & $2012 / 13$ & GP-L & PDL-G1 & PDG-L1 \\
\hline 19 & $2013 / 14$ & GP-L & PDL-G1 & PDG-L1 \\
\hline
\end{tabular}

*No ano das coletas de dados no sistema plantio convencional (CT) foi utilizada a cultura da soja e posterior pousio. No sistema NT1 foi realizado plantio direto com soja e segunda safra com sorgo. E no NT2 plantio direto com milho e segunda safra com o guandu.

Culturas cultivadas na safra: Leguminosas $(\mathrm{L}=$ soja); Gramíneas $(\mathrm{G}=$ milho). Culturas de segunda safra: Leguminosas $(\mathrm{L} 1=$ guandu $)$; Gramíneas $(\mathrm{G} 1=$ milheto $)$.

Sistema de preparo: $\mathrm{CP}=$ grade pesada; $\mathrm{AD}=$ arado de discos; $\mathrm{AV}=$ arado de aivecas. 

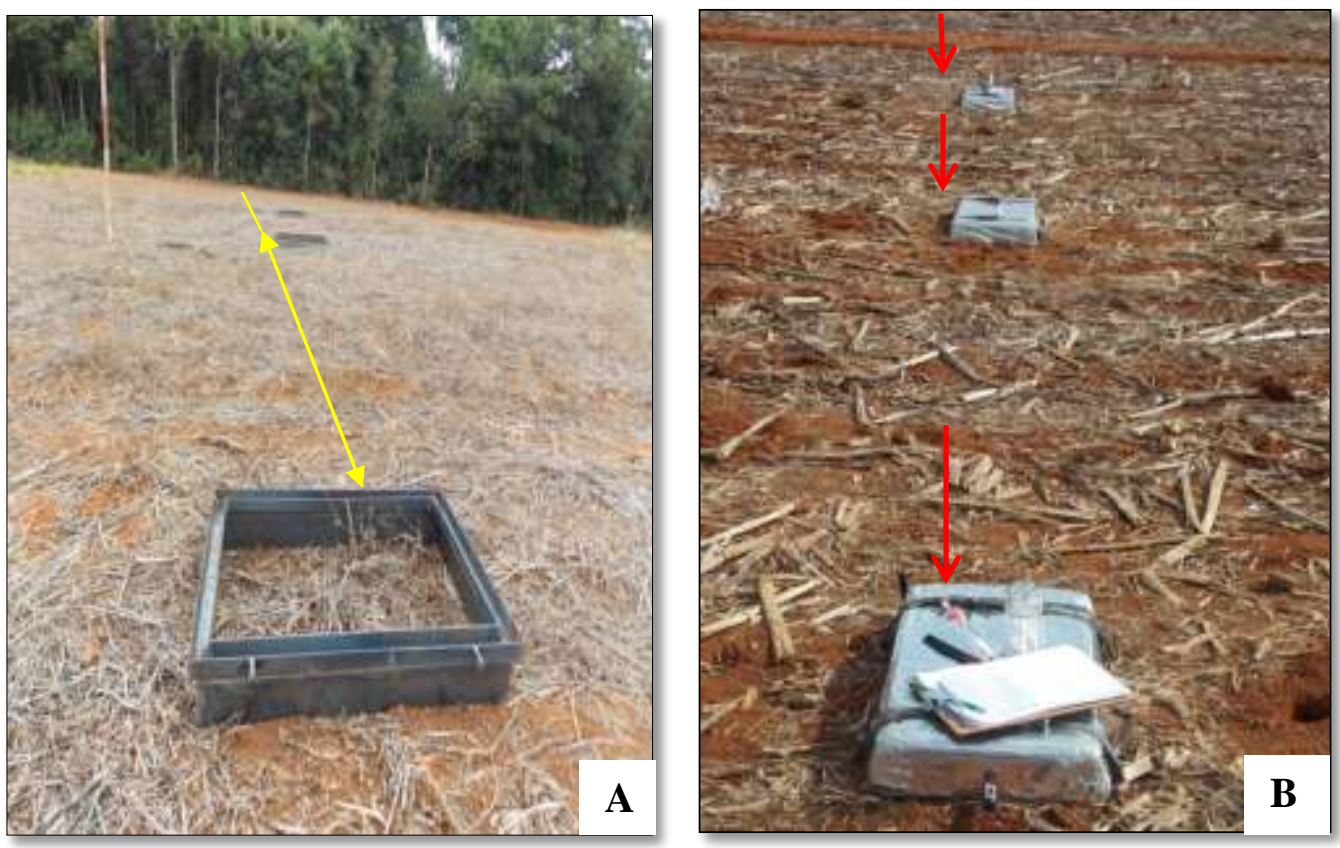

Figura A1. Instalação da base metálica da câmara estática antes do plantio (A) e medição do $\mathrm{N}_{2} \mathrm{O}$ em campo (B) após fechamento com parte superior de PVC que é revestida com manta térmica de alumínio.
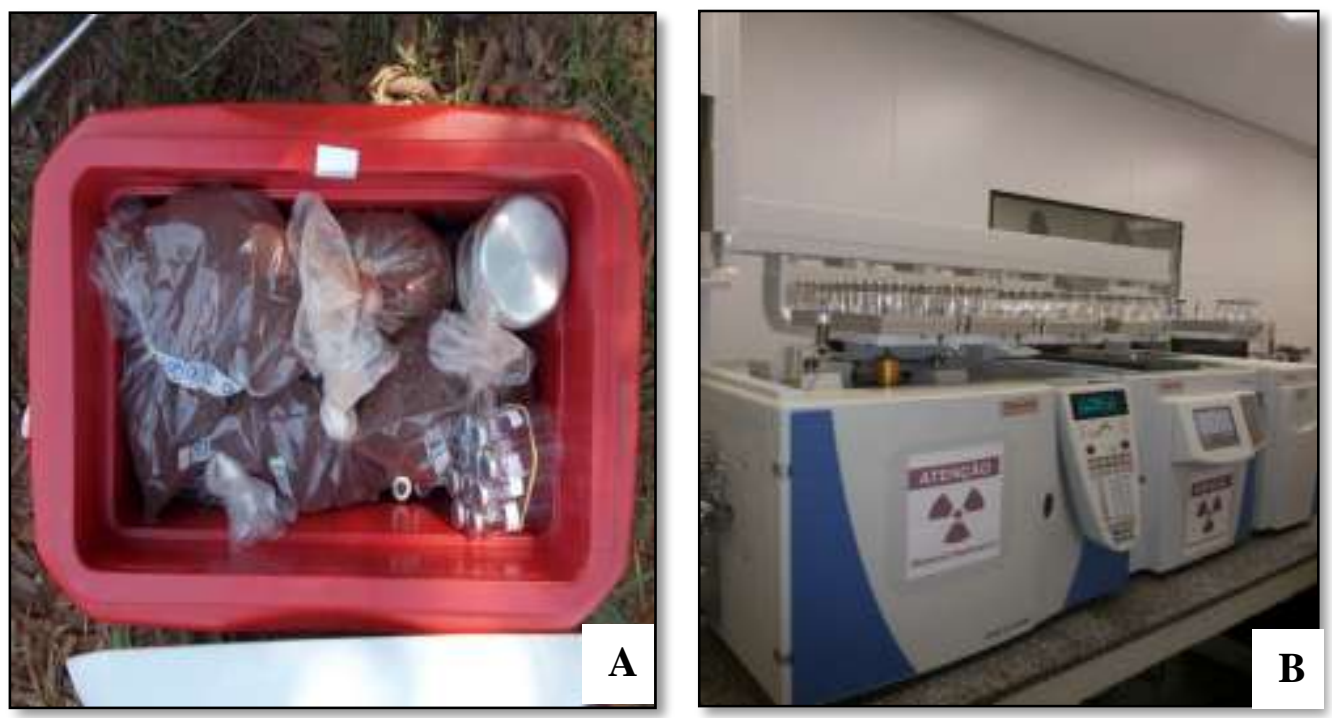

Figura A2. Vials com $\mathrm{N}_{2} \mathrm{O}$ e o solo para determinação de nitrato, amôríio e umidade armazenados em caixas térmicas em campo (A) e cromatógrafo (B) utilizado para determinação do $\mathrm{N}_{2} \mathrm{O}$ em laboratório. 

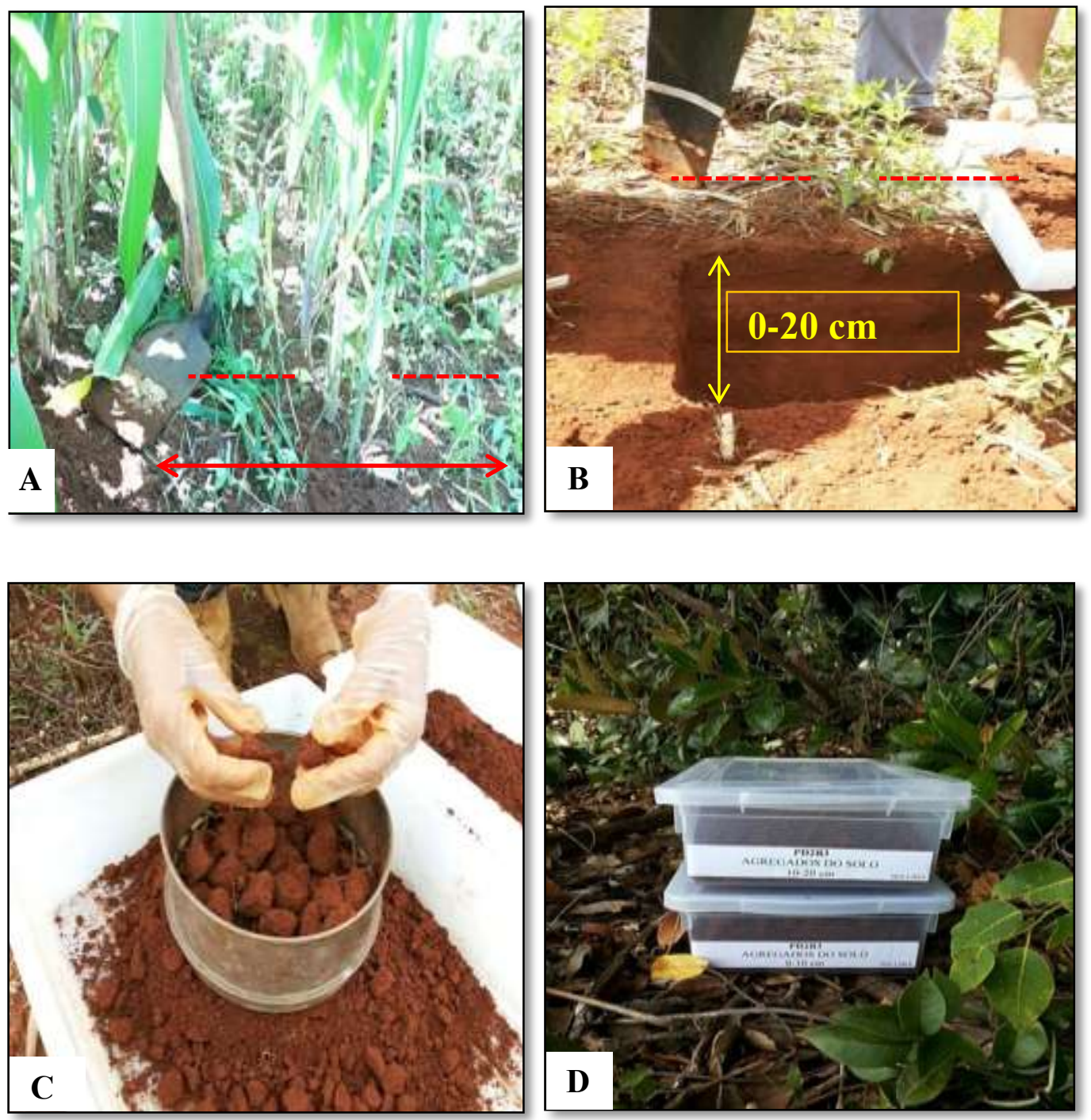

Figura A3. Marcação do local de coleta de solo em campo (A) por meio de minitrincheiras (B) para determinação dos agregados e teor de carbono, passados em peneira de $19 \mathrm{~mm}$ (C) e armazenados em caixas plásticas (D) para manutenção da estrutura do solo. 